\title{
Highlights
}

- Multivariate analysis of $\mathrm{N} 2 \mathrm{O}$ emissions and process variables in full-scale reactor

- Correlation between $\mathrm{N}_{2} \mathrm{O}, \mathrm{DO}, \mathrm{NH}_{4}-\mathrm{N}$ and $\mathrm{NO}_{3}-\mathrm{N}$ fluctuates in different periods

- Clusters group the different ranges of the process variables and $\mathrm{N} 2 \mathrm{O}$ emissions

- PCA shows the combined effect of process variables on the system and $\mathrm{N} 2 \mathrm{O}$ emissions 


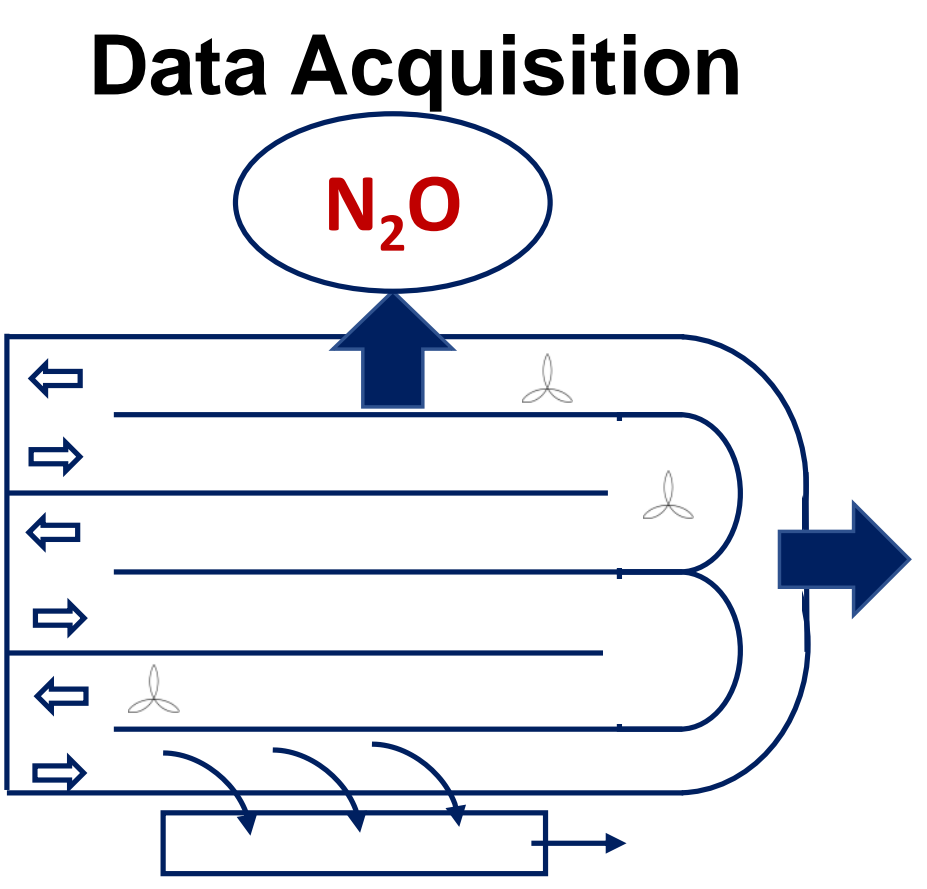

Carrousel Reactor

\section{Data-driven Analysis}

N2O Emissions

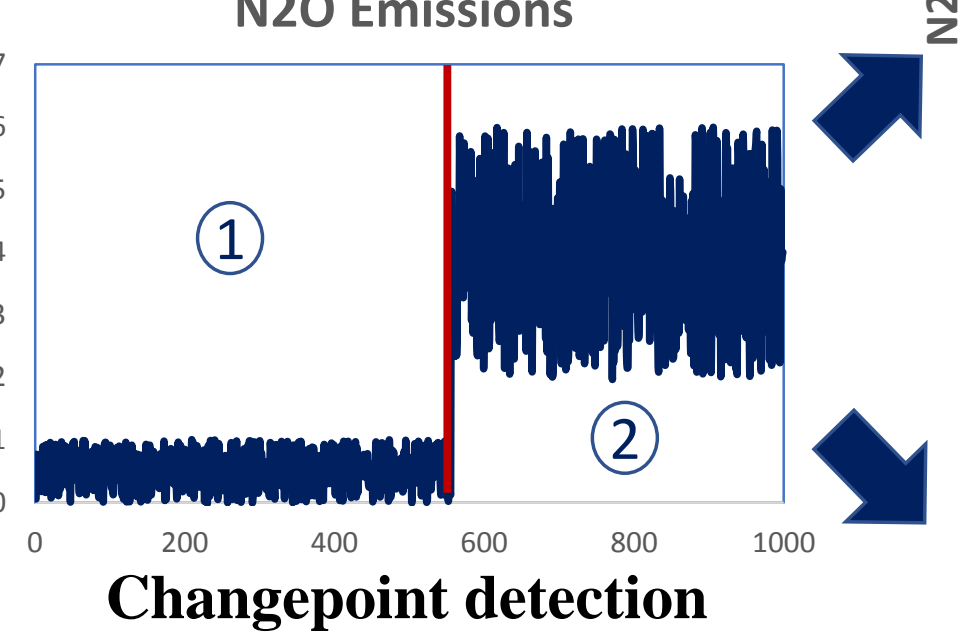

Changepoint detection
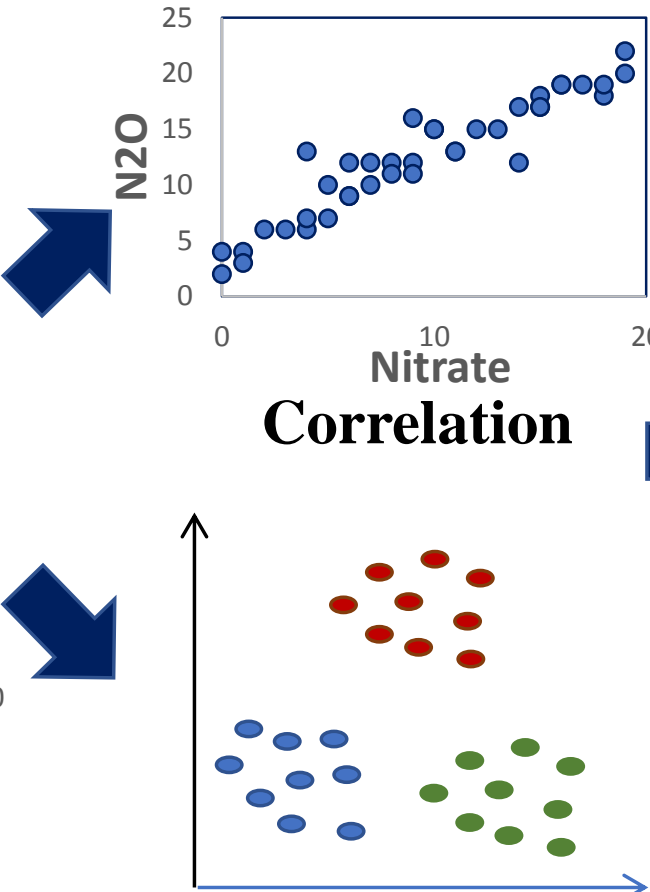

Clustering
PC 2

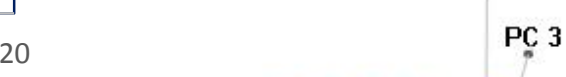

PÇ 3

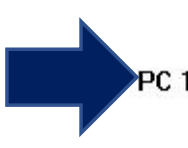

Principal Component Analysis

\section{$\mathrm{N}_{2} \mathrm{O}$ patterns and dependencies}


3 Vasilaki V., Volcke, E.I.P. $^{\mathrm{b}}$, Nandi A.K. ${ }^{\mathrm{c}}$, van Loosdrecht $^{\mathrm{d}}$, M.C.M., Katsou E. ${ }^{\mathrm{a}^{*}}$

$4 \quad{ }^{a}$ Department of Civil \& Environmental Engineering, Brunel University London, Uxbridge UB8 3PH, UK

5 b Department of Green Chemistry and Technology, Ghent University, Coupure Links 653, 9000 Gent, 6 Belgium

$7 \quad{ }^{c}$ Department of Electronic and Computer Engineering, Brunel University London, Uxbridge UB8 3PH, UK

$8{ }^{\mathrm{d}}$ Department of Biotechnology, Delft University of Technology, Van der Maasweg 9, 2629 HZ Delft, The 9 Netherlands

$10 *$ * Corresponding author. Department of Civil \& Environmental Engineering, Brunel University London,

11 Uxbridge UB8 3PH, UK. Email: evina.katsou@ brunel.ac.uk

12 Keywords: $\mathrm{N}_{2} \mathrm{O}$ emissions, long-term monitoring campaign, principal component analysis, hierarchical k13 means clustering 


\section{Abstract}

15 Multivariate statistical analysis was applied to investigate the dependencies and underlying patterns between

$16 \mathrm{~N}_{2} \mathrm{O}$ emissions and online operational variables (dissolved oxygen and nitrogen component concentrations, 17 temperature and influent flow-rate) during biological nitrogen removal from wastewater. The system under 18 study was a full-scale reactor, for which hourly sensor data were available. The 15 -month long monitoring 19 campaign was divided into 10 sub-periods based on the profile of $\mathrm{N}_{2} \mathrm{O}$ emissions, using Binary Segmentation.

20 The dependencies between operating variables and $\mathrm{N}_{2} \mathrm{O}$ emissions fluctuated according to Spearman's rank 21 correlation. The correlation between $\mathrm{N}_{2} \mathrm{O}$ emissions and nitrite concentrations ranged between 0.51-0.78 22 Correlation $>0.7$ between $\mathrm{N}_{2} \mathrm{O}$ emissions and nitrate concentrations was observed at sub-periods with average temperature lower than $12{ }^{\circ} \mathrm{C}$. Hierarchical k-means clustering and principal component analysis linked $\mathrm{N}_{2} \mathrm{O}$ emission peaks with precipitation events and ammonium concentrations higher than $2 \mathrm{mg} / \mathrm{L}$, especially in subperiods characterized by low $\mathrm{N}_{2} \mathrm{O}$ fluxes. Additionally, the highest ranges of measured $\mathrm{N}_{2} \mathrm{O}$ fluxes belonged to clusters corresponding with $\mathrm{NO}_{3}-\mathrm{N}$ concentration less than $1 \mathrm{mg} / \mathrm{L}$ in the upstream plug-flow reactor

27 (middle of oxic zone), indicating slow nitrification rates. The results showed that the range of $\mathrm{N}_{2} \mathrm{O}$ emissions partially depend on the prior behavior of the system. The principal component analysis validated the findings from the clustering analysis and showed that ammonium, nitrate, nitrite and temperature explained a considerable percentage of the variance in the system for the majority of the sub-periods. The applied statistical methods, linked the different ranges of emissions with the system variables, provided insights on the effect of operating conditions on $\mathrm{N}_{2} \mathrm{O}$ emissions in each sub-period and can be integrated into $\mathrm{N}_{2} \mathrm{O}$ emissions data processing at wastewater treatment plants. 


\section{Abbreviations}

AOR: Ammonia oxidation rate

$\mathrm{CH}_{4}: \quad$ Methane

$\mathrm{CO}_{2}: \quad$ Carbon dioxide

DO: Dissolved oxygen

GHG: Greenhouse gas

$\mathrm{N}_{2} \mathrm{O}: \quad$ Nitrous oxide

$\mathrm{NH}_{4}-\mathrm{N}: \quad$ Ammonium nitrogen

$\mathrm{NO}_{2}-\mathrm{N}: \quad$ Nitrite nitrogen

$\mathrm{NO}_{3}-\mathrm{N}: \quad$ Nitrate nitrogen

PC: $\quad$ Principal component

PCA: Principal component analysis

PLS: Partial least squares

TN: $\quad$ Total nitrogen

WWTP: Wastewater treatment plant 


\section{Introduction}

The increasing demand to reduce the carbon footprint of municipal wastewater treatment plants (WWTPs) by reducing greenhouse gas (GHG) emissions and energy consumption, is posing new challenges for the water industry (Flores-Alsina et al., 2014). The climate change pressures prompt the quantification and minimization of GHG emissions generated in WWTPs (Haas et al., 2014). Three main sources of GHG emissions prevail in WWTPs (Monteith et al., 2005; Mannina et al., 2016): (i) the direct emissions mainly nitrous oxide $\left(\mathrm{N}_{2} \mathrm{O}\right)$ (Kampschreur et al., 2009b). high nitrification efficiency and the potential biomass adaptation to continuously varying DO concentrations. Results from real-field $\mathrm{N}_{2} \mathrm{O}$ monitoring campaigns cannot fully explain long-term causes of $\mathrm{N}_{2} \mathrm{O}$ emissions 
60 (Jönsson et al., 2015). Long-term full-scale monitoring campaigns have shown that $\mathrm{N}_{2} \mathrm{O}$ fluxes are highly 61 dynamic with significant diurnal fluctuations and seasonal variations; however, the dynamics cannot be fully explained (Daelman et al., 2015; Kosonen et al., 2016).

63 Several mechanistic process models describing $\mathrm{N}_{2} \mathrm{O}$ emissions from wastewater treatment plants have been developed over the last few years (Massara et al., 2017). While they have been successfully applied to identify $\mathrm{N}_{2} \mathrm{O}$ formation mechanisms and pathways from experimental data (Ni et al., 2015; Pocquet et al., 2016), their calibration and validation to long-term process data remains a challenge. Domingo-Félez and F. Smets (2016) reported that substrate affinity constants for $\mathrm{NO}_{2}$ and $\mathrm{NO}$ reduction in existing $\mathrm{N}_{2} \mathrm{O}$ models differ by a factor of about 100. Additionally, calibration of models under specific operational conditions (i.e. dry weather) can affect their performance and accuracy when the system varies (Gernaey et al., 2004; Guo and Vanrolleghem, 2014). Moreover, full-scale $\mathrm{N}_{2} \mathrm{O}$ emission data show long-term trends that cannot be explained by commonly available operational data (Daelman et al., 2015) but are possibly caused by microbial population changes, which are hard to catch with the current models, typically describing single functional groups with fixed parameter sets. Multivariate statistical techniques are capable of identifying relationships between $\mathrm{N}_{2} \mathrm{O}$ emissions and a multitude of influencing factors, at the same time identifying various operating sub-periods for which this behaviour may differ. This will lead to increased understanding of experimental data, on its turn facilitating the application, calibration and validation of mechanistic models. As such, multivariate statistical techniques maximize the information acquired from $\mathrm{N}_{2} \mathrm{O}$ monitoring campaign data.

Statistical techniques have been used for the analysis of data from full-scale monitoring campaigns, to identify interconnections between operating and environmental variables on the one hand and $\mathrm{N}_{2} \mathrm{O}$ formation on the other hand. Through multiple linear regression analyses, Aboobakar et al. (2013) showed dependencies between $\mathrm{N}_{2} \mathrm{O}$ emissions and nitrogen load, temperature and dissolved oxygen (DO) in various compartments of a plug-flow reactor for biological nitrogen removal. Multi-regression analysis of one year of data with bimonthly sampling frequency, coming from a full-scale SBR (Sun et al., 2013) indicated negative correlation between $\mathrm{N}_{2} \mathrm{O}$ emissions and temperature, while COD/N ratio lower than 6 resulted in higher emissions. Brotto et al. (2015) used Spearman's rank correlation to explain the behavior of $\mathrm{N}_{2} \mathrm{O}$ emissions in an activated sludge 
process. The analysis showed negative correlation between $\mathrm{N}_{2} \mathrm{O}$ emissions and $\mathrm{pH}$ but positive correlation between $\mathrm{N}_{2} \mathrm{O}$ fluxes and temperature. However, most of the studies did not consider continuous long-term operational data, while further analysis is required to gain a better understanding on the dynamics and tradeoffs between $\mathrm{N}_{2} \mathrm{O}$ generation and the online monitored and controlled process variables. Multivariate analysis has been proven to be a suitable method for the identification of patterns and hidden relationships within WWTP data (Rosén and Lennox, 2001) and can be applied to provide insights on the combined effect of operational variables on $\mathrm{N}_{2} \mathrm{O}$ emissions in full-scale systems. Chemometric techniques have been applied to the wastewater treatment sector for 40 years (Rosén and Olsson, 1998), enabling the visualization and interpretation of the multi-dimensional interrelations of the operational variables monitored in biological processes (Platikanov et al., 2014). Their application can (i) improve the efficiency of process monitoring (Mirin and Wahab, 2014) and provide further insights of the biological processes (Moon et al., 2009), (ii) identify and isolate process faults (Haimi et al., 2016; Liu et al., 2014; Maere et al., 2012; Rosen and Yuan, 2001), sensor faults (Lee et al., 2004), and iii) predict significant operating variables in the biological systems that affect performance (Rustum et al., 2008). Furthermore, the gradual implementation of online sensors to monitor important parameters in the biological treatment train of WWTPs results in the production of time series, which require the application of specific statistical tools for their interpretation. The most widely applied approaches include methods aiming to reduce the dimensionality of large data-sets (i.e., principal component analysis (PCA), partial least squares (PLS)) and data clustering techniques (i.e., hierarchical clustering, k-means clustering) (Haimi et al., 2013). However, there are limited studies investigating the behavior of $\mathrm{N}_{2} \mathrm{O}$ emissions with the application of multivariate statistical techniques, especially utilizing online operational data in long-term monitoring.

The aim of this work is to investigate whether widely applied multivariate statistical techniques can be applied to the online data collected from real-field $\mathrm{N}_{2} \mathrm{O}$ monitoring campaigns in order to gain a better understanding on the dynamic behavior of $\mathrm{N}_{2} \mathrm{O}$ emissions and explain the combined effect of the operating variables monitored in wastewater treatment processes on $\mathrm{N}_{2} \mathrm{O}$ emissions. Hourly data from the operating variables monitored online and $\mathrm{N}_{2} \mathrm{O}$ emissions data in a full-scale carrousel reactor from the long-term monitoring 
112 campaign published by Daelman et al. (2015) were used for the analysis. A statistical methodological 113 approach was developed, applying changepoint detection techniques to identify changes in the $\mathrm{N}_{2} \mathrm{O}$ fluxes 114 behavior combined with hierarchical k-means clustering and PCA, to provide insights on $\mathrm{N}_{2} \mathrm{O}$ emissions 115 patterns and generation pathways. 


\subsection{Process description and data origin}

118 This work was based on the data obtained by Daelman et al. (2015) for the Kralingseveer WWTP, consisting 119 of a plug-flow reactor followed by two carrousel reactors in parallel (Figure 1). The plant treated $80.000 \mathrm{~m}^{3}$ $120 \mathrm{~d}^{-1}$ of domestic wastewater from a combined sewer system. The carrousel reactors were characterized by 121 alternating anoxic/oxic zones; aeration was performed through surface aerators, which were manipulated to 122 control the ammonium concentration in the effluent. Aerator 1 operates under on/off pattern, being on when 123 the ammonium concentration was higher than $1.2 \mathrm{mg} \mathrm{N} / \mathrm{L}$ ), while surface aerators 2 and 3 were always 124 operational to keep the solids from settling but operated at maximum capacity when the ammonium concentration became higher than 0.6 and $0.9 \mathrm{mg} / \mathrm{L}$, respectively. Over the monitoring period the average total nitrogen (TN) removal efficiency was $81 \pm 10 \%$; the average COD removal efficiency was equal to $87 \pm 5 \%$.

Ammonium nitrogen $\left(\mathrm{NH}_{4}-\mathrm{N}\right)$, nitrate nitrogen $\left(\mathrm{NO}_{3}-\mathrm{N}\right)$ and $\mathrm{DO}$ were monitored in the middle of the second oxic zone in the plug flow reactor (location 1, Figure 1). The carrousel reactors were equipped with, $\mathrm{NH}_{4}-\mathrm{N}$, temperature probes, and 3 DO probes (DO1, DO2, DO3) (locations 2, 3, 4, Figure 1). The Northern carrousel reactor was also equipped with a nitrite probe. All the reactors were covered, and the off-gas was collected in ducts and pumped to a Servomex gas analyzer, where $\mathrm{N}_{2} \mathrm{O}$ was measured. Table S1 lists all the variables monitored online (Supplementary material). The data matrix developed consists of the variables monitored in the carrousel reactor $\left(\mathrm{DO}, \mathrm{NH}_{4}-\mathrm{N} \mathrm{C}, \mathrm{NO}_{3}-\mathrm{N} \mathrm{C}, \mathrm{NO}_{2}-\mathrm{N} \mathrm{C}, \mathrm{N}_{2} \mathrm{O}\right.$ C), the influent flow-rate, as well as the $\mathrm{NH}_{4}$ -

$134 \mathrm{~N}$ and $\mathrm{NO}_{3}-\mathrm{N}$ concentrations from the plug-flow reactor. $24 \mathrm{~h}$ composite samples of influent and effluent, available about every 6 days, were used to support the analysis. Figure 2, summarizes the methodological framework applied to the online database.

[Figure 1]

\subsection{Methodological framework for data analysis}

139 The monitoring period was divided into distinct sub-periods based on the profile of $\mathrm{N}_{2} \mathrm{O}$ fluxes in the 140 carrousel reactor. Spearman's correlation analysis, k-means clustering, hierarchical clustering, and Principal 
141 component analysis were applied to the database. The application of clustering algorithms facilitated the 142 identification of operational modes that have historically resulted in specific ranges of $\mathrm{N}_{2} \mathrm{O}$ emissions. The 143 PCA reduced the dimensionality of the data-set transforming the sensor signals into useful knowledge that that 144 can be easily interpreted. The methodological framework is extensively described in the following sub145 sections.

147 The data-driven approach enabled the utilization of the information and patterns embedded in the real-time 148 monitored variables (from the system sensors) in the biological processes and GHG measurements. 149 Multivariate statistical analysis is an alternative to univariate analysis that is commonly applied for the 150 analysis of WWTP data. It enables the identification of patterns and interrelations in data-sets by examining 151 multiple variables simultaneously (Olsson et al., 2014). $\mathrm{R}$ software was used for the statistical analysis (R 152 Core Team, 2017). The complete list of packages used is provided in the supplementary material (Table S2).

\subsubsection{Preliminary data processing}

154 The preliminary data analysis included: (i) data synchronization under the same time-stamp, and ii) removal 155 of duplicate and unreliable measurements (multiple readings at the same time stamp for the same sensor). The data were aggregated into hourly averages in order to compensate for the missing data due to variation in

157 sampling frequency between the different variables monitored. Exponential moving average imputation was 158 applied when less than 24 consequential data were missing for each variable. Longer periods of missing data were excluded from the analysis.

\subsubsection{Binary segmentation changepoint detection}

161 Given a series of data, change point analysis investigates abrupt changes in a data-series when specific 162 properties change (i.e., mean and variance) (Kawahara and Sugiyama, 2012). The Binary Segmentation (Scott 163 and Knott, 1974) is a widely applied and computationally efficient changepoint detection algorithm (Killick et 164 al., 2012). The algorithm employs initially single changepoint detection method to the complete data-set as described in (Killick and Eckley, 2014). If a changepoint is identified the procedure is repeated to the two new 
segments formed; before and after the changepoint. The process continues splitting the data until there are no more changepoints identified. The computational cost of the algorithm is of the order of $O(n \log n)$ with $n$ being the number of data in the data-set and therefore it is applicable in large data-sets. A distribution-free test statistic was applied based on the work of Chen and Gupta, (1997). The penalty for the changepoints identification was equal to $\log (\mathrm{n})$. The algorithm requires independent data points. Therefore, first difference transformation of the $\mathrm{N}_{2} \mathrm{O}$ timeseries was performed and changes in variance were identified by the Binary segmentation algorithm. The profile of the $\mathrm{N}_{2} \mathrm{O}$ emissions was highly variable during the monitoring

173 campaign. Binary segmentation enabled the identification of the sub-periods characterized by different $\mathrm{N}_{2} \mathrm{O}$ 174 emissions' profile.

\section{$175 \quad 2.2 .3 \quad$ Spearman's rank correlation}

176 Spearman's rank correlation coefficient (Spearman, 1904) was used to detect bivariate temporal monotonic trends among the system variables for the different sub-periods; it served as a measure of the association 178 strength. This method is based on the rank of the values and therefore, is less sensitive to outliers than 179 Pearson's correlation. P values lower than .01 were considered to be significant.

\subsubsection{Hierarchical $k$-means clustering}

181 Clustering techniques are widely applied in data mining in order to identify and group the underling patterns that exist in high dimensional data sets (Jain, 2010). K-means clustering (Hartigan and Wong, 1979) is a 183 recognized clustering algorithm (Haimi at al., 2013). K-means clustering was applied to categorize the data in 184 groups of similar observations and to investigate the patterns of $\mathrm{N}_{2} \mathrm{O}$ emission fluxes, based on Euclidean distance. K-means algorithm begins with the selection of $\mathrm{k}$ random centroids of the same dimension within the original data. All the data-points are compared and assigned to the nearest centroid. During each iteration, the nearest data to each centroid are re-defined and centroids are recalculated in a way that squared distances of all points within a cluster to the cluster's centroid are minimized. However, the randomly selected initial centroids can result into locally optimized clustering results (Abu-Jamous et al., 2015). Therefore, hierarchical

190 k-means clustering that was proposed by Arai and Barakbah, (2007), was applied to the dataset. In this 
192 the centroids; Ward's method is used in order to divide the dataset in clusters (Ward Jr, 1963). The data were 193 normalized before the analysis. NBclust package in R (Charrad et al., 2014) was used to select the number of 194 clusters in each sub-period. The package applies a number cluster validity indexes (i.e. average silhouette 195 value (Rousseeuw, 1987); Hartigan's rule (Hartigan, 1975)).

196 Hierarchical k-means clustering was applied to the carrousel reactor data matrix from the different sub-periods 197 identified through binary segmentation, to investigate whether different temporal patterns of the operating 198 variables were responsible for the different behavior of $\mathrm{N}_{2} \mathrm{O}$ emissions. Hierarchical k-means clustering 199 enabled i) the detection of frequency and persistence of extreme ranges of operating variables, and ii) the 200 comparison of the operational modes between the plug-low and carrousel reactor. Ammonium and nitrate 201 probes in the plug-flow reactor were included in the analysis, since they can provide indirect feedback in terms of the carrousel reactor influent and additional information for the operational behavior of the system. 203 However, the analysis was repeated excluding plug-flow variables $\left(\mathrm{NH}_{4}-\mathrm{N}\right.$ and $\left.\mathrm{NO}_{3}-\mathrm{N}\right)$. Graphical comparisons of the clustered data-points versus time and boxplots of the variables in each identified cluster are displayed in the results' section.

\subsubsection{Principal component analysis}

207 Principal component analysis (PCA) (Jolliffe, 2002) was applied to the dataset in an effort to reduce the 208 dimensionality of the data by eliminating a small proportion of variance in the data. PCA transforms the 209 original correlated measured variables to uncorrelated variables, i.e., Principal components (PCs), explaining 210 the maximum observed variability. The principal components are linear combinations of the original data 211 variables. The loadings of the variables in each principal component can map their relationship with the 212 respective principal component. PC scores are a linear combination of the data, weighted by the PC loadings 213 for each variable. The scores of the principal components map the different samples in the new dimensional 214 space of the principal components facilitating the investigation of the different relationships between the 215 variables. The data matrices (X) consisting of $\mathrm{J}$ columns (variables) and I data rows (number of observations) 216 were normalized with mean equal to 0 and standard deviation equal to 1 . Each column of $\mathbf{X}, x_{j}=$ 
$217\left(x_{1 j}, \ldots x_{I j}\right) T, \mathrm{j}=1, \ldots \mathrm{J}$, represents a vector in the I-dimensional space. In PCA, eigenvalue decomposition is 218 used to factorize the data matrix $\mathrm{X}(\mathrm{I} X J)$ and to map the data matrix to a reduced dimensional space:

$$
X=T P^{T}+E
$$

219 where, $T$ : matrix $(I x S)$ representing the score of the principal components, $S$ : the number of principal 220 components selected, $P$ : matrix $(J x S)$ representing the loadings and $E$ : matrix of residuals.

221 The biplot of the first 2 PCs was used in order to visualize the combined behavior of significant variables that 222 affect the system. The biplots enabled the simultaneous visualization of i) the variables' loadings in the first 223 two principal components, ii) the scores of the first two principal components, and iii) the different clusters. 224 The temporal variations of the PC scores enabled the identification of occasions in which the behavior of the 225 system changes. PCA was applied to the data matrix of the carrousel reactor excluding $\mathrm{N}_{2} \mathrm{O}$ emissions time 226 series, i) to identify the most significant variables that affect the system, (ii) to analyze the structure of the sensor data, iii) to investigate if changes in the relationship of the system coincide with changes in the $\mathrm{N}_{2} \mathrm{O}$ emissions profile, and iv) to validate the results from hierarchical clustering. $\mathrm{N}_{2} \mathrm{O}$ emissions time series were excluded from the PCA in order to investigate the relationship between the PC scores and $\mathrm{N}_{2} \mathrm{O}$ emissions and to examine which PCs are most significantly linked to the behavior of $\mathrm{N}_{2} \mathrm{O}$ emissions. 


\section{Results and discussion}

\section{1 $\quad \mathrm{N}_{2} \mathrm{O}$ emissions profile and main dependencies}

233 The profile of all the variables monitored was fluctuating during the monitoring period, which can justify the 234 different profiles of $\mathrm{N}_{2} \mathrm{O}$ emissions that resulted from the Binary Segmentation algorithm. Overall, high 235 ranges of emissions were reported when nitrate concentration in the plug-flow reactor was low, whereas periods with lower ammonium concentrations in the plug-flow reactor were linked with lower $\mathrm{N}_{2} \mathrm{O}$ emissions.

Table 1 shows the average values and standard deviations of the variables monitored online and offline in the

238 Northern carrousel and plug-flow reactors. $\mathrm{N}_{2} \mathrm{O}$ fluxes peaked in March 2011 followed by a period 239 characterized by very low $\mathrm{N}_{2} \mathrm{O}$ emissions. Gradual decrease was observed until November 2011 and 240 negligible emissions again until January 2011 (Figure 3).

242 The application of Binary Segmentation algorithm to the $\mathrm{N}_{2} \mathrm{O}$ emissions of the Northern carrousel reactor 243 identified 9 changepoints that correspond to 10 sub-periods with distinct variance of the $\mathrm{N}_{2} \mathrm{O}$ timeseries first 244 difference (Figure 3). The analysis identified abrupt temporal changes in the emission dynamics that indicate 245 changes in the underlying mechanisms or environmental conditions responsible for the $\mathrm{N}_{2} \mathrm{O}$ formation.

247 Offline data were analyzed in the different sub-periods in order to investigate significant changes that can 248 contribute to the high $\mathrm{N}_{2} \mathrm{O}$ emissions in sub-periods 4 and 5. The average COD concentration in the influent 249 of the plug-flow reactor (effluent of primary sedimentation) was $239 \pm 80 \mathrm{mg}$ COD/L over the 15 -month monitoring period. The average plug-flow reactor influent and carrousel reactor effluent concentrations of COD, TKN, BOD, TP and the effluent $\mathrm{pH}$ for all sub-periods are given in the supplementary material (Table 252 S3). In sub-period 5, 27\% increase in the influent COD concentration to the plug flow reactor (compared to 253 average value) was observed, which could be attributed to less precipitation events and to the consequently 254 lower average influent flow-rate during this sub-period. Laboratory analyses did not show significant seasonal 
changes in the plug-flow COD loading $(19,934 \pm 13310 \mathrm{~kg}$ COD/day). The COD loading in sub-period 4

$256(16,160 \pm 2546 \mathrm{~kg}$ COD/day) was $17 \%$ less than in sub-period 1 . TKN and TP loadings were reduced in sub-

period 4 compared to sub-period, by $11 \%$ and $12 \%$ respectively. The COD:TKN:TP ratio remained quite stable, ranging between 1:0.17:0.02 (sub-period 2) and 1:0.20:0.03 (sub-period 4).

Figure 4 shows the different COD to TKN ratios measured for all the sub-periods. There were cases with lower than average $\mathrm{COD} / \mathrm{TKN}$ in the influent of the plug-flow reactor that coincided with increased $\mathrm{N}_{2} \mathrm{O}$ emissions, particularly in sub-periods 4 and 5. However, low ranges of COD/TKN $(<5)$ in sub-periods 1, 2, 7 and 6 corresponded with low $\mathrm{N}_{2} \mathrm{O}$ emissions. These observations indicate that limitation of $\mathrm{COD}$ cannot be considered the sole contributor of $\mathrm{N}_{2} \mathrm{O}$ emissions via heterotrophic denitrification in sub-periods 4 and 5 .

[Figure 4]

The COD removal efficiency remained relatively steady during the monitoring campaign ranging from $79 \%$ (sub-period 8) to 91\% (sub-period 5). The range of TN and TP removal efficiencies ranged from $73 \%$ (subperiods 1 and 9) to $92 \%$ (sub-period 5) and from 67\% (sub-period 7) to 87\% (sub-period 4). The effluent $\mathrm{pH}$ was steady $(\sim 8)$ and did not show seasonal variability that could influence the generation of $\mathrm{N}_{2} \mathrm{O}$ emissions.

On the other hand, a significant variation is observed for all variables monitored online by analyzing at the complete database. Table 2 summarizes the average values and standard deviations of the online monitored variables considered in the analysis for the target periods. In the carrousel reactor, the nitrite concentration is relatively high in sub-period 4 (average $=2.6 \mathrm{mg} / \mathrm{L})$ and in the first part of sub-period 10 (average $=2.1$ $\mathrm{mg} / \mathrm{L}$ ). The average temperature in both cases is $\sim 13{ }^{\circ} \mathrm{C}$. In biological reactors operating in continuous mode, appreciable (> $2 \mathrm{mg} \mathrm{N} / \mathrm{L}$ ) nitrite concentrations are usually not observed, since nitrite is directly oxidized by nitrite oxidizing bacteria into nitrate. However, in certain cases, high nitrite concentrations in biological processes have been observed, which have been linked with low temperatures that affect $\mathrm{N}_{2} \mathrm{O}$ reductase during denitrification enhancing $\mathrm{N}_{2} \mathrm{O}$ production (Holtan-Hartwig et al., 2002; Adouani et al., 2015).

Analyzing the whole profile, the emissions tended to be low at higher temperatures (sub-periods 6, 7, and 8). 
280 (i.e., sub-period 5). Ahn et al. (2010) demonstrated that $\mathrm{N}_{2} \mathrm{O}$ emissions can be significant at higher 281 temperatures due to the higher enzymatic activities of the bioprocesses producing $\mathrm{N}_{2} \mathrm{O}$. In the carrousel 282 reactor during sub-periods 4 and 5, the temperature increases from 11.8 to $20{ }^{\circ} \mathrm{C}$. Low $\mathrm{N}_{2} \mathrm{O}$ emissions were 283 also observed when ammonium concentration was lower than $13 \mathrm{mg} / \mathrm{L}$ and nitrate was higher than $2.5 \mathrm{mg} / \mathrm{L}$ 284 in the plug-flow reactor. The probe was located in the middle of the second oxic zone; thus, lower ammonium concentrations in the plug-flow reactor can indicate less ammonium loads in the carrousel reactor.

The analysis of the variables' ranges for the $\mathrm{N}_{2} \mathrm{O}$ emission profiles provides limited insight on the dependencies between the system variables monitored online, which is further analyzed in the following sections.

\subsection{Spearman's rank correlation analysis for carrousel reactor}

291 The application of Spearman's rank correlation coefficient to the data of the carrousel reactor could not identify significant correlations between the $\mathrm{N}_{2} \mathrm{O}$ emissions and the operating variables. The lack of monotonic univariate dependencies could be attributed to i) the temporal fluctuations of the influent characteristics, ii) the continuous variability in the operating conditions of the reactors, and iii) the seasonal variations of the environmental conditions in wastewater treatment processes. Fluctuating correlation coefficients between $\mathrm{N}_{2} \mathrm{O}$ emissions and carrousel reactor variables were identified (Supplementary, Figures S1:S2). The findings are in line with the study of Kosonen et al., (2016). The authors compared the results from two monitoring periods at the same biological system and identified different relationships between $\mathrm{N}_{2} \mathrm{O}$ emissions and $\mathrm{BOD}_{7(\mathrm{ATU})}$ loads.

The correlation coefficient between nitrite and $\mathrm{N}_{2} \mathrm{O}$ emissions ranged from 0.78 (sub-period 7) to 0.51 (subperiod 9). As a general remark, nitrite was correlated with $\mathrm{N}_{2} \mathrm{O}$ emissions in sub-periods 4,6 and 7, while lower correlation was observed during sub-periods 5 (Figure 5), 8 and 9. $\mathrm{N}_{2} \mathrm{O}$ emissions and $\mathrm{NO}_{3}-\mathrm{N}$ concentration in the carrousel reactor exhibited a positive correlation with coefficient higher than 0.7 for subperiods 2 (Figure 5), 4 and 10 (the temperature was lower than $13{ }^{\circ} \mathrm{C}$ in all cases). $\mathrm{N}_{2} \mathrm{O}$ emissions and $\mathrm{NO}_{3}-\mathrm{N}$ 
concentrations followed similar diurnal patterns, wherein peaks in nitrate concentration coincided with peaks in $\mathrm{N}_{2} \mathrm{O}$ emissions (Daelman et al., 2015). The accumulation of nitrate is potentially linked with higher nitrification than denitrification rates. This is in line with Daelman et al. (2015), considering that the nitrate utilization rate in these sub-periods is affected by the low temperatures (Elefsiniotis and Li, 2006). 309 Additionally, during times when $\mathrm{N}_{2} \mathrm{O}$ was positively correlated with $\mathrm{DO} 1(>0.5)$, medium to significant correlations between the $\mathrm{N}_{2} \mathrm{O}$ emissions and the ammonium concentration in the carrousel reactor were also observed (sub-periods 1, 6 and 7). Stripping of the already formed $\mathrm{N}_{2} \mathrm{O}$ can be a potential explanation. Given

312 that the surface aerator in the location of DO1 probe is manipulated to control the ammonium concentration in 313 the effluent, ammonium peaks trigger the surface aerators to start.

314 The correlation coefficient between any two of the system variables did not remain stable between the 315 different sub-periods. Figure 5 shows the correlograms for sub-periods 2 and 5 . These sub-periods were characterized by low and high ranges of $\mathrm{N}_{2} \mathrm{O}$ emissions and temperature respectively (Table 2). In sub-period the same reactor. The ammonium concentration in the carrousel reactor was positively correlated with DO1 only in sub-period 2. $\mathrm{NH}_{4}-\mathrm{N}$ concentration in the plug-flow reactor was correlated with the influent-flow rate only in sub-periods 4 and 5. However, the profiles of these two variables showed that in the majority of the sub-periods, abrupt and rapid increase of influent flow-rate (i.e., precipitation events) coincided with increase of the $\mathrm{NH}_{4}-\mathrm{N}$. However, the $\mathrm{NH}_{4}-\mathrm{N}$ concentration reduced more rapidly in the system than the influent flowrate. For example, in sub-period 3 the correlation coefficient between $\mathrm{NH}_{4}-\mathrm{N}$ in the plug-flow reactor and influent flow-rate was 0.26. However, when days with significant precipitation events (and thus high influent flow-rate) were omitted, the correlation coefficient was equal to 0.58 . The latter shows that, in this example, the lack of correlation between these two variables is most likely to be an indication that the interrelationships are not monotonic and that the method is not appropriate to identify complex relationships within the data. In order to verify that increased influent flow-rate was linked with precipitation events, daily precipitation data 
were extracted from the Royal Netherlands meteorological institute. Spearman's correlation coefficient

332 between two days moving average of influent flow-rate and daily precipitation in the Netherlands was equal to

333 0.69. Therefore, there is a direct link between higher than average flow-rates and precipitation events (the

334 timeseries are shown in Figure S3, supplementary material). The correlograms for all sub-periods are provided

335 in the Supplementary material (Figures S1:S2).

336 Spearman's rank correlation indicated structural changes in the dependencies between the system variables.

337 Therefore, the fluctuating structural dependencies had a different impact on the generation of $\mathrm{N}_{2} \mathrm{O}$ emissions.

338 Previous studies have shown that various monitored variables in the biological system $\left(\mathrm{NH}_{4}-\mathrm{N}, \mathrm{NO}_{3}-\mathrm{N}, \mathrm{NO}_{2^{-}}\right.$

$339 \mathrm{~N}$, Temperature) can affect $\mathrm{N}_{2} \mathrm{O}$ emissions generation. However, further analysis is required to investigate

340 their combined effect in $\mathrm{N}_{2} \mathrm{O}$ formation in full-scale complex systems.

[Figure 5]

\subsection{Hierarchical k-means clustering}

343 The application of hierarchical k-means clustering enabled the categorization of the different ranges of the 344 operating variables and $\mathrm{N}_{2} \mathrm{O}$ emissions within each sub-period

345 Hierarchical k-means clustering analysis was repeated excluding $\mathrm{NH}_{4}-\mathrm{N}$ and $\mathrm{NO}_{3}-\mathrm{N}$ concentrations in the plug-flow reactor. The results showed that the majority of the data points were allocated to the same clusters

347 for each sub-period even when the $\mathrm{NH}_{4}-\mathrm{N}$ and $\mathrm{NO}_{3}-\mathrm{N}$ concentrations in the plug-flow reactor were excluded. 348 In the majority of the sub-periods (i.e. sub-periods 1-6) more than $85 \%$ of the data points were assigned to the 349 same cluster. It can be concluded that specific patterns and ranges of $\mathrm{NH}_{4}-\mathrm{N}$ and $\mathrm{NO}_{3}-\mathrm{N}$ monitored in plug350 flow reactor, systematically resulted in specific responses to the carrousel reactor. The latter is supported by the Spearman's rank correlation analysis, where high correlations were observed between the variables in the two reactors for several sub-periods. For example, the correlation coefficient between $\mathrm{NH}_{4}-\mathrm{N}$ in the plug-flow and carrousel reactors is higher than 0.7 for sub-periods 1 to 7 . The similarity of the clusters for all the subperiods is shown in Table S4 in the Supporting Material. 
355 The range of $\mathrm{N}_{2} \mathrm{O}$ emissions was differentiated in the majority of the clusters. In all the sub-periods, two 356 major clusters were identified characterized by significant differences in the $\mathrm{NH}_{4}-\mathrm{N}$ and $\mathrm{NO}_{3}-\mathrm{N}$ 357 concentrations in the plug-flow reactor. In the majority of the sub-periods they represented the diurnal 358 variability of the system nutrient concentrations and influent-flow rate. Additionally, clustering distinguished occasions with high influent flow-rate and ammonium concentration in the carrousel reactor, which can be an indication of precipitation events. In sub-periods characterized by low average $\mathrm{N}_{2} \mathrm{O}$ emissions (i.e., 1, 2, 7, 8 and 9), clusters with increased $\mathrm{N}_{2} \mathrm{O}$ emissions (yet relatively low) were mainly linked to higher loading rates 362 due to the expected diurnal variability or to precipitation events. However, $\mathrm{N}_{2} \mathrm{O}$ emissions higher than 3.8 $363 \mathrm{~kg} / \mathrm{h}$ were observed when the average $\mathrm{NO}_{3}-\mathrm{N}$ concentration was constantly lower than $1 \mathrm{mg} / \mathrm{L}$ in the plug364 flow reactor and the $\mathrm{NO}_{3}-\mathrm{N}$ concentration was lower than $4 \mathrm{mg} / \mathrm{L}$ in the carrousel reactor. Table 3 compares the clustered average values for all the variables in sub-period 2 (average $\mathrm{N}_{2} \mathrm{O}$ emissions equal to $0.6 \mathrm{~kg} / \mathrm{h}-$ Table 2) and 4 (average $\mathrm{N}_{2} \mathrm{O}$ emissions equal to $5.6 \mathrm{~kg} / \mathrm{h}$ - Table 2). The average value of $\mathrm{N}_{2} \mathrm{O}$ emissions for a set of clusters in a specific sub-period (from Table 3) can be found taking into account the number of datapoints in the individual clusters. Sub-period 4 was characterized by very low $\mathrm{NO}_{3}-\mathrm{N}$ concentration in the middle of the oxic zone in the plug-flow reactor. The latter indicates slower oxidation of ammonia to nitrate or insufficient DO in the plug-flow nitrification lane. This can lead to higher $\mathrm{NH}_{4}-\mathrm{N}$ loading in the carrousel reactor. On the other hand, higher nitrification rates in the plug-flow reactor (i.e. sub-period 2) resulted in lower $\mathrm{N}_{2} \mathrm{O}$ emissions in the carrousel reactor. The average values of all the variables in each cluster during all the sub-periods are given as supplementary material (Table S5).

In clusters 2 and 16 the averages of operating variables had similar ranges (Table 3). However, in these two occasions the $\mathrm{N}_{2} \mathrm{O}$ emissions were different $(0.01$ and $0.51 \mathrm{~kg} / \mathrm{h})$. Similarly, in clusters 1,4 and 7 , the averages of operating variables were similar yet the $\mathrm{N}_{2} \mathrm{O}$ emissions were different $(0.09,0.87$ and $3.22 \mathrm{~kg} / \mathrm{h}$ respectively). A corollary to this also existed. In clusters 1 and 2 the averages of operating variables were different but the $\mathrm{N}_{2} \mathrm{O}$ emissions were similar (0.09 and 0.01). Similarly, in clusters 5 and 6 the averages of operating variables were different but the $\mathrm{N}_{2} \mathrm{O}$ emissions were similar $(0.21$ and 0.24$)$. Such observations indicate the underlying complexities of the interdependencies. Additionally, it can be concluded that the range 
of $\mathrm{N}_{2} \mathrm{O}$ emissions can partially depend on the preceding operational mode of the system. Figure 6 shows an example of the variables monitored online for two separate occasions in sub-periods 2 and 3 (from 00:00 am until 8:00 am) and the respective $\mathrm{N}_{2} \mathrm{O}$ emissions. All the variables showed a similar behavior (in terms of range and trends). $\mathrm{N}_{2} \mathrm{O}$ emission profiles had also the same trend; however, their range depended on the initial $\mathrm{N}_{2} \mathrm{O}$ fluxes at 00:00 am. The influent flow-rates, $\mathrm{NH}_{4}-\mathrm{N}$ and $\mathrm{NO}_{3}-\mathrm{N}$ concentrations in the plug-flow reactor also were similar in these two occasions. The average $\mathrm{N}_{2} \mathrm{O}$ fluxes were equal to 0.44 and $2.01 \mathrm{~kg} / \mathrm{h}$ for occasion 1 and 2 respectively. More extensive data are required for quantitative investigation.

[Table 3]

[Figure 6]

\subsection{Principal component analysis in the carrousel reactor}

PCA was applied to transform the original correlated measured variables to uncorrelated variables (Principal components) and explain the maximum observed variability. In sub-periods with low emissions $(1,2,7,8$, and 9) the PCA analysis showed that $\mathrm{N}_{2} \mathrm{O}$ emissions' peaks are related with $\mathrm{NH}_{4}-\mathrm{N}$ and influent flow-rate peaks in the carrousel reactor and with the effect of the diurnal variability of these variables' loading rates.

The current section discusses the PCA results for sub-period 2, as an example. The results for all the subperiods are given in the supplementary material (Tables S6-S13, Figures S4-S29). The application of PCA reduced the dimensionality of the data with 4 principal components (PCs) explaining $\sim 86 \%$ of the total variance $(\mathrm{PC} 1=39 \%, \mathrm{PC} 2=26 \%, \mathrm{PC} 3=12 \%$, and $\mathrm{PC} 4=9 \%)$. Loadings for the system variables in the 4 PCs are given in Table 4. The loadings of each component are an indication of the variation in the variables explained by a specific component. Influent flow-rate, ammonium concentration in the carrousel reactor $\left(\mathrm{NH}_{4}-\mathrm{N} \mathrm{C}\right)$ and the three DO (DO1, DO2 and DO3) concentrations had the highest negative loadings in PC1. This means that the first principal component increased with the increase of these variables. Nitrate concentration $\left(\mathrm{NO}_{3}-\mathrm{N}\right.$ PF) in the plug-flow reactor has a relatively high positive loading in $\mathrm{PC} 1(0.36)$. Therefore, $\mathrm{PC} 1$ describes how the carrousel reactor responds to the behavior of the upstream plug-flow reactor processes and conditions, the variation of the influent flow-rate and variations in ammonium and DO 
concentrations in the carrousel reactor. The latter can be indirectly connected with the control strategy of the carrousel reactor, since the surface aerators were manipulated based on the effluent ammonium concentration. PC2 linked ammonium concentration in the plug-flow reactor, nitrate concentration in the carrousel reactor and temperature (loadings higher than 0.47). In PC3 ammonium concentration in the carrousel reactor had high negative loading, while DO2 and DO3 concentrations had positive loadings that was not expected considering the control strategy of the system. Investigation of the variables' profiles, though, showed an increasing trend of $\mathrm{DO} 2$ and $\mathrm{DO} 3$, whereas the ammonium profile did not present a similar trend.

[Table 4]

414 The biplot of the first 2 PCs is used to visualize the combined behavior of significant variables that affect the system. Data points assigned to cluster 6 (Figure 7), had negative scores in PC2 and PC1. Therefore, ammonium concentration in the carrousel reactor and influent flow rate were higher than average, while the nitrate concentration in the system was lower than average. Figure 8 shows the profile of $\mathrm{N}_{2} \mathrm{O}$ emissions and

$418 \mathrm{NH}_{4}-\mathrm{N}$ in the carrousel reactor for sub-period 2. The colored points in the diagram represent the identified 419 clusters. Peaks in emissions coincided with peaks in the $\mathrm{NH}_{4}-\mathrm{N} \mathrm{C}$ profile, whereas peaks in $\mathrm{NH}_{4}-\mathrm{N} \mathrm{C}$ 420 coincided with precipitation events (cluster 6).

[Figure 7]

422 The scores of the data-points in cluster 5 were mainly positive in PC1 and negative in PC2 (Figure 7). PC2 423 increased with the increase of $\mathrm{NH}_{4}-\mathrm{N}$ concentration in the plug-flow reactor (Table 4). Given that PC2 had an 424 average equal to 0 (data are standardized), data-points with negative scores in PC2 represent occasions with 425 lower than average $\mathrm{NH}_{4}-\mathrm{N}$ concentration in the plug-flow reactor. This is supported by the correlation plot 426 (Figure 7), where the arrow of $\mathrm{NH}_{4}-\mathrm{N}$ concentration in the plug-flow reactor points to the direction of 428 higher than average ammonium concentration in the plug-flow reactor. Similarly, $\mathrm{NO}_{3}-\mathrm{N}$ concentration in the 429 plug-flow reactor had relatively significant positive loading in PC1 (0.36 - Table 4). The latter indicates that $430 \mathrm{NH}_{4}-\mathrm{N}$ and DO concentrations (measured by three probes) in the carrousel reactor (that had negative loadings 
431 in $\mathrm{PC} 1$ - Table 5) tended to decrease when $\mathrm{NO}_{3}-\mathrm{N}$ concentration in the plug-flow reactor increased. Given 432 that all data-points in cluster 5 had positive scores in PC1, it can be concluded that they are characterized by 433 lower than average $\mathrm{NH}_{4}-\mathrm{N}$ concentration in the carrousel reactor and higher than average $\mathrm{NO}_{3}-\mathrm{N}$ 434 concentration in the plug-flow reactor. According to the clustering results the latter can be an indication of the 435 high nitrogen loadings of the normal diurnal variability in the reactor. This finding is supported from the 436 results presented in Figure 8, where the data-points of cluster 5 correspond to the daily low range of ammonium concentrations in both reactors.

[Figure 8]

439 Figure 9 summarizes scores of the PC2 and the respective clusters (colored points in the diagram) indicating 440 strong diurnal cyclic fluctuations of the water quality during this sub-period. It also shows that after each precipitation event, a sudden temperature drop occurred; the system was disturbed and cannot recover immediately. Spearman's rank correlation coefficient between PC2 and $\mathrm{N}_{2} \mathrm{O}$ emissions is equal to 0.72 .

444 In sub-period 4, mechanisms triggering high $\mathrm{N}_{2} \mathrm{O}$ emissions in the carrousel reactor prevailed (average $=5.6$ $445 \mathrm{~kg} / \mathrm{h}$ ). The PCA loadings were similar to sub-period 2, while the clustering results indicated 3 clusters; 446 clusters 10 and 11 were affected by the diurnal variability and cluster 12 was affected by the precipitation 447 events (Table 3). Again, the DO data obtained from the 3 sensors in the carrousel reactor had significant negative loadings in PC1. However, ammonium concentration in the carrousel reactor was not identified as a 449 significant variable affecting the system in the first two PCs. This can be attributed to the fact that less $\mathrm{NH}_{4}-\mathrm{N}$ 450 concentration peaks were observed in the effluent of the carrousel reactor (17 data points belong to cluster 12). The correlation coefficient of $\mathrm{PC} 1$ with $\mathrm{NH}_{4}-\mathrm{N}$ concentration in the carrousel reactor was -0.75 . 452 Therefore, PCA analysis shows that PC1 is a good indicator of the ammonium concentration in the carrousel reactor. The DO concentrations in this sub-period especially for cluster 10 (with average $\mathrm{NH}_{4}-\mathrm{N}$ concentration in the carrousel reactor equal to $1.26 \mathrm{mg} / \mathrm{L}$ ) was the highest observed in all the clusters with similar $\mathrm{NH}_{4}-\mathrm{N}$ concentrations in the carrousel effluent. The alternation of aerobic and anaerobic conditions observed in this 
reactor, combined with high $\mathrm{NH}_{4}-\mathrm{N}$ and $\mathrm{DO}$ concentrations has been identified as a significant cause of nitrification sourced emissions (Yu et al., 2010).

In $\mathrm{PC} 2$, the $\mathrm{NO}_{3}-\mathrm{N}$ concentration and temperature had significant positive loadings (Table 5). The score plot of PC2 (Figure 10a) presented an increasing trend and therefore, showed that nitrate and temperature increased. The latter was verified by the profiles of $\mathrm{NO}_{3}-\mathrm{N}$ concentrations in the carrousel reactor (Figure 10b) and $\mathrm{NO}_{3}-\mathrm{N}$ concentration and temperature in the plug-flow reactor (Supplementary material S30). In the beginning of the sub-period 4 very low concentrations of nitrate were observed in the system and they gradually increased especially after the $28^{\text {th }}$ of March. The Spearman's correlation coefficient between $\mathrm{N}_{2} \mathrm{O}$ emissions and PC2 scores were relatively high and equal to 0.62 . However, contrary to sub-period 2, the clustering analysis showed that there is no nitrate accumulation (Table 3). The average nitrate concentration in the plug-flow reactor was equal to $0.2 \mathrm{mg} / \mathrm{L}$ until the $28^{\text {th }}$ of March and increased up to $1.6 \mathrm{mg} / \mathrm{L}$ until the end of the sub-period. Therefore, the observations in section 3.3 are supported by the PCA results (low nitrate in the plug flow resulted in increased loadings in the subsequent carrousel reactor and the denitrification activity in the carrousel reactor is affected by the low temperature resulting in nitrite accumulation).

472 In the section, the combination of hierarchical k-means clustering and PCA was used in order to link the 473 different emission ranges with all the online monitored variables (i.e. Figure 7). Even though, the online 474 dynamics of significant variables that can trigger $\mathrm{N}_{2} \mathrm{O}$ emissions in biological processes (i.e. $\mathrm{COD}$, $\mathrm{pH}$ ) were 475 not available, the applied methodology enabled the identification of a set of variables that are connected with $476 \mathrm{~N}_{2} \mathrm{O}$ emissions in each sub-period (i.e. Figure 8). Considering that online data were not available for the 477 influent of the carrousel reactor, higher $\mathrm{NH}_{4}-\mathrm{N}$ loadings in the carrousel reactor were linked with clusters 478 characterized by higher than average influent flow-rates and ammonium concentration and lower than average $479 \mathrm{NO}_{3}-\mathrm{N}$ concentration in the plug-flow reactor. The latter can be supported by the fact that the behavior of 480 variables in the carrousel reactor was significantly dependent on the nutrient concentrations in the plug-flow 
reactor (Table S4 - clustering results). Additionally, more intense aeration in the carrousel reactor (that can

482 affect the stripping of dissolved $\mathrm{N}_{2} \mathrm{O}$ ) was linked with clusters characterized by higher than average $\mathrm{NH}_{4}-\mathrm{N}$ 483 concentration in the carrousel reactor (since the surface aerators were manipulated by the effluent ammonium 484 concentration).

\section{5 $\quad \mathrm{N}_{2} \mathrm{O}$ generation pathways}

In line with Daelman et al. (2015) findings, both AOB pathways can be considered responsible for the $\mathrm{N}_{2} \mathrm{O}$ emissions observed in the carrousel rector. The combination of nitrite accumulation and low oxygen concentrations can be linked with the nitrifier denitrification pathway, whereas higher AOR (ammonia oxidation rate), correlation of $\mathrm{NH}_{4}-\mathrm{N}$ concentration in the carrousel reactor with $\mathrm{N}_{2} \mathrm{O}$ emissions and higher DO concentrations can be linked with the hydroxylamine oxidation pathway (Law et al., 2012). $\mathrm{N}_{2} \mathrm{O}$ generation via heterotrophic denitrification can be also significant especially in periods with nitrate accumulation, suggesting insufficient anoxic conditions (Daelman et. al., 2015).

In terms of the offline monitored variables, low $\mathrm{pH}$, accompanied with nitrite accumulation, as observed in sub-period 4 has been identified as a significant factor inhibiting $\mathrm{N}_{2} \mathrm{O}$ reduction during denitrification (Pan et a denitrifying-Enhanced Biological Phosphorus Removal culture was the main contributor to $\mathrm{N}_{2} \mathrm{O}$ emissions production even at low concentrations equal to $0.0007-0.001 \mathrm{mg} \mathrm{HNO}{ }_{2}-\mathrm{N} / \mathrm{L}$ (nitrite concentration 3-4 mg/L at $\mathrm{pH} 7)$. Additionally, high $\mathrm{pH}$ values (>7) combined low DO concentration ( $\sim 0.55 \mathrm{mg} / \mathrm{L})$ have been reported to be responsible for nitrification driven $\mathrm{N}_{2} \mathrm{O}$ emissions via the nitrifier denitrification pathway (Law et al., 2011). The latter is attributed to increasing ammonium oxidation rate (due to the $\mathrm{pH}$ increase), enhancing the nitrifier denitrification pathway through electrons provision. On the other hand, lower $\mathrm{pH}(<7)$ has been linked with elevated nitrification driven $\mathrm{N}_{2} \mathrm{O}$ emissions at higher DO concentrations ( $3 \mathrm{mg} / \mathrm{L}$ ) (Li et al., 2015). The authors argued, that at higher $\mathrm{pH}$ the electrons available from the ammonium oxidation rate are mainly used to form water from molecular oxygen and $\mathrm{H}^{+}$. In the current study, the $\mathrm{pH}$ in the effluent of the reactor was steady during the monitoring campaign $(\sim 8 \pm 0.2)$. However, online $\mathrm{pH}$ data showing the exact dynamics of the 
507 Low $\mathrm{COD} / \mathrm{N}$ ratios have been reported to be responsible for denitrification induced $\mathrm{N}_{2} \mathrm{O}$ emissions

508 (Schulthess and Gujer, 1996). The offline data showed that COD/TKN ratio in the influent remained relatively 509 steady during the monitoring campaign with a slight decrease in sub-periods 4 and $5(<5)$ where emissions 510 were higher $(5.6$ and $2.6 \mathrm{~kg} / \mathrm{h}$ respectively). However, low COD/TKN $(<5)$ was also observed in other sub511 periods and did not result into high $\mathrm{N}_{2} \mathrm{O}$ emissions (Figure 4). The frequency of the offline data ( 6 days) did 512 not enable the identification of the exact contribution of COD loading to the system. Figure 4 shows that COD 513 limitation is not the sole contributor to the increased $\mathrm{N}_{2} \mathrm{O}$ emissions in sub-period 4. Therefore, the results 514 indicate that heterotrophic denitrification induced by COD/TN limitation was not the main $\mathrm{N}_{2} \mathrm{O}$ emissions 515 source in sub-periods 4 and 5.

516 The results from the application of multivariate statistical techniques can be used for the identification and 517 explanation of potential pathways for $\mathrm{N}_{2} \mathrm{O}$ generation. In sub-periods with lower average $\mathrm{N}_{2} \mathrm{O}$ emission fluxes 518 (1, 6, and 7), emission peaks coincided with ammonium peaks in the plug-flow reactor and therefore in the 519 influent carrousel reactor. In that case, average emission fluxes ranged from $0.05 \mathrm{~kg} / \mathrm{h}$ (sub-period 1 ) to 2.54 $520 \mathrm{~kg} / \mathrm{h}$ (sub-period 6). Wunderlin et al., (2012) demonstrated that $\mathrm{N}_{2} \mathrm{O}$ production through hydroxylamine 521 oxidation is accompanied by excess ammonia, low nitrite concentration and high ammonia oxidation rate. 522 Additionally, in these sub-periods, $\mathrm{N}_{2} \mathrm{O}$ emissions were higher at higher temperatures and $\mathrm{DO}$ concentrations. 523 The high DO concentrations coincided with peaks in nitrite and nitrate concentrations indicating also insufficient denitrification zones in the reactor. AOB can use nitrite instead of oxygen as electron acceptor 525 (Kampschreur et al., 2009a) especially in oxygen limiting conditions (low DO zones exist even when all 526 surface aerators are under operation); thus, nitrifier denitrification by AOB could potentially contribute in $\mathrm{N}_{2} \mathrm{O}$ emissions. Burgess et al. (2002) found strong dependency between nitrite accumulation and $\mathrm{N}_{2} \mathrm{O}$ emissions, especially at sudden increase of ammonia loading.

Overall, $\mathrm{N}_{2} \mathrm{O}$ emissions increased significantly and peaked at low nitrate concentrations in both reactors (i.e., sub-periods 3 and 4) and high nitrite concentrations in the carrousel reactor (i.e., sub-period 4). Under aerobic conditions, nitrite accumulates in the system when the ammonia oxidation rate to nitrite exceeds the nitrite oxidation rate to nitrate (Guisasola et al., 2005) inducing the nitrifier denitrification pathway. Sub-optimum 
DO, COD and $\mathrm{pH}$ can also result in nitrite accumulation during denitrification (Schulthess et al., 1994; Yang

et al., 2012). Zheng et al., (2015) observed a synergistic $\mathrm{N}_{2} \mathrm{O}$ generation between nitrifier denitrification and

heterotrophic denitrification in a pilot carrousel reactor where the nitrite built-up during denitrification boosted nitrifier denitrification pathway. The latter is in line with the $\mathrm{N}_{2} \mathrm{O}$ profiles observed in this study in sub-periods with high emissions. The combined results of PCA and hierarchical k-means clustering can guide through the most significant $\mathrm{N}_{2} \mathrm{O}$ production pathways in different sub-periods (supplementary material).

\section{Conclusions}

$\mathrm{N}_{2} \mathrm{O}$ emissions depend on a set of interacting biological and chemical conversions and physical processes.

This complex interaction obscures the determination of the governing processes in individual treatment plants.

With multivariate analysis correlations between influential factors in a complex system might be revealed.

- A data-driven approach consisting of statistical-based methods was applied to analyze long-term $\mathrm{N}_{2} \mathrm{O}$ emission dynamics and generation mechanisms based on available high temporal resolution (hourly) data. Applying binary segmentation to the $\mathrm{N}_{2} \mathrm{O}$ emission profile allowed to split up the 15 -month $\mathrm{N}_{2} \mathrm{O}$ monitoring campaign into 10 sub-periods.

- Spearman's rank correlation analysis showed significant univariate correlations between $\mathrm{N}_{2} \mathrm{O}$ emissions and ammonium, nitrate and nitrite concentrations. The correlation coefficients fluctuated between the 10 sub-periods. Low values for the correlation coefficients indicated non-monotonic interrelationships that Spearman's rank correlation cannot identify.

- Hierarchical k-means clustering provided information on the existence of reoccurring patterns and their effect on $\mathrm{N}_{2} \mathrm{O}$ emissions. $\mathrm{N}_{2} \mathrm{O}$ emission peaks were linked with the diurnal behavior of the nutrients' concentrations and with rain events, whereas low nitrate concentrations in the preceding plug flow reactor $(<1 \mathrm{mg} / \mathrm{L})$ resulted in increased ammonium loadings and high $\mathrm{N}_{2} \mathrm{O}$ emissions in the subsequent carrousel reactor.

- Principal component analysis validated the findings from the clustering analysis and showed that ammonium, nitrate, nitrite, influent flow-rate and temperature, explained more than $65 \%$ of the variance in the system for the majority of the sub-periods. The first principal component corresponded to the control strategy of the reactor.

- The proposed methodological approach can detect and visualize disturbances in the system (i.e., precipitation events, high $\mathrm{NH}_{4}-\mathrm{N}$ concentrations, etc.) and their effect on $\mathrm{N}_{2} \mathrm{O}$ emissions. 
Additionally, the ranges of operating variables that have historically resulted in low or high ranges of $\mathrm{N}_{2} \mathrm{O}$ emissions can be identified. Overall, multivariate analysis can assist researchers and operators to understand and control the $\mathrm{N}_{2} \mathrm{O}$ emissions using long term historical data.

\section{Acknowledgements}

This paper is supported by the Horizon 2020 research and innovation programme, SMART-Plant under grant agreement No 690323. The authors acknowledge Alex Sengers and David Philo from Hoogheemraadschap van Schieland en de Krimpenerwaard, the Water Board of Schieland and Krimpenerwaard. for sharing their 570 knowledge regarding the Kralingseveer WWTP operation.

\section{References}

572 Aboobakar, A., Cartmell, E., Stephenson, T., Jones, M., Vale, P., Dotro, G., 2013. Nitrous oxide emissions 573 and dissolved oxygen profiling in a full-scale nitrifying activated sludge treatment plant. Water Res. 47, 524574 534. https://doi.org/10.1016/j.watres.2012.10.004

575 Abu-Jamous, B., Nandi, A.K., Fa, R., 2015. Integrative Cluster Analysis in Bioinformatics. John Wiley \& 576 Sons.

577 Adouani, N., Limousy, L., Lendormi, T., Sire, O., 2015. $\mathrm{N}_{2} \mathrm{O}$ and $\mathrm{NO}$ emissions during wastewater 578 denitrification step: Influence of temperature on the biological process. Comptes Rendus Chim., International 579 Chemical Engineering Congress (ICEC) 2013: From fundamentals to applied chemistry and biochemistry 18, 580 15-22. https://doi.org/10.1016/j.crci.2014.11.005

581 Ahn, J.H., Kim, S., Park, H., Katehis, D., Pagilla, K., Chandran, K., 2010. Spatial and Temporal Variability in 582 Atmospheric Nitrous Oxide Generation and Emission from Full-Scale Biological Nitrogen Removal and NonBNR Processes. Water Environ. Res. 82, 2362-2372. https://doi.org/10.2175/106143010X12681059116897

Arai, K., Barakbah, A.R., 2007. Hierarchical K-means: an algorithm for centroids initialization for K-means. Rep. Fac. Sci. Eng. 36, 25-31. 
586 Brotto, A.C., Kligerman, D.C., Andrade, S.A., Ribeiro, R.P., Oliveira, J.L.M., Chandran, K., Mello, W.Z. de, 587 2015. Factors controlling nitrous oxide emissions from a full-scale activated sludge system in the tropics. 588 Environ. Sci. Pollut. Res. 22, 11840-11849. https://doi.org/10.1007/s11356-015-4467-x

589 Burgess, J.E., Colliver, B.B., Stuetz, R.M., Stephenson, T., 2002. Dinitrogen oxide production by a mixed 590 culture of nitrifying bacteria during ammonia shock loading and aeration failure. J. Ind. Microbiol. $591 \quad$ Biotechnol. 29, 309-313.

592 Charrad, M., Ghazzali, N., Boiteau, V., Niknafs, A., 2014. NbClust: An R Package for Determining the 593 Relevant Number of Clusters in a Data Set. Journal of Statistical Software 61. 594 https://doi.org/10.18637/jss.v061.i06

595 Chen, J., Gupta, A.K., 1997. Testing and Locating Variance Changepoints with Application to Stock Prices. J. 596 Am. Stat. Assoc. 92, 739-747. https://doi.org/10.2307/2965722

597 Daelman, M.R.J., van Voorthuizen, E.M., van Dongen, U.G.J.M., Volcke, E.I.P., van Loosdrecht, M.C.M., 598 2015. Seasonal and diurnal variability of $\mathrm{N}_{2} \mathrm{O}$ emissions from a full-scale municipal wastewater treatment 599 plant. Sci. Total Environ. 536, 1-11. https://doi.org/10.1016/j.scitotenv.2015.06.122

600 Daelman, M.R.J., van Voorthuizen, E.M., van Dongen, L.G.J.M., Volcke, E.I.P., van Loosdrecht, M.C.M., 601 2013. Methane and nitrous oxide emissions from municipal wastewater treatment - results from a long-term 602 study. Water Sci. Technol. 67, 2350-2355. https://doi.org/10.2166/wst.2013.109

603 Domingo-Félez, C., F. Smets, B., 2016. A consilience model to describe N 2 O production during biological N 604

EEA Report, 2017. Annual European Union greenhouse gas inventory 1990-2015 and inventory report 2017. 606 Technical report No 6/2017, European Environment Agency, Copenhagen, Denmark.

607 Elefsiniotis, P., Li, D., 2006. The effect of temperature and carbon source on denitrification using volatile 608 fatty acids. Biochem. Eng. J. 28, 148-155. 
609 Flores-Alsina, X., Arnell, M., Amerlinck, Y., Corominas, L., Gernaey, K.V., Guo, L., Lindblom, E., Nopens,

610 I., Porro, J., Shaw, A., Snip, L., Vanrolleghem, P.A., Jeppsson, U., 2014. Balancing effluent quality, economic 611 cost and greenhouse gas emissions during the evaluation of (plant-wide) control/operational strategies in 612 WWTPs. Sci. Total Environ. 466-467, 616-624. https://doi.org/10.1016/j.scitotenv.2013.07.046

613 Gernaey, K.V., van Loosdrecht, M.C., Henze, M., Lind, M., Jørgensen, S.B., 2004. Activated sludge wastewater treatment plant modelling and simulation: state of the art. Environ. Model. Softw. 19, 763-783.

615 Guisasola, A., Jubany, I., Baeza, J.A., Carrera, J., Lafuente, J., 2005. Respirometric estimation of the oxygen 616 affinity constants for biological ammonium and nitrite oxidation. J. Chem. Technol. Biotechnol. 80, 388-396. 617 https://doi.org/10.1002/jctb.1202

618 Guo, L., Vanrolleghem, P.A., 2014. Calibration and validation of an activated sludge model for greenhouse 619 gases no. 1 (ASMG1): prediction of temperature-dependent $\mathrm{N}<$ Subscript $>2</$ Subscript $>\mathrm{O}$ emission dynamics. 620 Bioprocess Biosyst. Eng. 37, 151-163. https://doi.org/10.1007/s00449-013-0978-3

621 Haas, D.W. de, Pepperell, C., Foley, J., 2014. Perspectives on greenhouse gas emission estimates based on 622 Australian wastewater treatment plant operating data. Water Sci. Technol. 69, 451-463. https://doi.org/10.2166/wst.2013.572

624 Haimi, H., Mulas, M., Corona, F., Marsili-Libelli, S., Lindell, P., Heinonen, M., Vahala, R., 2016. Adaptive 625 data-derived anomaly detection in the activated sludge process of a large-scale wastewater treatment plant. 626 Eng. Appl. Artif. Intell. 52, 65-80. https://doi.org/10.1016/j.engappai.2016.02.003

627 Haimi, H., Mulas, M., Corona, F., Vahala, R., 2013. Data-derived soft-sensors for biological wastewater 628 treatment plants: An overview. Environ. Model. Softw. 47, 88-107. 629 https://doi.org/10.1016/j.envsoft.2013.05.009

630 Hartigan, J.A., 1975. Clustering algorithms. CERN Doc. Serv. URL http://cds.cern.ch/record/105051. 
631 Hartigan, J.A., Wong, M.A., 1979. Algorithm AS 136: A k-means clustering algorithm. Journal of the Royal 632 Statistical Society. Series C (Applied Statistics) 28, 100-108.

633 Holtan-Hartwig, L., Dörsch, P., Bakken, L.R., 2002. Low temperature control of soil denitrifying 634 communities: kinetics of N 2 O production and reduction. Soil Biol. Biochem. 34, 1797-1806.

635 IPCC, 2013. The physical science basis. Contribution of working group I to the fifth assessment report of the 636 intergovernmental panel on climate change. USA: Cambridge University Press.

637 Jain, A.K., 2010. Data clustering: 50 years beyond K-means. Pattern Recognit. Lett., Award winning papers 638 from the 19th International Conference on Pattern Recognition (ICPR) 31, 651-666. 639 https://doi.org/10.1016/j.patrec.2009.09.011

640 Jolliffe, I.T., 2002. Principal component analysis and factor analysis, chap 7. Principal component analysis. 641 Springer series in statistics, pp 150-166. Springer, New York

642 Jönsson, H., Junestedt, C., Willén, A., Yang, J., Tjus, K., Baresel, C., Rodhe, L., Trela, J., Pell, M., 643 Andersson, S., 2015. Minska utsläpp av växthusgaser från rening av avlopp och hantering av avloppsslam. 644 Sven. Vatten Utveckl. Rapp. 2015-02.

645 Kampschreur, M.J., Poldermans, R., Kleerebezem, R., Star, W.R.L. van der, Haarhuis, R., Abma, W.R., 646 Jetten, M.S.M., Loosdrecht, M.C.M. van, 2009a. Emission of nitrous oxide and nitric oxide from a full-scale 647 single-stage nitritation-anammox reactor. Water Sci. Technol. 60, 3211-3217. $648 \quad$ https://doi.org/10.2166/wst.2009.608

649 Kampschreur, M.J., Tan, N.C.G., Kleerebezem, R., Picioreanu, C., Jetten, M.S.M., Loosdrecht, M.C.M. van, 650 2008. Effect of Dynamic Process Conditions on Nitrogen Oxides Emission from a Nitrifying Culture. 651 Environ. Sci. Technol. 42, 429-435. https://doi.org/10.1021/es071667p 
652 Kampschreur, M.J., Temmink, H., Kleerebezem, R., Jetten, M.S.M., van Loosdrecht, M.C.M., 2009b. Nitrous

653 oxide emission during wastewater treatment. Water Res. 43, 4093-4103.

654 https://doi.org/10.1016/j.watres.2009.03.001

655 Kaufman, L., Rousseeuw, P.J., 1990. Finding groups in data. John Wiley and Sons, Inc., New York.

656 Kawahara, Y., Sugiyama, M., 2012. Sequential change-point detection based on direct density-ratio 657 estimation. Stat. Anal. Data Min. ASA Data Sci. J. 5, 114-127.

658 Killick, R., Eckley, I., 2014. changepoint: An R package for changepoint analysis. J. Stat. Softw. 58, 1-19.

659 Killick, R., Fearnhead, P., Eckley, I.A., 2012. Optimal detection of changepoints with a linear computational 660 cost. J. Am. Stat. Assoc. 107, 1590-1598. https://doi.org/10.1080/01621459.2012.737745

661 Kosonen, H., Heinonen, M., Mikola, A., Haimi, H., Mulas, M., Corona, F., Vahala, R., 2016. Nitrous Oxide 662 Production at a Fully Covered Wastewater Treatment Plant: Results of a Long-Term Online Monitoring 663 Campaign. Environ. Sci. Technol. 50, 5547-5554. https://doi.org/10.1021/acs.est.5b04466

664 Law, Y., Lant, P., Yuan, Z., 2011. The effect of $\mathrm{pH}$ on N $2 \mathrm{O}$ production under aerobic conditions in a partial 665 nitritation system. Water Res. 45, 5934-5944.

666 Law, Y., Ye, L., Pan, Y., Yuan, Z., 2012. Nitrous oxide emissions from wastewater treatment processes. Phil 667 Trans R Soc B 367, 1265-1277. https://doi.org/10.1098/rstb.2011.0317

668 Lee, C., Choi, S.W., Lee, I.-B., 2004. Sensor fault identification based on time-lagged PCA in dynamic 669 processes. Chemom. Intell. Lab. Syst. 70, 165-178. https://doi.org/10.1016/j.chemolab.2003.10.011

670 Li, P., Wang, S., Peng, Y., Liu, Y., He, J., 2015. The synergistic effects of dissolved oxygen and pH on $\mathrm{N}_{2} \mathrm{O}$ 671 production in biological domestic wastewater treatment under nitrifying conditions. Environ. Technol. 36, 672 1623-1631. https://doi.org/10.1080/09593330.2014.1002862 
673 Liu, R.-T., Wang, X.-H., Zhang, Y., Wang, M.-Y., Gao, M.-M., Wang, S.-G., 2016. Optimization of operation 674 conditions for the mitigation of nitrous oxide $\left(\mathrm{N}_{2} \mathrm{O}\right)$ emissions from aerobic nitrifying granular sludge system. 675 Environ. Sci. Pollut. Res. 23, 9518-9528. https://doi.org/10.1007/s11356-016-6178-3

676 Liu, Y., Pan, Y., Sun, Z., Huang, D., 2014. Statistical Monitoring of Wastewater Treatment Plants Using 677 Variational Bayesian PCA. Ind. Eng. Chem. Res. 53, 3272-3282. https://doi.org/10.1021/ie403788v

678 Maere, T., Villez, K., Marsili-Libelli, S., Naessens, W., Nopens, I., 2012. Membrane bioreactor fouling 679 behaviour assessment through principal component analysis and fuzzy clustering. Water Res. 46, 6132-6142. 680 https://doi.org/10.1016/j.watres.2012.08.027

681 Mampaey, K.E., De Kreuk, M.K., van Dongen, U.G.J.M., van Loosdrecht, M.C.M., Volcke, E.I.P., 2016. 682 Identifying $\mathrm{N}_{2} \mathrm{O}$ formation and emissions from a full-scale partial nitritation reactor. Water Res. 88, 575-585. 683 https://doi.org/10.1016/j.watres.2015.10.047

684 Mannina, G., Ekama, G., Caniani, D., Cosenza, A., Esposito, G., Gori, R., Garrido-Baserba, M., Rosso, D., 685 Olsson, G., 2016. Greenhouse gases from wastewater treatment - A review of modelling tools. Sci. Total 686 Environ. 551-552, 254-270. https://doi.org/10.1016/j.scitotenv.2016.01.163

687 Massara, T.M., Malamis, S., Guisasola, A., Baeza, J.A., Noutsopoulos, C., Katsou, E., 2017. A review on 688 nitrous oxide (N 2 O) emissions during biological nutrient removal from municipal wastewater and sludge 689 reject water. Sci. Total Environ. 596, 106-123.

690 Mirin, S.N.S., Wahab, N.A., 2014. Fault Detection and Monitoring Using Multiscale Principal Component 691 Analysis at a Sewage Treatment Plant. J. Teknol. 70.

692 Monteith, H.D., Sahely, H.R., MacLean, H.L., Bagley, D.M., 2005. A Rational Procedure for Estimation of 693 Greenhouse-Gas Emissions from Municipal Wastewater Treatment Plants. Water Environ. Res. 77, 390-403. 694 https://doi.org/10.2175/106143005X51978 
Moon, T.S., Kim, Y.J., Kim, J.R., Cha, J.H., Kim, D.H., Kim, C.W., 2009. Identification of process operating

696 state with operational map in municipal wastewater treatment plant. J. Environ. Manage. 90, 772-778. 697 https://doi.org/10.1016/j.jenvman.2008.01.008

698 Ni, B.-J., Pan, Y., van den Akker, B., Ye, L., Yuan, Z., 2015. Full-Scale Modeling Explaining Large Spatial 699 Variations of Nitrous Oxide Fluxes in a Step-Feed Plug-Flow Wastewater Treatment Reactor. Environ. Sci. 700 Technol. 49, 9176-9184. https://doi.org/10.1021/acs.est.5b02038

Olsson, G., Carlsson, B., Comas, J., Copp, J., Gernaey, K.V., Ingildsen, P., Jeppsson, U., Kim, C., Rieger, L., 702 Rodriguez-Roda, I., others, 2014. Instrumentation, control and automation in wastewater-from London 1973 to Narbonne 2013. Water Sci. Technol. 69, 1373-1385.

704 Pan, Y., van den Akker, B., Ye, L., Ni, B.-J., Watts, S., Reid, K., Yuan, Z., 2016. Unravelling the spatial variation of nitrous oxide emissions from a step-feed plug-flow full scale wastewater treatment plant. Sci. Rep. 6. https://doi.org/10.1038/srep20792

Pan, Y., Ye, L., Ni, B.-J., Yuan, Z., 2012. Effect of $\mathrm{pH}$ on $\mathrm{N}_{2} \mathrm{O}$ reduction and accumulation during 708 denitrification by methanol utilizing denitrifiers. Water Res. 46, 4832-4840. https://doi.org/10.1016/j.watres.2012.06.003

Platikanov, S., Rodriguez-Mozaz, S., Huerta, B., Barceló, D., Cros, J., Batle, M., Poch, G., Tauler, R., 2014. Chemometrics quality assessment of wastewater treatment plant effluents using physicochemical parameters and UV absorption measurements. J. Environ. Manage. 140, 33-44.

713 Pocquet, M., Wu, Z., Queinnec, I., Spérandio, M., 2016. A two pathway model for $\mathrm{N}_{2} \mathrm{O}$ emissions by 714 ammonium oxidizing bacteria supported by the $\mathrm{NO} / \mathrm{N}_{2} \mathrm{O}$ variation. Water Res. 88, 948-959. 715 https://doi.org/10.1016/j.watres.2015.11.029

716 R Core Team, 2017. R: A language and environment for statistical computing. R Foundation for Statistical Computing, Vienna, Austria [WWW Document]. URL https://www.R-project.org/ 
718 Ravishankara, A.R., Daniel, J.S., Portmann, R.W., 2009. Nitrous oxide $\left(\mathrm{N}_{2} \mathrm{O}\right)$ : the dominant ozone-depleting 719 substance emitted in the 21st century. science $326,123-125$.

720 Rodriguez-Caballero, A., Aymerich, I., Poch, M., Pijuan, M., 2014. Evaluation of process conditions 721 triggering emissions of green-house gases from a biological wastewater treatment system. Sci. Total Environ. 722 493, 384-391. https://doi.org/10.1016/j.scitotenv.2014.06.015

723 Rosén, C., Lennox, J.A., 2001. Multivariate and multiscale monitoring of wastewater treatment operation. 724 Water Res. 35, 3402-3410.

725 Rosén, C., Olsson, G., 1998. Disturbance detection in wastewater treatment plants. Water Sci. Technol. 37, $726 \quad 197-205$.

727 Rosen, C., Yuan, Z., 2001. Supervisory control of wastewater treatment plants by combining principal 728 component analysis and fuzzy c-means clustering. Water Sci. Technol. 43, 147-156.

729 Rousseeuw, P.J., 1987. Silhouettes: a graphical aid to the interpretation and validation of cluster analysis. 730 Journal of computational and applied mathematics 20, 53-65.

731 Rustum, R., Adeloye, A.J., Scholz, M., 2008. Applying Kohonen Self-Organizing Map as a Software Sensor 732 to Predict Biochemical Oxygen Demand. Water Environ. Res. 80, 32-40. 733 https://doi.org/10.2175/106143007X184500

734 Schulthess, R.V., Gujer, W., 1996. Release of nitrous oxide $\left(\mathrm{N}_{2} \mathrm{O}\right)$ from denitrifying activated sludge: 735 Verification and application of a mathematical model. Water Res. 30, 521-530. https://doi.org/10.1016/0043$736 \quad \underline{1354(95) 00204-9}$

737 Schulthess, R. von, Wild, D., Gujer, W., 1994. Nitric and nitrous oxides from denitrifying activated sludge at 738 low oxygen concentration. Water Sci. Technol. 30, 123-132.

739 Scott, A.J., Knott, M., 1974. A cluster analysis method for grouping means in the analysis of variance. $740 \quad$ Biometrics 507-512. 
741 Spearman, C., 1904. “General Intelligence,” Objectively Determined and Measured. Am. J. Psychol. 15, 201742 292. https://doi.org/10.2307/1412107

743 Sun, S., Cheng, X., Sun, D., 2013. Emission of $\mathrm{N}_{2} \mathrm{O}$ from a full-scale sequencing batch reactor wastewater 744 treatment plant: Characteristics and influencing factors. Int. Biodeterior. Biodegrad. 85, 545-549. 745 https://doi.org/10.1016/j.ibiod.2013.03.034

746 Ward Jr, J.H., 1963. Hierarchical grouping to optimize an objective function. J. Am. Stat. Assoc. 58, 236-244.

747 Wunderlin, P., Mohn, J., Joss, A., Emmenegger, L., Siegrist, H., 2012. Mechanisms of $\mathrm{N}_{2} \mathrm{O}$ production in 748 biological wastewater treatment under nitrifying and denitrifying conditions. Water Res. 46, 1027-1037. 749 https://doi.org/10.1016/j.watres.2011.11.080

750 Yang, X., Wang, S., Zhou, L., 2012. Effect of carbon source, C/N ratio, nitrate and dissolved oxygen 751 concentration on nitrite and ammonium production from denitrification process by Pseudomonas stutzeri D6. 752 Bioresour. Technol. 104, 65-72. https://doi.org/10.1016/j.biortech.2011.10.026

753 Yu, R., Kampschreur, M.J., Loosdrecht, M.C.M. van, Chandran, K., 2010. Mechanisms and Specific 754 Directionality of Autotrophic Nitrous Oxide and Nitric Oxide Generation during Transient Anoxia. Environ. 755 Sci. Technol. 44, 1313-1319. https://doi.org/10.1021/es902794a

756 Zheng, M., Tian, Y., Liu, T., Ma, T., Li, L., Li, C., Ahmad, M., Chen, Q., Ni, J., 2015. Minimization of 757 nitrous oxide emission in a pilot-scale oxidation ditch: Generation, spatial variation and microbial 758 interpretation. Bioresour. Technol. 179, 510-517.

759 Zhou, Y.A.N., Pijuan, M., Zeng, R.J., Yuan, Z., 2008. Free nitrous acid inhibition on nitrous oxide reduction 760 by a denitrifying-enhanced biological phosphorus removal sludge. Environmental Science \& Technology 42 , $761 \quad 8260-8265$ 
Table 1:Average value and standard deviation (std) of variables monitored in the Northern carrousel reactor

(C: carrousel reactor, N: Northern, PF: plug-flow reactor)

\begin{tabular}{lcclcc}
\hline \multicolumn{1}{c}{ Online variables } & Average & Std & Offline variables & Average & Std \\
\hline $\mathrm{N}_{2} \mathrm{O}(\mathrm{kg} / \mathrm{h})$ & 1.4 & 2.1 & COD influent $(\mathrm{mg}$ COD/ L) & 238.8 & 79.5 \\
$\mathrm{NH}_{4}-\mathrm{N} \mathrm{C}(\mathrm{mg} / \mathrm{L})$ & 1.63 & 2.2 & TKN influent $(\mathrm{mg} / \mathrm{L})$ & 42.1 & 10.0 \\
$\mathrm{NO}_{3}-\mathrm{N} \mathrm{C}(\mathrm{mg} / \mathrm{L})$ & 5.8 & 4 & TP influent $(\mathrm{mg} / \mathrm{L})$ & 7.0 & 2.1 \\
$\mathrm{NO}_{2}-\mathrm{N} \mathrm{C}(\mathrm{mg} / \mathrm{L})$ & 1.2 & 1.1 & Flow-rate $\left(\mathrm{m}^{3} / \mathrm{d}\right)$ & 85,898 & 41,786 \\
$\mathrm{DO} 1(\mathrm{mg} / \mathrm{L})$ & 0.6 & 0.9 & COD effluent $(\mathrm{mg} / \mathrm{L})$ & 36.9 & 6.9 \\
$\mathrm{DO} 2(\mathrm{mg} / \mathrm{L})$ & 0.8 & 0.9 & TKN efffluent $(\mathrm{mg} / \mathrm{L})$ & 2.8 & 1.2 \\
$\mathrm{DO} 3(\mathrm{mg} / \mathrm{L})$ & 1.9 & 0.6 & TP effluent $(\mathrm{mg} / \mathrm{L})$ & 1.1 & 0.6 \\
$\mathrm{Temperature}\left({ }^{\circ} \mathrm{C}\right)$ & 16 & 3.5 & $\mathrm{pH}$ effluent & 8.0 & 0.2 \\
$\mathrm{~N}_{2} \mathrm{O}$ PF $(\mathrm{kg} / \mathrm{h})$ & 0.71 & 1.21 & & & \\
$\mathrm{NH}_{4}-\mathrm{N} \mathrm{PF}(\mathrm{mg} / \mathrm{L})$ & 12.41 & 5.35 & & & \\
$\mathrm{NO}_{3}-\mathrm{N} \mathrm{PF}(\mathrm{mg} / \mathrm{L})$ & 2.38 & 2.2 & & & \\
Influent Flow-rate $\left(\mathrm{m}^{3} / \mathrm{h}\right)$ & 3973 & 2375 & & & \\
$\mathrm{DO} \mathrm{PF}(\mathrm{mg} / \mathrm{L})$ & 2.61 & 0.65 & & & \\
\hline
\end{tabular}


766

\begin{tabular}{|c|c|c|c|c|c|c|c|c|c|c|c|c|c|c|c|c|c|c|c|c|}
\hline \multirow[t]{2}{*}{ Variables } & \multicolumn{2}{|c|}{$\begin{array}{c}\mathrm{N}_{2} \mathrm{O} \\
(\mathrm{kg} / \mathrm{h})\end{array}$} & \multicolumn{2}{|c|}{$\begin{array}{c}\mathrm{NO}_{3}-\mathrm{C} \mathrm{N} \\
(\mathrm{mg} / \mathrm{l})\end{array}$} & \multicolumn{2}{|c|}{$\begin{array}{c}\mathrm{NO}_{3}-\mathrm{N} \text { PF } \\
(\mathrm{mg} / \mathrm{l})\end{array}$} & \multicolumn{2}{|c|}{$\begin{array}{c}\mathrm{NH}_{4}-\mathrm{N} \mathrm{C} \\
(\mathrm{mg} / \mathrm{l})\end{array}$} & \multicolumn{2}{|c|}{$\begin{array}{c}\mathrm{NH}_{4}-\mathrm{N} \text { PF } \\
(\mathrm{mg} / \mathrm{l})\end{array}$} & \multicolumn{2}{|c|}{$\begin{array}{c}\mathrm{NO}_{2}-\mathrm{N} \mathrm{C}^{*} \\
(\mathrm{mg} / \mathrm{l})\end{array}$} & \multicolumn{2}{|c|}{$\begin{array}{c}\text { Temperature } \\
\left({ }^{\circ} \mathrm{C}\right)\end{array}$} & \multicolumn{2}{|c|}{$\begin{array}{c}\mathrm{DO} 1 \\
(\mathrm{mg} / \mathrm{l})\end{array}$} & \multicolumn{2}{|c|}{$\begin{array}{c}\mathrm{DO} 2 \\
(\mathrm{mg} / \mathrm{l})\end{array}$} & \multicolumn{2}{|c|}{$\begin{array}{c}\mathrm{DO} 3 \\
(\mathrm{mg} / \mathrm{l})\end{array}$} \\
\hline & Mean & Std & Mean & Std & Mean & Std & Mean & Std & Mean & Std & Mean & Std & Mean & Std & Mean & Std & Mean & Std & Mean & $\mathrm{Std}$ \\
\hline 1 & 0 & 0.1 & 6.1 & 3.1 & 1.8 & 1.6 & 1.8 & 2.67 & 11.4 & 4.1 & & & 15.7 & 1.4 & 0.62 & 0.7 & 0.62 & 0.5 & 1.5 & 0.4 \\
\hline 2 & 0.6 & 0.6 & 7.2 & 3.1 & 2.5 & 2 & 1.5 & 1.7 & 13 & 4 & & & 11.2 & 1. & 0.77 & 1 & .31 & 0.8 & 2 & 0.4 \\
\hline 3 & 2.7 & 1.4 & 6.1 & 3.2 & 1.6 & 2.1 & 1.6 & 2.1 & 15.2 & 4.5 & & & 11.5 & 0.7 & 0.67 & 0.8 & 1.49 & 1 & 2.07 & 0.4 \\
\hline 4 & 5.6 & 2. 6 & 3 & 0.1 & 0.5 & 0.7 & 1.3 & 1.6 & 15 & 4.8 & 2.6 & 1.9 & 12.9 & 1.1 & 0.64 & 0.9 & 1.95 & 0.9 & 1.9 & 0.4 \\
\hline 5 & 2.6 & 2.2 & 4.3 & 4.2 & 3.1 & 1.9 & 1.3 & 2 & 11.5 & 5.2 & 0.8 & 1 & 18.2 & 1.7 & 0.34 & 0.7 & 0.39 & 0.8 & 1.94 & 0.5 \\
\hline 6 & 0.8 & 1.4 & 3.3 & 3.2 & 2.3 & 1.9 & 2 & 3.1 & 14.7 & 6.1 & 0.5 & 0.5 & 20 & 1.0 & 0.42 & 0.7 & 0.26 & 0.5 & 2.27 & 0.5 \\
\hline 7 & 0.2 & 0.3 & 7.2 & 5 & 2.8 & 2.4 & 2 & 3.1 & 9.8 & 5.2 & 0.6 & 0.4 & 20 & 0.7 & 0.42 & 0.6 & 0.29 & 0.4 & 2.64 & 0.5 \\
\hline 8 & 0.1 & 0.2 & 10.1 & 5.7 & 5.2 & 2.6 & 1.4 & 1 & 9.6 & 5.5 & 0.8 & 0.5 & 19.6 & 0.5 & 0.27 & 0.5 & 0.2 & 0.5 & 2.71 & 0.6 \\
\hline 9 & 0.1 & 0.2 & 7.9 & 3.6 & 2.8 & 2.8 & 2 & 2 & 13.2 & 5.4 & 1.9 & 0.8 & 12.9 & 2.1 & 1.12 & 1.2 & 1.07 & 1 & 1.58 & 0.4 \\
\hline 10 & 1.3 & 1.1 & 6.3 & 3.5 & 1.4 & 0.9 & 1.6 & 3.7 & 16.4 & 4.3 & 2.1 & 0.9 & 13 & 0.7 & 0.58 & 1.0 & 1.04 & 1 & 1.52 & 0.3 \\
\hline
\end{tabular}

$* \mathrm{NO}_{2}-\mathrm{N}$ concentration was monitored between 11/03/2011 and 19/01/2012 
Table 3: Operating variables (average) for all clusters defined by hierarchical clustering in the carrousel reactor (P: Sub-period, Cl: Clusters)

\begin{tabular}{|c|c|c|c|c|c|c|c|c|c|c|c|}
\hline $\mathrm{P}$ & $\mathrm{Cl}$ & $\begin{array}{c}\mathrm{N}_{2} \mathrm{O} \\
\mathrm{C}\end{array}$ & $\begin{array}{l}\mathrm{NH}_{4^{-}} \\
\mathrm{NPF}\end{array}$ & $\begin{array}{l}\mathrm{NO}_{3^{-}} \\
\mathrm{N} \quad \mathrm{PF}\end{array}$ & Influent & $\begin{array}{l}\mathrm{NH}_{4^{-}} \\
\mathrm{N} \mathrm{C}\end{array}$ & $\begin{array}{l}\mathrm{NO}_{3^{-}} \\
\mathrm{N} \quad \mathrm{C}\end{array}$ & DO1 & DO2 & DO3 & $\begin{array}{c}\mathrm{NO}_{2-} \\
\mathrm{N}\end{array}$ \\
\hline & & $\mathrm{kg} / \mathrm{h}$ & $\mathrm{mg} / \mathrm{l}$ & $\mathrm{mg} / \mathrm{l}$ & $\mathrm{m}^{3} / \mathrm{h}$ & $\mathrm{mg} / \mathrm{l}$ & $\mathrm{mg} / \mathrm{l}$ & $\mathrm{mg} / \mathrm{l}$ & $\mathrm{mg} / \mathrm{l}$ & $\mathrm{mg} / \mathrm{l}$ & $\mathrm{mg} / \mathrm{l}$ \\
\hline \multirow{3}{*}{1} & 1 & 0.09 & 14.13 & 1.48 & 3883 & 1.47 & 8.66 & 1.04 & 0.78 & 1.72 & \\
\hline & 2 & 0.01 & 8.55 & 2.41 & 3824 & 0.87 & 4.26 & 0.13 & 0.47 & 1.25 & \\
\hline & 3 & 0.05 & 14.74 & 0.30 & 8892 & 7.91 & 4.63 & 1.37 & 0.77 & 1.58 & \\
\hline \multirow{3}{*}{2} & 4 & 0.87 & 15.30 & 2.05 & 3827 & 1.51 & 8.61 & 0.94 & 1.53 & 2.22 & \\
\hline & 5 & 0.21 & 9.13 & 3.69 & 3419 & 0.74 & 5.28 & 0.03 & 0.62 & 1.41 & \\
\hline & 6 & 0.24 & 12.51 & 0.81 & 11132 & 4.52 & 5.42 & 2.27 & 2.31 & 2.22 & \\
\hline \multirow{3}{*}{3} & 7 & 3.22 & 16.85 & 1.52 & 3383 & 1.36 & 7.36 & 0.87 & 1.88 & 2.35 & \\
\hline & 8 & 1.72 & 10.96 & 1.91 & 3672 & 0.82 & 4.29 & 0.05 & 0.85 & 1.56 & \\
\hline & 9 & 2.40 & 21.40 & 0.12 & 7935 & 7.52 & 4.15 & 2.10 & 1.28 & 2.10 & \\
\hline \multirow{3}{*}{4} & 10 & 6.60 & 17.30 & 0.32 & 3207 & 1.26 & 3.79 & 2.14 & 0.95 & 2.41 & 4.10 \\
\hline & 11 & 3.83 & 10.82 & 0.77 & 2747 & 0.79 & 1.80 & 1.51 & 0.05 & 1.20 & 1.40 \\
\hline & 12 & 6.89 & 25.45 & 0.48 & 6375 & 10.86 & 3.62 & 1.98 & 2.12 & 2.34 & 4.28 \\
\hline \multirow[b]{2}{*}{6} & 15 & 2.54 & 17.66 & 0.75 & 5922 & 5.00 & 5.07 & 1.30 & 0.73 & 2.34 & 1.08 \\
\hline & 16 & 0.51 & 8.20 & 2.84 & 3811 & 0.98 & 2.64 & 0.10 & 0.10 & 2.21 & 0.35 \\
\hline
\end{tabular}

$* \mathrm{NO}_{2}-\mathrm{N}$ concentration was monitored between 11/03/2011 and 19/01/2012 
Table 4: PCA loadings sub-period 2, carrousel reactor

\begin{tabular}{ccccc}
\hline Variable & $\mathrm{PC} 1$ & $\mathrm{PC} 2$ & $\mathrm{PC} 3$ & $\mathrm{PC} 4$ \\
\hline $\mathrm{NH}_{4}-\mathrm{N} \mathrm{PF}$ & -0.28 & 0.47 & -0.24 & 0.29 \\
$\mathrm{NO}_{3}-\mathrm{N} \mathrm{PF}$ & 0.36 & 0.21 & 0.14 & -0.67 \\
Influent & -0.38 & -0.31 & -0.09 & -0.37 \\
$\mathrm{NH}_{4}-\mathrm{N} \mathrm{C}$ & -0.34 & 0.03 & -0.59 & -0.29 \\
$\mathrm{NO}_{3}-\mathrm{N} \mathrm{C}$ & -0.04 & 0.58 & 0.21 & -0.31 \\
$\mathrm{DO} 1$ & -0.43 & 0.06 & -0.15 & -0.18 \\
$\mathrm{DO} 2$ & -0.40 & 0.08 & 0.48 & -0.17 \\
$\mathrm{DO} 3$ & -0.37 & 0.21 & 0.40 & 0.28 \\
Temperature & 0.22 & 0.49 & -0.33 & 0.11 \\
\hline
\end{tabular}

772

773 
Table 5: PCA loadings sub-period 4, carrousel reactor

\begin{tabular}{ccccc}
\hline & PC1 & PC2 & PC3 & PC4 \\
\hline $\mathrm{NH}_{4}-\mathrm{N} \mathrm{PF}$ & -0.48 & 0.04 & -0.11 & 0.25 \\
$\mathrm{NO}_{3}-\mathrm{N} \mathrm{PF}$ & 0.26 & 0.56 & -0.04 & -0.35 \\
Influent & -0.33 & -0.07 & -0.52 & -0.17 \\
$\mathrm{NH}_{4}-\mathrm{N} \mathrm{C}$ & -0.28 & 0.14 & -0.50 & -0.46 \\
$\mathrm{NO}_{3}-\mathrm{N} \mathrm{C}$ & -0.17 & 0.59 & 0.32 & 0.04 \\
$\mathrm{DO} 1$ & -0.37 & 0.24 & -0.13 & 0.59 \\
$\mathrm{DO} 2$ & -0.40 & 0.08 & 0.41 & -0.14 \\
$\mathrm{DO} 3$ & -0.37 & 0.01 & 0.33 & -0.40 \\
Temperature & 0.23 & 0.51 & -0.27 & 0.19 \\
\hline
\end{tabular}


3 Vasilaki V., Volcke, E.I.P. $^{\mathrm{b}}$, Nandi A.K. ${ }^{\mathrm{c}}$, van Loosdrecht ${ }^{\mathrm{d}}$, M.C.M., Katsou E. ${ }^{\mathrm{a}^{*}}$

$4 \quad{ }^{a}$ Department of Civil \& Environmental Engineering, Brunel University London, Uxbridge UB8 3PH, UK

5 b Department of Green Chemistry and Technology, Ghent University, Coupure Links 653, 9000 Gent, 6 Belgium

$7 \quad{ }^{c}$ Department of Electronic and Computer Engineering, Brunel University London, Uxbridge UB8 3PH, UK

$8{ }^{\mathrm{d}}$ Department of Biotechnology, Delft University of Technology, Van der Maasweg 9, 2629 HZ Delft, The 9 Netherlands

$10 *$ Corresponding author. Department of Civil \& Environmental Engineering, Brunel University London,

11 Uxbridge UB8 3PH, UK. Email: evina.katsou@brunel.ac.uk

12 Keywords: $\mathrm{N}_{2} \mathrm{O}$ emissions, long-term monitoring campaign, principal component analysis, hierarchical k13 means clustering 


\section{Abstract}

15 Multivariate statistical analysis was applied to investigate the dependencies and underlying patterns between

$16 \mathrm{~N}_{2} \mathrm{O}$ emissions and online operational variables (dissolved oxygen and nitrogen component concentrations, 17 temperature and influent flow-rate) during biological nitrogen removal from wastewater. The system under 18 study was a full-scale reactor, for which hourly sensor data were available. The 15 -month long monitoring 19 campaign was divided into 10 sub-periods based on the profile of $\mathrm{N}_{2} \mathrm{O}$ emissions, using Binary Segmentation.

20 The dependencies between operating variables and $\mathrm{N}_{2} \mathrm{O}$ emissions fluctuated according to Spearman's rank 21 correlation. The correlation between $\mathrm{N}_{2} \mathrm{O}$ emissions and nitrite concentrations ranged between 0.51-0.78 22 Correlation $>0.7$ between $\mathrm{N}_{2} \mathrm{O}$ emissions and nitrate concentrations was observed at sub-periods with average temperature lower than $12{ }^{\circ} \mathrm{C}$. Hierarchical k-means clustering and principal component analysis linked $\mathrm{N}_{2} \mathrm{O}$ emission peaks with precipitation events and ammonium concentrations higher than $2 \mathrm{mg} / \mathrm{L}$, especially in subperiods characterized by low $\mathrm{N}_{2} \mathrm{O}$ fluxes. Additionally, the highest ranges of measured $\mathrm{N}_{2} \mathrm{O}$ fluxes belonged to clusters corresponding with $\mathrm{NO}_{3}-\mathrm{N}$ concentration less than $1 \mathrm{mg} / \mathrm{L}$ in the upstream plug-flow reactor

27 (middle of oxic zone), indicating slow nitrification rates. The results showed that the range of $\mathrm{N}_{2} \mathrm{O}$ emissions partially depend on the-prior behavior of the system. The principal component analysis validated the findings from the clustering analysis and showed that ammonium, nitrate, nitrite and temperature explained a considerable percentage of the variance in the system for the majority of the sub-periods. The applied statistical methods, linked the different ranges of emissions with the system variables, provided insights on the effect of operating conditions on $\mathrm{N}_{2} \mathrm{O}$ emissions in each sub-period and can be integrated into $\mathrm{N}_{2} \mathrm{O}$ emissions data processing at wastewater treatment plants. 


\section{Abbreviations}

AOR: Ammonia oxidation rate

$\mathrm{CH}_{4}: \quad$ Methane

$\mathrm{CO}_{2}: \quad$ Carbon dioxide

DO: Dissolved oxygen

GHG: Greenhouse gas

$\mathrm{N}_{2} \mathrm{O}: \quad$ Nitrous oxide

$\mathrm{NH}_{4}-\mathrm{N}: \quad$ Ammonium nitrogen

$\mathrm{NO}_{2}-\mathrm{N}: \quad$ Nitrite nitrogen

$\mathrm{NO}_{3}-\mathrm{N}: \quad$ Nitrate nitrogen

PC: $\quad$ Principal component

PCA: Principal component analysis

PLS: Partial least squares

TN: $\quad$ Total nitrogen

WWTP: Wastewater treatment plant 


\section{Introduction}

The increasing demand to reduce the carbon footprint of municipal wastewater treatment plants (WWTPs) by reducing greenhouse gas (GHG) emissions and energy consumption, is posing new challenges for the water industry (Flores-Alsina et al., 2014). The climate change pressures prompt the quantification and minimization of GHG emissions generated in WWTPs (Haas et al., 2014). Three main sources of GHG emissions prevail in WWTPs (Monteith et al., 2005; Mannina et al., 2016): (i) the direct emissions mainly nitrous oxide $\left(\mathrm{N}_{2} \mathrm{O}\right)$ (Kampschreur et al., 2009b).

With the potential contribution of 265 times more than $\mathrm{CO}_{2}$ for a 100 -year time horizon to global warming

al., 2009). WWTPs are significant generators of $\mathrm{N}_{2} \mathrm{O}$ and are responsible for $3.1 \%$ of the $\mathrm{N}_{2} \mathrm{O}$ emissions in Europe (EEA Report, 2017). $\mathrm{N}_{2} \mathrm{O}$ is generated mainly during the autotrophic nitrification and heterotrophic denitrification (Kampschreur et al., 2008) and can contribute up to 78\% (Daelman et al., 2013) of the footprint of a WWTP's operation. Recent studies have focused on the understanding, quantification, control and minimization of $\mathrm{N}_{2} \mathrm{O}$ emissions (Aboobakar et al., 2013; Mampaey et al., 2016; Pan et al., 2016). However, several studies have resulted in contradicting findings on the influence of operating and environmental variables on $\mathrm{N}_{2} \mathrm{O}$ generation (Liu et al., 2016; Massara et al., 2017). For instance, several studies have reported increasing $\mathrm{N}_{2} \mathrm{O}$ emissions with decreasing DO concentrations during nitrification (Kampschreur et al., 2009b). However, Rodriguez-Caballero et al. (2014) found that $\mathrm{N}_{2} \mathrm{O}$ emission profiles in a full-scale biological reactor did not change even for DO variations higher than $1.5 \mathrm{mg} / \mathrm{L}$. The latter, was attributed to the high nitrification efficiency and the potential biomass adaptation to continuously varying DO concentrations. Results from real-field $\mathrm{N}_{2} \mathrm{O}$ monitoring campaigns cannot fully explain long-term causes of $\mathrm{N}_{2} \mathrm{O}$ emissions and the combined effect of operating, environmental and external factors that influence the biological systems 
60 (Jönsson et al., 2015). Long-term full-scale monitoring campaigns have shown that $\mathrm{N}_{2} \mathrm{O}$ fluxes are highly 61 dynamic with significant diurnal fluctuations and seasonal variations; however, the dynamics cannot be fully explained (Daelman et al., 2015; Kosonen et al., 2016).

63 Several mechanistic process models describing $\mathrm{N}_{2} \mathrm{O}$ emissions from wastewater treatment plants have been developed over the last few years (Massara et al., 2017). While they have been successfully applied to identify $\mathrm{N}_{2} \mathrm{O}$ formation mechanisms and pathways from experimental data (Ni et al., 2015; Pocquet et al., 2016), their calibration and validation to long-term process data remains a challenge. Domingo-Félez and F. Smets (2016) reported that substrate affinity constants for $\mathrm{NO}_{2}$ and $\mathrm{NO}$ reduction in existing $\mathrm{N}_{2} \mathrm{O}$ models differ by a factor of about 100. Additionally, calibration of models under specific operational conditions (i.e. dry weather) can affect their performance and accuracy when the system varies (Gernaey et al., 2004; Guo and Vanrolleghem, 2014). Moreover, full-scale $\mathrm{N}_{2} \mathrm{O}$ emission data show long-term trends that cannot be explained multivariate statistical techniques maximize the information acquired from $\mathrm{N}_{2} \mathrm{O}$ monitoring campaign data. by commonly available operational data (Daelman et al., 2015) but are possibly caused by microbial population changes, which are hard to catch with the current models, typically describing single functional groups with fixed parameter sets. Multivariate statistical techniques are capable of identifying relationships between $\mathrm{N}_{2} \mathrm{O}$ emissions and a multitude of influencing factors, at the same time identifying various operating sub-periods for which this behaviour may differ. This will lead to increased understanding of experimental data, on its turn facilitating the application, calibration and validation of mechanistic models. As such,

Statistical techniques have been used for the analysis of data from full-scale monitoring campaigns, to identify interconnections between operating and environmental variables on the one hand and $\mathrm{N}_{2} \mathrm{O}$ formation on the other hand. Through multiple linear regression analyses, Aboobakar et al. (2013) showed dependencies between $\mathrm{N}_{2} \mathrm{O}$ emissions and nitrogen load, temperature and dissolved oxygen (DO) in various compartments of a plug-flow reactor for biological nitrogen removal. Multi-regression analysis of one year of data with bimonthly sampling frequency, coming from a full-scale SBR (Sun et al., 2013) indicated negative correlation between $\mathrm{N}_{2} \mathrm{O}$ emissions and temperature, while COD/N ratio lower than 6 resulted in higher emissions. Brotto et al. (2015) used Spearman's rank correlation to explain the behavior of $\mathrm{N}_{2} \mathrm{O}$ emissions in an activated sludge 
process. The analysis showed negative correlation between $\mathrm{N}_{2} \mathrm{O}$ emissions and $\mathrm{pH}$ but positive correlation between $\mathrm{N}_{2} \mathrm{O}$ fluxes and temperature. However, most of the studies did not consider continuous long-term operational data, while further analysis is required to gain a better understanding on the dynamics and tradeoffs between $\mathrm{N}_{2} \mathrm{O}$ generation and the online monitored and controlled process variables.

Multivariate analysis has been proven to be a suitable method for the identification of patterns and hidden relationships within WWTP data (Rosén and Lennox, 2001) and can be applied to provide insights on the combined effect of operational variables on $\mathrm{N}_{2} \mathrm{O}$ emissions in full-scale systems. Chemometric techniques have been applied to the wastewater treatment sector for 40 years (Rosén and Olsson, 1998), enabling the visualization and interpretation of the multi-dimensional interrelations of the operational variables monitored in biological processes (Platikanov et al., 2014). Their application can (i) improve the efficiency of process monitoring (Mirin and Wahab, 2014) and provide further insights of the biological processes (Moon et al., 2009), (ii) identify and isolate process faults (Haimi et al., 2016; Liu et al., 2014; Maere et al., 2012; Rosen and Yuan, 2001), sensor faults (Lee et al., 2004), and iii) predict significant operating variables in the biological systems that affect performance (Rustum et al., 2008). Furthermore, the gradual implementation of online sensors to monitor important parameters in the biological treatment train of WWTPs results in the production of time series, which require the application of specific statistical tools for their interpretation. The most widely applied approaches include methods aiming to reduce the dimensionality of large data-sets (i.e., principal component analysis (PCA), partial least squares (PLS)) and data clustering techniques (i.e., hierarchical clustering, k-means clustering) (Haimi et al., 2013). However, there are limited studies investigating the behavior of $\mathrm{N}_{2} \mathrm{O}$ emissions with the application of multivariate statistical techniques, especially utilizing online operational data in long-term monitoring.

The aim of this work is to investigate whether widely applied multivariate statistical techniques can be applied to the online data collected from real-field $\mathrm{N}_{2} \mathrm{O}$ monitoring campaigns in order to gain a better understanding on the dynamic behavior of $\mathrm{N}_{2} \mathrm{O}$ emissions and explain the combined effect of the operating variables monitored in wastewater treatment processes on $\mathrm{N}_{2} \mathrm{O}$ emissions. Hourly data from the operating variables monitored online and $\mathrm{N}_{2} \mathrm{O}$ emissions data in a full-scale carrousel reactor from the long-term monitoring 
112 campaign published by Daelman et al. (2015) were used for the analysis. A statistical methodological 113 approach was developed, applying changepoint detection techniques to identify changes in the $\mathrm{N}_{2} \mathrm{O}$ fluxes 114 behavior combined with hierarchical k-means clustering and PCA, to provide insights on $\mathrm{N}_{2} \mathrm{O}$ emissions 115 patterns and generation pathways. 


\subsection{Process description and data origin}

118 This work was based on the data obtained by Daelman et al. (2015) for the Kralingseveer WWTP, consisting 119 of a plug-flow reactor followed by two carrousel reactors in parallel (Figure 1). The plant treated $80.000 \mathrm{~m}^{3}$ $120 \mathrm{~d}^{-1}$ of domestic wastewater from a combined sewer system. The carrousel reactors were characterized by 121 alternating anoxic/oxic zones; aeration was performed through surface aerators, which were manipulated to 122 control the ammonium concentration in the effluent. Aerator 1 operates under on/off pattern, being on when 123 the ammonium concentration was higher than $1.2 \mathrm{mg} \mathrm{N} / \mathrm{L}$ ), while surface aerators 2 and 3 were always 124 operational to keep the solids from settling but operated at maximum capacity when the ammonium 125 concentration became higher than 0.6 and $0.9 \mathrm{mg} / \mathrm{L}$, respectively. Over the monitoring period the average total 126 nitrogen (TN) removal efficiency was $81 \pm 10 \%$; the average COD removal efficiency was equal to $87 \pm 5 \%$.

127 Ammonium nitrogen $\left(\mathrm{NH}_{4}-\mathrm{N}\right)$, nitrate nitrogen $\left(\mathrm{NO}_{3}-\mathrm{N}\right)$ and $\mathrm{DO}$ were monitored in the middle of the second 128 oxic zone in the plug flow reactor (location 1, Figure 1). The carrousel reactors were equipped with, $\mathrm{NH}_{4}-\mathrm{N}$, 129 temperature probes, and 3 DO probes (DO1, DO2, DO3) (locations 2, 3, 4, Figure 1). The Northern carrousel 130 reactor was also equipped with a nitrite probe. All the reactors were covered, and the off-gas was collected in 131 ducts and pumped to a Servomex gas analyzer, where $\mathrm{N}_{2} \mathrm{O}$ was measured. Table $\mathrm{S} 1$ lists all the variables 132 monitored online (Supplementary material). The data matrix developed consists of the variables monitored in 133 the carrousel reactor ( $\mathrm{DO}, \mathrm{NH}_{4}-\mathrm{N} \mathrm{C}, \mathrm{NO}_{3}-\mathrm{N} \mathrm{C}, \mathrm{NO}_{2}-\mathrm{N} \mathrm{C}, \mathrm{N}_{2} \mathrm{O}$ C), the influent flow-rate, as well as the $\mathrm{NH}_{4}-$ $134 \mathrm{~N}$ and $\mathrm{NO}_{3}-\mathrm{N}$ concentrations from the plug-flow reactor. $24 \mathrm{~h}$ composite samples of influent and effluent, 135 available about every 6 days, were used to support the analysis. Figure 2, summarizes the methodological 136 framework applied to the online database.

[Figure 1]

\subsection{Methodological framework for data analysis}

139 The monitoring period was divided into distinct sub-periods based on the profile of $\mathrm{N}_{2} \mathrm{O}$ fluxes in the 140 carrousel reactor. Spearman's correlation analysis, k-means clustering, hierarchical clustering, and Principal 
141 component analysis were applied to the database. The application of clustering algorithms facilitated the 142 identification of operational modes that have historically resulted in specific ranges of $\mathrm{N}_{2} \mathrm{O}$ emissions. The 143 PCA reduced the dimensionality of the data-set transforming the sensor signals into useful knowledge that that 144 can be easily interpreted. The methodological framework is extensively described in the following sub145 sections.

147 The data-driven approach enabled the utilization of the information and patterns embedded in the real-time 148 monitored variables (from the system sensors) in the biological processes and GHG measurements. 149 Multivariate statistical analysis is an alternative to univariate analysis that is commonly applied for the 150 analysis of WWTP data. It enables the identification of patterns and interrelations in data-sets by examining 151 multiple variables simultaneously (Olsson et al., 2014). $\mathrm{R}$ software was used for the statistical analysis (R 152 Core Team, 2017). The complete list of packages used is provided in the supplementary material (Table S2).

\subsubsection{Preliminary data processing}

154 The preliminary data analysis included: (i) data synchronization under the same time-stamp, and ii) removal 155 of duplicate and unreliable measurements (multiple readings at the same time stamp for the same sensor). The data were aggregated into hourly averages in order to compensate for the missing data due to variation in sampling frequency between the different variables monitored. Exponential moving average imputation was 158 applied when less than 24 consequential data were missing for each variable. Longer periods of missing data were excluded from the analysis.

\subsubsection{Binary segmentation changepoint detection}

161 Given a series of data, change point analysis investigates abrupt changes in a data-series when specific 162 properties change (i.e., mean and variance) (Kawahara and Sugiyama, 2012). The Binary Segmentation (Scott 163 and Knott, 1974) is a widely applied and computationally efficient changepoint detection algorithm (Killick et 164 al., 2012). The algorithm employs initially single changepoint detection method to the complete data-set as described in (Killick and Eckley, 2014). If a changepoint is identified the procedure is repeated to the two new 
segments formed; before and after the changepoint. The process continues splitting the data until there are no more changepoints identified. The computational cost of the algorithm is of the order of $O(n \log n)$ with $n$ being the number of data in the data-set and therefore it is applicable in large data-sets. A distribution-free test statistic was applied based on the work of Chen and Gupta, (1997). The penalty for the changepoints identification was equal to $\log (n)$. The algorithm requires independent data points. Therefore, first difference transformation of the $\mathrm{N}_{2} \mathrm{O}$ timeseries was performed and changes in variance were identified by the Binary segmentation algorithm. The profile of the $\mathrm{N}_{2} \mathrm{O}$ emissions was highly variable during the monitoring

173 campaign. Binary segmentation enabled the identification of the sub-periods characterized by different $\mathrm{N}_{2} \mathrm{O}$ 174 emissions' profile.

\section{$175 \quad 2.2 .3 \quad$ Spearman's rank correlation}

176 Spearman's rank correlation coefficient (Spearman, 1904) was used to detect bivariate temporal monotonic trends among the system variables for the different sub-periods; it served as a measure of the association 178 strength. This method is based on the rank of the values and therefore, is less sensitive to outliers than 179 Pearson's correlation. P values lower than .01 were considered to be significant.

\subsubsection{Hierarchical k-means clustering}

181 Clustering techniques are widely applied in data mining in order to identify and group the underling patterns that exist in high dimensional data sets (Jain, 2010). K-means clustering (Hartigan and Wong, 1979) is a 183 recognized clustering algorithm (Haimi at al., 2013). K-means clustering was applied to categorize the data in 184 groups of similar observations and to investigate the patterns of $\mathrm{N}_{2} \mathrm{O}$ emission fluxes, based on Euclidean distance. K-means algorithm begins with the selection of $\mathrm{k}$ random centroids of the same dimension within the original data. All the data-points are compared and assigned to the nearest centroid. During each iteration, the nearest data to each centroid are re-defined and centroids are recalculated in a way that squared distances of all points within a cluster to the cluster's centroid are minimized. However, the randomly selected initial centroids can result into locally optimized clustering results (Abu-Jamous et al., 2015). Therefore, hierarchical

190 k-means clustering that was proposed by Arai and Barakbah, (2007), was applied to the dataset. In this 
192 the centroids; Ward's method is used in order to divide the dataset in clusters (Ward Jr, 1963). The data were

193 normalized before the analysis. NBclust package in R (Charrad et al., 2014) was used to select the number of 194 clusters in each sub-period. The package applies a number cluster validity indexes (i.e. average silhouette 195 value (Rousseeuw, 1987); Hartigan's rule (Hartigan, 1975)).

196 Hierarchical k-means clustering was applied to the carrousel reactor data matrix from the different sub-periods 197 identified through binary segmentation, to investigate whether different temporal patterns of the operating 198 variables were responsible for the different behavior of $\mathrm{N}_{2} \mathrm{O}$ emissions. Hierarchical k-means clustering 199 enabled i) the detection of frequency and persistence of extreme ranges of operating variables, and ii) the 200 comparison of the operational modes between the plug-low and carrousel reactor. Ammonium and nitrate 201 probes in the plug-flow reactor were included in the analysis, since they can provide indirect feedback in terms of the carrousel reactor influent and additional information for the operational behavior of the system. 203 However, the analysis was repeated excluding plug-flow variables $\left(\mathrm{NH}_{4}-\mathrm{N}\right.$ and $\left.\mathrm{NO}_{3}-\mathrm{N}\right)$. Graphical comparisons of the clustered data-points versus time and boxplots of the variables in each identified cluster are displayed in the results' section.

\subsubsection{Principal component analysis}

207 Principal component analysis (PCA) (Jolliffe, 2002) was applied to the dataset in an effort to reduce the 208 dimensionality of the data by eliminating a small proportion of variance in the data. PCA transforms the 209 original correlated measured variables to uncorrelated variables, i.e., Principal components (PCs), explaining 210 the maximum observed variability. The principal components are linear combinations of the original data 211 variables. The loadings of the variables in each principal component can map their relationship with the 212 respective principal component. PC scores are a linear combination of the data, weighted by the PC loadings 213 for each variable. The scores of the principal components map the different samples in the new dimensional 214 space of the principal components facilitating the investigation of the different relationships between the 215 variables. The data matrices (X) consisting of $\mathrm{J}$ columns (variables) and I data rows (number of observations) 216 were normalized with mean equal to 0 and standard deviation equal to 1 . Each column of $\mathbf{X}, x_{j}=$ 
$217\left(x_{1 j}, \ldots x_{I j}\right) T, \mathrm{j}=1, \ldots \mathrm{J}$, represents a vector in the I-dimensional space. In PCA, eigenvalue decomposition is 218 used to factorize the data matrix $\mathrm{X}(\mathrm{I} X J)$ and to map the data matrix to a reduced dimensional space:

$$
X=T P^{T}+E
$$

219 where, $T$ : matrix $\left(\begin{array}{lll}I & x & S\end{array}\right)$ representing the score of the principal components, $S$ : the number of principal 220 components selected, $P$ : matrix $(J x S)$ representing the loadings and $E$ : matrix of residuals.

221 The biplot of the first 2 PCs was used in order to visualize the combined behavior of significant variables that 222 affect the system. The biplots enabled the simultaneous visualization of i) the variables' loadings in the first 223 two principal components, ii) the scores of the first two principal components, and iii) the different clusters. 224 The temporal variations of the PC scores enabled the identification of occasions in which the behavior of the 225 system changes. PCA was applied to the data matrix of the carrousel reactor excluding $\mathrm{N}_{2} \mathrm{O}$ emissions time 226 series, i) to identify the most significant variables that affect the system, (ii) to analyze the structure of the sensor data, iii) to investigate if changes in the relationship of the system coincide with changes in the $\mathrm{N}_{2} \mathrm{O}$ emissions profile, and iv) to validate the results from hierarchical clustering. $\mathrm{N}_{2} \mathrm{O}$ emissions time series were excluded from the PCA in order to investigate the relationship between the PC scores and $\mathrm{N}_{2} \mathrm{O}$ emissions and to examine which PCs are most significantly linked to the behavior of $\mathrm{N}_{2} \mathrm{O}$ emissions. 


\section{Results and discussion}

\section{1 $\quad \mathrm{N}_{2} \mathrm{O}$ emissions profile and main dependencies}

233 The profile of all the variables monitored was fluctuating during the monitoring period, which can justify the 234 different profiles of $\mathrm{N}_{2} \mathrm{O}$ emissions that resulted from the Binary Segmentation algorithm. Overall, high 235 ranges of emissions were reported when nitrate concentration in the plug-flow reactor was low, whereas 236 periods with lower ammonium concentrations in the plug-flow reactor were linked with lower $\mathrm{N}_{2} \mathrm{O}$ emissions.

237 Table 1 shows the average values and standard deviations of the variables monitored online and offline in the 238 Northern carrousel and plug-flow reactors. $\mathrm{N}_{2} \mathrm{O}$ fluxes peaked in March 2011 followed by a period 239 characterized by very low $\mathrm{N}_{2} \mathrm{O}$ emissions. Gradual decrease was observed until November 2011 and 240 negligible emissions again until January 2011 (Figure 3).

242 The application of Binary Segmentation algorithm to the $\mathrm{N}_{2} \mathrm{O}$ emissions of the Northern carrousel reactor 243 identified 9 changepoints that correspond to 10 sub-periods with distinct variance of the $\mathrm{N}_{2} \mathrm{O}$ timeseries first 244 difference (Figure 3). The analysis identified abrupt temporal changes in the emission dynamics that indicate 245 changes in the underlying mechanisms or environmental conditions responsible for the $\mathrm{N}_{2} \mathrm{O}$ formation.

247 Offline data were analyzed in the different sub-periods in order to investigate significant changes that can 248 contribute to the high $\mathrm{N}_{2} \mathrm{O}$ emissions in sub-periods 4 and 5. The average COD concentration in the influent 249 of the plug-flow reactor (effluent of primary sedimentation) was $239 \pm 80 \mathrm{mg}$ COD/L over the 15 -month monitoring period. The average plug-flow reactor influent and carrousel reactor effluent concentrations of COD, TKN, BOD, TP and the effluent $\mathrm{pH}$ for all sub-periods are given in the supplementary material (Table 252 S3). In sub-period 5, 27\% increase in the influent COD concentration to the plug flow reactor (compared to 253 average value) was observed, which could be attributed to less precipitation events and to the consequently 254 lower average influent flow-rate during this sub-period. Laboratory analyses did not show significant seasonal 
changes in the plug-flow COD loading $(19,934 \pm 13310 \mathrm{~kg}$ COD/day). The COD loading in sub-period 4 $256(16,160 \pm 2546 \mathrm{~kg} \mathrm{COD} /$ day $)$ was $17 \%$ less than in sub-period 1 . TKN and TP loadings were reduced in subperiod 4 compared to sub-period, by $11 \%$ and $12 \%$ respectively. The COD:TKN:TP ratio remained quite stable, ranging between 1:0.17:0.02 (sub-period 2) and 1:0.20:0.03 (sub-period 4).

Figure 4 shows the different COD to TKN ratios measured for all the sub-periods. There were cases with lower than average COD/TKN in the influent of the plug-flow reactor that coincided with increased $\mathrm{N}_{2} \mathrm{O}$ emissions, particularly in sub-periods 4 and 5. However, low ranges of COD/TKN $(<5)$ in sub-periods $1,2,7$ and 6 corresponded with low $\mathrm{N}_{2} \mathrm{O}$ emissions. These observations indicate that limitation of COD cannot be considered the sole contributor of $\mathrm{N}_{2} \mathrm{O}$ emissions via heterotrophic denitrification in sub-periods 4 and 5 .

The COD removal efficiency remained relatively steady during the monitoring campaign ranging from $79 \%$ (sub-period 8) to $91 \%$ (sub-period 5). The range of TN and TP removal efficiencies ranged from $73 \%$ (subperiods 1 and 9) to $92 \%$ (sub-period 5) and from 67\% (sub-period 7) to $87 \%$ (sub-period 4). The effluent $\mathrm{pH}$ was steady $(\sim 8)$ and did not show seasonal variability that could influence the generation of $\mathrm{N}_{2} \mathrm{O}$ emissions.

On the other hand, a significant variation is observed for all variables monitored online by analyzing at the complete database. Table 2 summarizes the average values and standard deviations of the online monitored variables considered in the analysis for the target periods. In the carrousel reactor, the nitrite concentration is relatively high in sub-period 4 (average $=2.6 \mathrm{mg} / \mathrm{L})$ and in the first part of sub-period 10 (average $=2.1$ $\mathrm{mg} / \mathrm{L}$ ). The average temperature in both cases is $\sim 13{ }^{\circ} \mathrm{C}$. In biological reactors operating in continuous mode, appreciable (> $2 \mathrm{mg} \mathrm{N} / \mathrm{L}$ ) nitrite concentrations are usually not observed, since nitrite is directly oxidized by nitrite oxidizing bacteria into nitrate. However, in certain cases, high nitrite concentrations in biological processes have been observed, which have been linked with low temperatures that affect $\mathrm{N}_{2} \mathrm{O}$ reductase during denitrification enhancing $\mathrm{N}_{2} \mathrm{O}$ production (Holtan-Hartwig et al., 2002; Adouani et al., 2015).

Analyzing the whole profile, the emissions tended to be low at higher temperatures (sub-periods 6, 7, and 8). 
280 (i.e., sub-period 5). Ahn et al. (2010) demonstrated that $\mathrm{N}_{2} \mathrm{O}$ emissions can be significant at higher 281 temperatures due to the higher enzymatic activities of the bioprocesses producing $\mathrm{N}_{2} \mathrm{O}$. In the carrousel 282 reactor during sub-periods 4 and 5, the temperature increases from 11.8 to $20{ }^{\circ} \mathrm{C}$. Low $\mathrm{N}_{2} \mathrm{O}$ emissions were 283 also observed when ammonium concentration was lower than $13 \mathrm{mg} / \mathrm{L}$ and nitrate was higher than $2.5 \mathrm{mg} / \mathrm{L}$ 284 in the plug-flow reactor. The probe was located in the middle of the second oxic zone; thus, lower ammonium concentrations in the plug-flow reactor can indicate less ammonium loads in the carrousel reactor.

The analysis of the variables' ranges for the $\mathrm{N}_{2} \mathrm{O}$ emission profiles provides limited insight on the dependencies between the system variables monitored online, which is further analyzed in the following sections.

\subsection{Spearman's rank correlation analysis for carrousel reactor}

291 The application of Spearman's rank correlation coefficient to the data of the carrousel reactor could not identify significant correlations between the $\mathrm{N}_{2} \mathrm{O}$ emissions and the operating variables. The lack of monotonic univariate dependencies could be attributed to i) the temporal fluctuations of the influent characteristics, ii) the continuous variability in the operating conditions of the reactors, and iii) the seasonal variations of the environmental conditions in wastewater treatment processes. Fluctuating correlation coefficients between $\mathrm{N}_{2} \mathrm{O}$ emissions and carrousel reactor variables were identified (Supplementary, Figures S1:S2). The findings are in line with the study of Kosonen et al., (2016). The authors compared the results from two monitoring periods at the same biological system and identified different relationships between $\mathrm{N}_{2} \mathrm{O}$ emissions and $\mathrm{BOD}_{7(\mathrm{ATU})}$ loads.

The correlation coefficient between nitrite and $\mathrm{N}_{2} \mathrm{O}$ emissions ranged from 0.78 (sub-period 7) to 0.51 (subperiod 9). As a general remark, nitrite was correlated with $\mathrm{N}_{2} \mathrm{O}$ emissions in sub-periods 4,6 and 7, while lower correlation was observed during sub-periods 5 (Figure 5), 8 and $9 . \mathrm{N}_{2} \mathrm{O}$ emissions and $\mathrm{NO}_{3}-\mathrm{N}$ concentration in the carrousel reactor exhibited a positive correlation with coefficient higher than 0.7 for subperiods 2 (Figure 5), 4 and 10 (the temperature was lower than $13{ }^{\circ} \mathrm{C}$ in all cases). $\mathrm{N}_{2} \mathrm{O}$ emissions and $\mathrm{NO}_{3}-\mathrm{N}$ 
concentrations followed similar diurnal patterns, wherein peaks in nitrate concentration coincided with peaks in $\mathrm{N}_{2} \mathrm{O}$ emissions (Daelman et al., 2015). The accumulation of nitrate is potentially linked with higher nitrification than denitrification rates. This is in line with Daelman et al. (2015), considering that the nitrate utilization rate in these sub-periods is affected by the low temperatures (Elefsiniotis and Li, 2006). 309 Additionally, during times when $\mathrm{N}_{2} \mathrm{O}$ was positively correlated with $\mathrm{DO} 1(>0.5)$, medium to significant correlations between the $\mathrm{N}_{2} \mathrm{O}$ emissions and the ammonium concentration in the carrousel reactor were also observed (sub-periods 1, 6 and 7). Stripping of the already formed $\mathrm{N}_{2} \mathrm{O}$ can be a potential explanation. Given

312 that the surface aerator in the location of DO1 probe is manipulated to control the ammonium concentration in 313 the effluent, ammonium peaks trigger the surface aerators to start.

314 The correlation coefficient between any two of the system variables did not remain stable between the 315 different sub-periods. Figure 5 shows the correlograms for sub-periods 2 and 5 . These sub-periods were characterized by low and high ranges of $\mathrm{N}_{2} \mathrm{O}$ emissions and temperature respectively (Table 2). In sub-period 2, the average $\mathrm{NO}_{3}-\mathrm{N}$ concentration in the plug-flow reactor was equal to $2.5 \mathrm{mg} / \mathrm{L}$ (Table 2) and correlated the same reactor. The ammonium concentration in the carrousel reactor was positively correlated with DO1 only in sub-period 2. $\mathrm{NH}_{4}-\mathrm{N}$ concentration in the plug-flow reactor was correlated with the influent-flow rate only in sub-periods 4 and 5 . However, the profiles of these two variables showed that in the majority of the sub-periods, abrupt and rapid increase of influent flow-rate (i.e., precipitation events) coincided with increase of the $\mathrm{NH}_{4}-\mathrm{N}$. However, the $\mathrm{NH}_{4}-\mathrm{N}$ concentration reduced more rapidly in the system than the influent flowrate. For example, in sub-period 3 the correlation coefficient between $\mathrm{NH}_{4}-\mathrm{N}$ in the plug-flow reactor and influent flow-rate was 0.26. However, when days with significant precipitation events (and thus high influent flow-rate) were omitted, the correlation coefficient was equal to 0.58 . The latter shows that, in this example, the lack of correlation between these two variables is most likely to be an indication that the interrelationships are not monotonic and that the method is not appropriate to identify complex relationships within the data. In order to verify that increased influent flow-rate was linked with precipitation events, daily precipitation data 
331 were extracted from the Royal Netherlands meteorological institute. Spearman's correlation coefficient 332 between two days moving average of influent flow-rate and daily precipitation in the Netherlands was equal to 333 0.69. Therefore, there is a direct link between higher than average flow-rates and precipitation events (the 334 timeseries are shown in Figure S3, supplementary material). The correlograms for all sub-periods are provided 335 in the Supplementary material (Figures S1:S2).

336 Spearman's rank correlation indicated structural changes in the dependencies between the system variables. 337 Therefore, the fluctuating structural dependencies had a different impact on the generation of $\mathrm{N}_{2} \mathrm{O}$ emissions 338 Previous studies have shown that various monitored variables in the biological system $\left(\mathrm{NH}_{4}-\mathrm{N}, \mathrm{NO}_{3}-\mathrm{N}, \mathrm{NO}_{2^{-}}\right.$ $339 \mathrm{~N}$, Temperature) can affect $\mathrm{N}_{2} \mathrm{O}$ emissions generation. However, further analysis is required to investigate 340 their combined effect in $\mathrm{N}_{2} \mathrm{O}$ formation in full-scale complex systems.

[Figure 5]

\subsection{Hierarchical k-means clustering}

343 The application of hierarchical k-means clustering enabled the categorization of the different ranges of the 344 operating variables and $\mathrm{N}_{2} \mathrm{O}$ emissions within each sub-period.

345 Hierarchical k-means clustering analysis was repeated excluding $\mathrm{NH}_{4}-\mathrm{N}$ and $\mathrm{NO}_{3}-\mathrm{N}$ concentrations in the plug-flow reactor. The results showed that the majority of the data points were allocated to the same clusters

347 for each sub-period even when the $\mathrm{NH}_{4}-\mathrm{N}$ and $\mathrm{NO}_{3}-\mathrm{N}$ concentrations in the plug-flow reactor were excluded. 348 In the majority of the sub-periods (i.e. sub-periods 1-6) more than $85 \%$ of the data points were assigned to the 349 same cluster. It can be concluded that specific patterns and ranges of $\mathrm{NH}_{4}-\mathrm{N}$ and $\mathrm{NO}_{3}-\mathrm{N}$ monitored in plug350 flow reactor, systematically resulted in specific responses to the carrousel reactor. The latter is supported by the Spearman's rank correlation analysis, where high correlations were observed between the variables in the two reactors for several sub-periods. For example, the correlation coefficient between $\mathrm{NH}_{4}-\mathrm{N}$ in the plug-flow and carrousel reactors is higher than 0.7 for sub-periods 1 to 7 . The similarity of the clusters for all the subperiods is shown in Table S4 in the Supporting Material. 
355 The range of $\mathrm{N}_{2} \mathrm{O}$ emissions was differentiated in the majority of the clusters. In all the sub-periods, two 356 major clusters were identified characterized by significant differences in the $\mathrm{NH}_{4}-\mathrm{N}$ and $\mathrm{NO}_{3}-\mathrm{N}$ 357 concentrations in the plug-flow reactor. In the majority of the sub-periods they represented the diurnal 358 variability of the system nutrient concentrations and influent-flow rate. Additionally, clustering distinguished 359 occasions with high influent flow-rate and ammonium concentration in the carrousel reactor, which can be an 360 indication of precipitation events. In sub-periods characterized by low average $\mathrm{N}_{2} \mathrm{O}$ emissions (i.e., $1,2,7,8$ and 9), clusters with increased $\mathrm{N}_{2} \mathrm{O}$ emissions (yet relatively low) were mainly linked to higher loading rates 362 due to the expected diurnal variability or to precipitation events. However, $\mathrm{N}_{2} \mathrm{O}$ emissions higher than 3.8 $363 \mathrm{~kg} / \mathrm{h}$ were observed when the average $\mathrm{NO}_{3}-\mathrm{N}$ concentration was constantly lower than $1 \mathrm{mg} / \mathrm{L}$ in the plug364 flow reactor and the $\mathrm{NO}_{3}-\mathrm{N}$ concentration was lower than $4 \mathrm{mg} / \mathrm{L}$ in the carrousel reactor. Table 3 compares 365 the clustered average values for all the variables in sub-period 2 (average $\mathrm{N}_{2} \mathrm{O}$ emissions equal to $0.6 \mathrm{~kg} / \mathrm{h}-$ 366 Table 2) and 4 (average $\mathrm{N}_{2} \mathrm{O}$ emissions equal to $5.6 \mathrm{~kg} / \mathrm{h}$ - Table 2). The average value of $\mathrm{N}_{2} \mathrm{O}$ emissions for 367 a set of clusters in a specific sub-period (from Table 3) can be found taking into account the number of data368 points in the individual clusters. Sub-period 4 was characterized by very low $\mathrm{NO}_{3}-\mathrm{N}$ concentration in the 369 middle of the oxic zone in the plug-flow reactor. The latter indicates slower oxidation of ammonia to nitrate or 370 insufficient $\mathrm{DO}$ in the plug-flow nitrification lane. This can lead to higher $\mathrm{NH}_{4}-\mathrm{N}$ loading in the carrousel reactor. On the other hand, higher nitrification rates in the plug-flow reactor (i.e. sub-period 2) resulted in 372 lower $\mathrm{N}_{2} \mathrm{O}$ emissions in the carrousel reactor. The average values of all the variables in each cluster during all 373 the sub-periods are given as supplementary material (Table S5).

374 In clusters 2 and 16 the averages of operating variables had similar ranges (Table 3). However, in these two 375 occasions the $\mathrm{N}_{2} \mathrm{O}$ emissions were different $(0.01$ and $0.51 \mathrm{~kg} / \mathrm{h})$. Similarly, in clusters 1,4 and 7 , the averages of operating variables were similar yet the $\mathrm{N}_{2} \mathrm{O}$ emissions were different $(0.09,0.87$ and $3.22 \mathrm{~kg} / \mathrm{h}$ respectively). A corollary to this also existed. In clusters 1 and 2 the averages of operating variables were different but the $\mathrm{N}_{2} \mathrm{O}$ emissions were similar (0.09 and 0.01). Similarly, in clusters 5 and 6 the averages of operating variables were different but the $\mathrm{N}_{2} \mathrm{O}$ emissions were similar $(0.21$ and 0.24$)$. Such observations indicate the underlying complexities of the interdependencies. Additionally, it can be concluded that the range 
of $\mathrm{N}_{2} \mathrm{O}$ emissions can partially depend on the preceding operational mode of the system. Figure 6 shows an example of the variables monitored online for two separate occasions in sub-periods 2 and 3 (from 00:00 am until 8:00 am) and the respective $\mathrm{N}_{2} \mathrm{O}$ emissions. All the variables showed a similar behavior (in terms of range and trends). $\mathrm{N}_{2} \mathrm{O}$ emission profiles had also the same trend; however, their range depended on the initial $\mathrm{N}_{2} \mathrm{O}$ fluxes at 00:00 am. The influent flow-rates, $\mathrm{NH}_{4}-\mathrm{N}$ and $\mathrm{NO}_{3}-\mathrm{N}$ concentrations in the plug-flow reactor also were similar in these two occasions. The average $\mathrm{N}_{2} \mathrm{O}$ fluxes were equal to 0.44 and $2.01 \mathrm{~kg} / \mathrm{h}$ for occasion 1 and 2 respectively. More extensive data are required for quantitative investigation.

[Table 3]

[Figure 6]

\subsection{Principal component analysis in the carrousel reactor}

391 PCA was applied to transform the original correlated measured variables to uncorrelated variables (Principal 392 components) and explain the maximum observed variability. In sub-periods with low emissions $(1,2,7,8$, and 393 9) the $\mathrm{PCA}$ analysis showed that $\mathrm{N}_{2} \mathrm{O}$ emissions' peaks are related with $\mathrm{NH}_{4}-\mathrm{N}$ and influent flow-rate peaks in 394 the carrousel reactor and with the effect of the diurnal variability of these variables' loading rates.

395 The current section discusses the PCA results for sub-period 2, as an example. The results for all the subperiods are given in the supplementary material (Tables S6-S13, Figures S4-S29). The application of PCA reduced the dimensionality of the data with 4 principal components (PCs) explaining $\sim 86 \%$ of the total variance $(\mathrm{PC} 1=39 \%, \mathrm{PC} 2=26 \%, \mathrm{PC} 3=12 \%$, and $\mathrm{PC} 4=9 \%)$. Loadings for the system variables in the 4 PCs are given in Table 4. The loadings of each component are an indication of the variation in the variables explained by a specific component. Influent flow-rate, ammonium concentration in the carrousel reactor $\left(\mathrm{NH}_{4}-\mathrm{N} \mathrm{C}\right)$ and the three DO (DO1, DO2 and DO3) concentrations had the highest negative loadings in PC1. This means that the first principal component increased with the increase of these variables. Nitrate concentration $\left(\mathrm{NO}_{3}-\mathrm{N}\right.$ PF) in the plug-flow reactor has a relatively high positive loading in $\mathrm{PC} 1(0.36)$.

404 Therefore, PC1 describes how the carrousel reactor responds to the behavior of the upstream plug-flow reactor 
concentrations in the carrousel reactor. The latter can be indirectly connected with the control strategy of the

407 carrousel reactor, since the surface aerators were manipulated based on the effluent ammonium concentration.

408 PC2 linked ammonium concentration in the plug-flow reactor, nitrate concentration in the carrousel reactor 409 and temperature (loadings higher than 0.47). In PC3 ammonium concentration in the carrousel reactor had 410 high negative loading, while DO2 and DO3 concentrations had positive loadings that was not expected 411 considering the control strategy of the system. Investigation of the variables' profiles, though, showed an 412 increasing trend of $\mathrm{DO} 2$ and $\mathrm{DO} 3$, whereas the ammonium profile did not present a similar trend

[Table 4]

414 The biplot of the first 2 PCs is used to visualize the combined behavior of significant variables that affect the 415 system. Data points assigned to cluster 6 (Figure 7), had negative scores in PC2 and PC1. Therefore, 416 ammonium concentration in the carrousel reactor and influent flow rate were higher than average, while the 417 nitrate concentration in the system was lower than average. Figure 8 shows the profile of $\mathrm{N}_{2} \mathrm{O}$ emissions and $418 \mathrm{NH}_{4}-\mathrm{N}$ in the carrousel reactor for sub-period 2. The colored points in the diagram represent the identified 419 clusters. Peaks in emissions coincided with peaks in the $\mathrm{NH}_{4}-\mathrm{N} \mathrm{C}$ profile, whereas peaks in $\mathrm{NH}_{4}-\mathrm{N} \mathrm{C}$ 420 coincided with precipitation events (cluster 6).

422 The scores of the data-points in cluster 5 were mainly positive in PC1 and negative in PC2 (Figure 7). PC2 423 increased with the increase of $\mathrm{NH}_{4}-\mathrm{N}$ concentration in the plug-flow reactor (Table 4). Given that PC2 had an 424 average equal to 0 (data are standardized), data-points with negative scores in PC2 represent occasions with 425 lower than average $\mathrm{NH}_{4}-\mathrm{N}$ concentration in the plug-flow reactor. This is supported by the correlation plot 426 (Figure 7), where the arrow of $\mathrm{NH}_{4}-\mathrm{N}$ concentration in the plug-flow reactor points to the direction of plug-flow reactor had relatively significant positive loading in PC1 (0.36 - Table 4). The latter indicates that 
431 in $\mathrm{PC} 1$ - Table 5) tended to decrease when $\mathrm{NO}_{3}-\mathrm{N}$ concentration in the plug-flow reactor increased. Given 432 that all data-points in cluster 5 had positive scores in PC1, it can be concluded that they are characterized by 433 lower than average $\mathrm{NH}_{4}-\mathrm{N}$ concentration in the carrousel reactor and higher than average $\mathrm{NO}_{3}-\mathrm{N}$ 434 concentration in the plug-flow reactor. According to the clustering results the latter can be an indication of the 435 high nitrogen loadings of the normal diurnal variability in the reactor. This finding is supported from the 436 results presented in Figure 8, where the data-points of cluster 5 correspond to the daily low range of 437 ammonium concentrations in both reactors.

[Figure 8]

439 Figure 9 summarizes scores of the PC2 and the respective clusters (colored points in the diagram) indicating 440 strong diurnal cyclic fluctuations of the water quality during this sub-period. It also shows that after each 441 precipitation event, a sudden temperature drop occurred; the system was disturbed and cannot recover immediately. Spearman's rank correlation coefficient between PC2 and $\mathrm{N}_{2} \mathrm{O}$ emissions is equal to 0.72 .

444 In sub-period 4, mechanisms triggering high $\mathrm{N}_{2} \mathrm{O}$ emissions in the carrousel reactor prevailed (average $=5.6$ $445 \mathrm{~kg} / \mathrm{h}$ ). The PCA loadings were similar to sub-period 2, while the clustering results indicated 3 clusters; 446 clusters 10 and 11 were affected by the diurnal variability and cluster 12 was affected by the precipitation 447 events (Table 3). Again, the DO data obtained from the 3 sensors in the carrousel reactor had significant 448 negative loadings in PC1. However, ammonium concentration in the carrousel reactor was not identified as a 449 significant variable affecting the system in the first two PCs. This can be attributed to the fact that less $\mathrm{NH}_{4}-\mathrm{N}$ 450 concentration peaks were observed in the effluent of the carrousel reactor (17 data points belong to cluster 451 12). The correlation coefficient of $\mathrm{PC} 1$ with $\mathrm{NH}_{4}-\mathrm{N}$ concentration in the carrousel reactor was -0.75. 452 Therefore, PCA analysis shows that PC1 is a good indicator of the ammonium concentration in the carrousel 453 reactor. The DO concentrations in this sub-period especially for cluster 10 (with average $\mathrm{NH}_{4}-\mathrm{N}_{\text {concentration }}$ 454 in the carrousel reactor equal to $1.26 \mathrm{mg} / \mathrm{L}$ ) was the highest observed in all the clusters with similar $\mathrm{NH}_{4}-\mathrm{N}$ 455 concentrations in the carrousel effluent. The alternation of aerobic and anaerobic conditions observed in this 
reactor, combined with high $\mathrm{NH}_{4}-\mathrm{N}$ and DO concentrations has been identified as a significant cause of nitrification sourced emissions (Yu et al., 2010).

In $\mathrm{PC} 2$, the $\mathrm{NO}_{3}-\mathrm{N}$ concentration and temperature had significant positive loadings (Table 5). The score plot of PC2 (Figure 10a) presented an increasing trend and therefore, showed that nitrate and temperature increased. The latter was verified by the profiles of $\mathrm{NO}_{3}-\mathrm{N}$ concentrations in the carrousel reactor (Figure 10b) and $\mathrm{NO}_{3}-\mathrm{N}$ concentration and temperature in the plug-flow reactor (Supplementary material S30). In the beginning of the sub-period 4 very low concentrations of nitrate were observed in the system and they gradually increased especially after the $28^{\text {th }}$ of March. The Spearman's correlation coefficient between $\mathrm{N}_{2} \mathrm{O}$ emissions and PC2 scores were relatively high and equal to 0.62 . However, contrary to sub-period 2, the clustering analysis showed that there is no nitrate accumulation (Table 3). The average nitrate concentration in the plug-flow reactor was equal to $0.2 \mathrm{mg} / \mathrm{L}$ until the $28^{\text {th }}$ of March and increased up to $1.6 \mathrm{mg} / \mathrm{L}$ until the end of the sub-period. Therefore, the observations in section 3.3 are supported by the PCA results (low nitrate in the plug flow resulted in increased loadings in the subsequent carrousel reactor and the denitrification activity in the carrousel reactor is affected by the low temperature resulting in nitrite accumulation).

472 In the section, the combination of hierarchical k-means clustering and PCA was used in order to link the 473 different emission ranges with all the online monitored variables (i.e. Figure 7). Even though, the online 474 dynamics of significant variables that can trigger $\mathrm{N}_{2} \mathrm{O}$ emissions in biological processes (i.e. $\mathrm{COD}, \mathrm{pH}$ ) were 475 not available, the applied methodology enabled the identification of a set of variables that are connected with $476 \mathrm{~N}_{2} \mathrm{O}$ emissions in each sub-period (i.e. Figure 8). Considering that online data were not available for the 477 influent of the carrousel reactor, higher $\mathrm{NH}_{4}-\mathrm{N}$ loadings in the carrousel reactor were linked with clusters 478 characterized by higher than average influent flow-rates and ammonium concentration and lower than average $479 \mathrm{NO}_{3}-\mathrm{N}$ concentration in the plug-flow reactor. The latter can be supported by the fact that the behavior of 480 variables in the carrousel reactor was significantly dependent on the nutrient concentrations in the plug-flow 
reactor (Table S4 - clustering results). Additionally, more intense aeration in the carrousel reactor (that can

482 affect the stripping of dissolved $\mathrm{N}_{2} \mathrm{O}$ ) was linked with clusters characterized by higher than average $\mathrm{NH}_{4}-\mathrm{N}$ 483 concentration in the carrousel reactor (since the surface aerators were manipulated by the effluent ammonium 484 concentration)

\section{$3.5 \quad \mathrm{~N}_{2} \mathrm{O}$ generation pathways}

In line with Daelman et al. (2015) findings, both AOB pathways can be considered responsible for the $\mathrm{N}_{2} \mathrm{O}$ emissions observed in the carrousel rector. The combination of nitrite accumulation and low oxygen concentrations can be linked with the nitrifier denitrification pathway, whereas higher AOR (ammonia oxidation rate), correlation of $\mathrm{NH}_{4}-\mathrm{N}$ concentration in the carrousel reactor with $\mathrm{N}_{2} \mathrm{O}$ emissions and higher DO concentrations can be linked with the hydroxylamine oxidation pathway (Law et al., 2012). $\mathrm{N}_{2} \mathrm{O}$ generation via heterotrophic denitrification can be also significant especially in periods with nitrate accumulation, suggesting insufficient anoxic conditions (Daelman et. al., 2015).

In terms of the offline monitored variables, low $\mathrm{pH}$, accompanied with nitrite accumulation, as observed in sub-period 4 has been identified as a significant factor inhibiting $\mathrm{N}_{2} \mathrm{O}$ reduction during denitrification (Pan et al., 2012). Zhou et al. (2008) reported that under these conditions the production of free nitrous acid (FNA) in a denitrifying-Enhanced Biological Phosphorus Removal culture was the main contributor to $\mathrm{N}_{2} \mathrm{O}$ emissions production even at low concentrations equal to $0.0007-0.001 \mathrm{mg} \mathrm{HNO}_{2}-\mathrm{N} / \mathrm{L}$ (nitrite concentration 3-4 mg/L at $\mathrm{pH} 7)$. Additionally, high $\mathrm{pH}$ values ( $>7)$ combined low DO concentration $(\sim 0.55 \mathrm{mg} / \mathrm{L})$ have been reported to be responsible for nitrification driven $\mathrm{N}_{2} \mathrm{O}$ emissions via the nitrifier denitrification pathway (Law et al., 2011). The latter is attributed to increasing ammonium oxidation rate (due to the $\mathrm{pH}$ increase), enhancing the nitrifier denitrification pathway through electrons provision. On the other hand, lower $\mathrm{pH}(<7)$ has been linked with elevated nitrification driven $\mathrm{N}_{2} \mathrm{O}$ emissions at higher DO concentrations ( $\sim 3 \mathrm{mg} / \mathrm{L}$ ) (Li et al., 2015). The authors argued, that at higher $\mathrm{pH}$ the electrons available from the ammonium oxidation rate are mainly used to form water from molecular oxygen and $\mathrm{H}^{+}$. In the current study, the $\mathrm{pH}$ in the effluent of the reactor was steady during the monitoring campaign $(\sim 8 \pm 0.2)$. However, online $\mathrm{pH}$ data showing the exact dynamics of the $\mathrm{pH}$ in the carrousel reactor were not available. 
507 Low $\mathrm{COD} / \mathrm{N}$ ratios have been reported to be responsible for denitrification induced $\mathrm{N}_{2} \mathrm{O}$ emissions 508 (Schulthess and Gujer, 1996). The offline data showed that COD/TKN ratio in the influent remained relatively 509 steady during the monitoring campaign with a slight decrease in sub-periods 4 and $5(<5)$ where emissions 510 were higher $(5.6$ and $2.6 \mathrm{~kg} / \mathrm{h}$ respectively). However, low COD/TKN $(<5)$ was also observed in other sub511 periods and did not result into high $\mathrm{N}_{2} \mathrm{O}$ emissions (Figure 4). The frequency of the offline data ( 6 days) did 512 not enable the identification of the exact contribution of COD loading to the system. Figure 4 shows that COD 513 limitation is not the sole contributor to the increased $\mathrm{N}_{2} \mathrm{O}$ emissions in sub-period 4. Therefore, the results 514 indicate that heterotrophic denitrification induced by COD/TN limitation was not the main $\mathrm{N}_{2} \mathrm{O}$ emissions 515 source in sub-periods 4 and 5.

516 The results from the application of multivariate statistical techniques can be used for the identification and 517 explanation of potential pathways for $\mathrm{N}_{2} \mathrm{O}$ generation. In sub-periods with lower average $\mathrm{N}_{2} \mathrm{O}$ emission fluxes 518 (1, 6, and 7), emission peaks coincided with ammonium peaks in the plug-flow reactor and therefore in the 519 influent carrousel reactor. In that case, average emission fluxes ranged from $0.05 \mathrm{~kg} / \mathrm{h}$ (sub-period 1 ) to 2.54 $520 \mathrm{~kg} / \mathrm{h}$ (sub-period 6). Wunderlin et al., (2012) demonstrated that $\mathrm{N}_{2} \mathrm{O}$ production through hydroxylamine 521 oxidation is accompanied by excess ammonia, low nitrite concentration and high ammonia oxidation rate. 522 Additionally, in these sub-periods, $\mathrm{N}_{2} \mathrm{O}$ emissions were higher at higher temperatures and DO concentrations. 523 The high DO concentrations coincided with peaks in nitrite and nitrate concentrations indicating also 524 insufficient denitrification zones in the reactor. AOB can use nitrite instead of oxygen as electron acceptor 525 (Kampschreur et al., 2009a) especially in oxygen limiting conditions (low DO zones exist even when all 526 surface aerators are under operation); thus, nitrifier denitrification by AOB could potentially contribute in $\mathrm{N}_{2} \mathrm{O}$ 527 emissions. Burgess et al. (2002) found strong dependency between nitrite accumulation and $\mathrm{N}_{2} \mathrm{O}$ emissions, 528 especially at sudden increase of ammonia loading.

529 Overall, $\mathrm{N}_{2} \mathrm{O}$ emissions increased significantly and peaked at low nitrate concentrations in both reactors (i.e., 530 sub-periods 3 and 4) and high nitrite concentrations in the carrousel reactor (i.e., sub-period 4). Under aerobic 531 conditions, nitrite accumulates in the system when the ammonia oxidation rate to nitrite exceeds the nitrite 532 oxidation rate to nitrate (Guisasola et al., 2005) inducing the nitrifier denitrification pathway. Sub-optimum 
DO, COD and $\mathrm{pH}$ can also result in nitrite accumulation during denitrification (Schulthess et al., 1994; Yang et al., 2012). Zheng et al., (2015) observed a synergistic $\mathrm{N}_{2} \mathrm{O}$ generation between nitrifier denitrification and heterotrophic denitrification in a pilot carrousel reactor where the nitrite built-up during denitrification boosted nitrifier denitrification pathway. The latter is in line with the $\mathrm{N}_{2} \mathrm{O}$ profiles observed in this study in sub-periods with high emissions. The combined results of PCA and hierarchical k-means clustering can guide through the most significant $\mathrm{N}_{2} \mathrm{O}$ production pathways in different sub-periods (supplementary material).

\section{Conclusions}

$\mathrm{N}_{2} \mathrm{O}$ emissions depend on a set of interacting biological and chemical conversions and physical processes.

This complex interaction obscures the determination of the governing processes in individual treatment plants. With multivariate analysis correlations between influential factors in a complex system might be revealed.

- A data-driven approach consisting of statistical-based methods was applied to analyze long-term $\mathrm{N}_{2} \mathrm{O}$ emission dynamics and generation mechanisms based on available high temporal resolution (hourly) data. Applying binary segmentation to the $\mathrm{N}_{2} \mathrm{O}$ emission profile allowed to split up the 15 -month $\mathrm{N}_{2} \mathrm{O}$ monitoring campaign into 10 sub-periods.

- Spearman's rank correlation analysis showed significant univariate correlations between $\mathrm{N}_{2} \mathrm{O}$ emissions and ammonium, nitrate and nitrite concentrations. The correlation coefficients fluctuated between the 10 sub-periods. Low values for the correlation coefficients indicated non-monotonic interrelationships that Spearman's rank correlation cannot identify.

- Hierarchical k-means clustering provided information on the existence of reoccurring patterns and their effect on $\mathrm{N}_{2} \mathrm{O}$ emissions. $\mathrm{N}_{2} \mathrm{O}$ emission peaks were linked with the diurnal behavior of the nutrients' concentrations and with rain events, whereas low nitrate concentrations in the preceding plug flow reactor $(<1 \mathrm{mg} / \mathrm{L})$ resulted in increased ammonium loadings and high $\mathrm{N}_{2} \mathrm{O}$ emissions in the subsequent carrousel reactor.

- Principal component analysis validated the findings from the clustering analysis and showed that ammonium, nitrate, nitrite, influent flow-rate and temperature, explained more than $65 \%$ of the variance in the system for the majority of the sub-periods. The first principal component corresponded to the control strategy of the reactor.

- The proposed methodological approach can detect and visualize disturbances in the system (i.e., precipitation events, high $\mathrm{NH}_{4}-\mathrm{N}$ concentrations, etc.) and their effect on $\mathrm{N}_{2} \mathrm{O}$ emissions. 
Additionally, the ranges of operating variables that have historically resulted in low or high ranges of $\mathrm{N}_{2} \mathrm{O}$ emissions can be identified. Overall, multivariate analysis can assist researchers and operators to understand and control the $\mathrm{N}_{2} \mathrm{O}$ emissions using long term historical data.

This paper is supported by the Horizon 2020 research and innovation programme, SMART-Plant under grant

\section{References}

572 Aboobakar, A., Cartmell, E., Stephenson, T., Jones, M., Vale, P., Dotro, G., 2013. Nitrous oxide emissions and dissolved oxygen profiling in a full-scale nitrifying activated sludge treatment plant. Water Res. 47, 524 534. https://doi.org/10.1016/j.watres.2012.10.004

Abu-Jamous, B., Nandi, A.K., Fa, R., 2015. Integrative Cluster Analysis in Bioinformatics. John Wiley \& Sons.

Adouani, N., Limousy, L., Lendormi, T., Sire, O., 2015. $\mathrm{N}_{2} \mathrm{O}$ and $\mathrm{NO}$ emissions during wastewater denitrification step: Influence of temperature on the biological process. Comptes Rendus Chim., International 579 Chemical Engineering Congress (ICEC) 2013: From fundamentals to applied chemistry and biochemistry 18,

Ahn, J.H., Kim, S., Park, H., Katehis, D., Pagilla, K., Chandran, K., 2010. Spatial and Temporal Variability in Atmospheric Nitrous Oxide Generation and Emission from Full-Scale Biological Nitrogen Removal and NonBNR Processes. Water Environ. Res. 82, 2362-2372. https://doi.org/10.2175/106143010X12681059116897

Arai, K., Barakbah, A.R., 2007. Hierarchical K-means: an algorithm for centroids initialization for K-means. 
586 Brotto, A.C., Kligerman, D.C., Andrade, S.A., Ribeiro, R.P., Oliveira, J.L.M., Chandran, K., Mello, W.Z. de, 587 2015. Factors controlling nitrous oxide emissions from a full-scale activated sludge system in the tropics. 588 Environ. Sci. Pollut. Res. 22, 11840-11849. https://doi.org/10.1007/s11356-015-4467-x

589 Burgess, J.E., Colliver, B.B., Stuetz, R.M., Stephenson, T., 2002. Dinitrogen oxide production by a mixed 590 culture of nitrifying bacteria during ammonia shock loading and aeration failure. J. Ind. Microbiol. $591 \quad$ Biotechnol. 29, 309-313.

592 Charrad, M., Ghazzali, N., Boiteau, V., Niknafs, A., 2014. NbClust: An R Package for Determining the 593 Relevant Number of Clusters in a Data Set. Journal of Statistical Software 61. 594 https://doi.org/10.18637/jss.v061.i06

595 Chen, J., Gupta, A.K., 1997. Testing and Locating Variance Changepoints with Application to Stock Prices. J. 596 Am. Stat. Assoc. 92, 739-747. https://doi.org/10.2307/2965722

597 Daelman, M.R.J., van Voorthuizen, E.M., van Dongen, U.G.J.M., Volcke, E.I.P., van Loosdrecht, M.C.M., 598 2015. Seasonal and diurnal variability of $\mathrm{N}_{2} \mathrm{O}$ emissions from a full-scale municipal wastewater treatment 599 plant. Sci. Total Environ. 536, 1-11. https://doi.org/10.1016/j.scitotenv.2015.06.122

600 Daelman, M.R.J., van Voorthuizen, E.M., van Dongen, L.G.J.M., Volcke, E.I.P., van Loosdrecht, M.C.M., 601 2013. Methane and nitrous oxide emissions from municipal wastewater treatment - results from a long-term 602 study. Water Sci. Technol. 67, 2350-2355. https://doi.org/10.2166/wst.2013.109

603 Domingo-Félez, C., F. Smets, B., 2016. A consilience model to describe N 2 O production during biological N 604

EEA Report, 2017. Annual European Union greenhouse gas inventory 1990-2015 and inventory report 2017. 606 Technical report No 6/2017, European Environment Agency, Copenhagen, Denmark.

607 Elefsiniotis, P., Li, D., 2006. The effect of temperature and carbon source on denitrification using volatile 608 fatty acids. Biochem. Eng. J. 28, 148-155. 
609 Flores-Alsina, X., Arnell, M., Amerlinck, Y., Corominas, L., Gernaey, K.V., Guo, L., Lindblom, E., Nopens,

610 I., Porro, J., Shaw, A., Snip, L., Vanrolleghem, P.A., Jeppsson, U., 2014. Balancing effluent quality, economic 611 cost and greenhouse gas emissions during the evaluation of (plant-wide) control/operational strategies in 612 WWTPs. Sci. Total Environ. 466-467, 616-624. https://doi.org/10.1016/j.scitotenv.2013.07.046

613 Gernaey, K.V., van Loosdrecht, M.C., Henze, M., Lind, M., Jørgensen, S.B., 2004. Activated sludge wastewater treatment plant modelling and simulation: state of the art. Environ. Model. Softw. 19, 763-783.

615 Guisasola, A., Jubany, I., Baeza, J.A., Carrera, J., Lafuente, J., 2005. Respirometric estimation of the oxygen 616 affinity constants for biological ammonium and nitrite oxidation. J. Chem. Technol. Biotechnol. 80, 388-396. 617 https://doi.org/10.1002/jctb.1202

618 Guo, L., Vanrolleghem, P.A., 2014. Calibration and validation of an activated sludge model for greenhouse 619 gases no. 1 (ASMG1): prediction of temperature-dependent $\mathrm{N}<$ Subscript $>2</$ Subscript $>\mathrm{O}$ emission dynamics. 620 Bioprocess Biosyst. Eng. 37, 151-163. https://doi.org/10.1007/s00449-013-0978-3

621 Haas, D.W. de, Pepperell, C., Foley, J., 2014. Perspectives on greenhouse gas emission estimates based on 622 Australian wastewater treatment plant operating data. Water Sci. Technol. 69, 451-463. https://doi.org/10.2166/wst.2013.572

624 Haimi, H., Mulas, M., Corona, F., Marsili-Libelli, S., Lindell, P., Heinonen, M., Vahala, R., 2016. Adaptive 625 data-derived anomaly detection in the activated sludge process of a large-scale wastewater treatment plant. 626 Eng. Appl. Artif. Intell. 52, 65-80. https://doi.org/10.1016/j.engappai.2016.02.003

627 Haimi, H., Mulas, M., Corona, F., Vahala, R., 2013. Data-derived soft-sensors for biological wastewater 628 treatment plants: An overview. Environ. Model. Softw. 47, 88-107. 629 https://doi.org/10.1016/j.envsoft.2013.05.009

630 Hartigan, J.A., 1975. Clustering algorithms. CERN Doc. Serv. URL http://cds.cern.ch/record/105051. 
631 Hartigan, J.A., Wong, M.A., 1979. Algorithm AS 136: A k-means clustering algorithm. Journal of the Royal 632 Statistical Society. Series C (Applied Statistics) 28, 100-108.

633 Holtan-Hartwig, L., Dörsch, P., Bakken, L.R., 2002. Low temperature control of soil denitrifying 634 communities: kinetics of N 2 O production and reduction. Soil Biol. Biochem. 34, 1797-1806.

635 IPCC, 2013. The physical science basis. Contribution of working group I to the fifth assessment report of the 636 intergovernmental panel on climate change. USA: Cambridge University Press.

637 Jain, A.K., 2010. Data clustering: 50 years beyond K-means. Pattern Recognit. Lett., Award winning papers 638 from the 19th International Conference on Pattern Recognition (ICPR) 31, 651-666. 639 https://doi.org/10.1016/j.patrec.2009.09.011

640 Jolliffe, I.T., 2002. Principal component analysis and factor analysis, chap 7. Principal component analysis. 641 Springer series in statistics, pp 150-166. Springer, New York

642 Jönsson, H., Junestedt, C., Willén, A., Yang, J., Tjus, K., Baresel, C., Rodhe, L., Trela, J., Pell, M., 643 Andersson, S., 2015. Minska utsläpp av växthusgaser från rening av avlopp och hantering av avloppsslam. 644 Sven. Vatten Utveckl. Rapp. 2015-02.

645 Kampschreur, M.J., Poldermans, R., Kleerebezem, R., Star, W.R.L. van der, Haarhuis, R., Abma, W.R., 646 Jetten, M.S.M., Loosdrecht, M.C.M. van, 2009a. Emission of nitrous oxide and nitric oxide from a full-scale 647 single-stage nitritation-anammox reactor. Water Sci. Technol. 60, 3211-3217. $648 \quad$ https://doi.org/10.2166/wst.2009.608

649 Kampschreur, M.J., Tan, N.C.G., Kleerebezem, R., Picioreanu, C., Jetten, M.S.M., Loosdrecht, M.C.M. van, 650 2008. Effect of Dynamic Process Conditions on Nitrogen Oxides Emission from a Nitrifying Culture. 651 Environ. Sci. Technol. 42, 429-435. https://doi.org/10.1021/es071667p 
652 Kampschreur, M.J., Temmink, H., Kleerebezem, R., Jetten, M.S.M., van Loosdrecht, M.C.M., 2009b. Nitrous

653 oxide emission during wastewater treatment. Water Res. 43, 4093-4103.

654 https://doi.org/10.1016/j.watres.2009.03.001

655 Kaufman, L., Rousseeuw, P.J., 1990. Finding groups in data. John Wiley and Sons, Inc., New York.

656 Kawahara, Y., Sugiyama, M., 2012. Sequential change-point detection based on direct density-ratio 657 estimation. Stat. Anal. Data Min. ASA Data Sci. J. 5, 114-127.

658 Killick, R., Eckley, I., 2014. changepoint: An R package for changepoint analysis. J. Stat. Softw. 58, 1-19.

659 Killick, R., Fearnhead, P., Eckley, I.A., 2012. Optimal detection of changepoints with a linear computational 660 cost. J. Am. Stat. Assoc. 107, 1590-1598. https://doi.org/10.1080/01621459.2012.737745

661 Kosonen, H., Heinonen, M., Mikola, A., Haimi, H., Mulas, M., Corona, F., Vahala, R., 2016. Nitrous Oxide 662 Production at a Fully Covered Wastewater Treatment Plant: Results of a Long-Term Online Monitoring 663 Campaign. Environ. Sci. Technol. 50, 5547-5554. https://doi.org/10.1021/acs.est.5b04466

664 Law, Y., Lant, P., Yuan, Z., 2011. The effect of $\mathrm{pH}$ on N $2 \mathrm{O}$ production under aerobic conditions in a partial 665 nitritation system. Water Res. 45, 5934-5944.

666 Law, Y., Ye, L., Pan, Y., Yuan, Z., 2012. Nitrous oxide emissions from wastewater treatment processes. Phil 667 Trans R Soc B 367, 1265-1277. https://doi.org/10.1098/rstb.2011.0317

668 Lee, C., Choi, S.W., Lee, I.-B., 2004. Sensor fault identification based on time-lagged PCA in dynamic 669 processes. Chemom. Intell. Lab. Syst. 70, 165-178. https://doi.org/10.1016/j.chemolab.2003.10.011

670 Li, P., Wang, S., Peng, Y., Liu, Y., He, J., 2015. The synergistic effects of dissolved oxygen and pH on $\mathrm{N}_{2} \mathrm{O}$ 671 production in biological domestic wastewater treatment under nitrifying conditions. Environ. Technol. 36, 672 1623-1631. https://doi.org/10.1080/09593330.2014.1002862 
673 Liu, R.-T., Wang, X.-H., Zhang, Y., Wang, M.-Y., Gao, M.-M., Wang, S.-G., 2016. Optimization of operation 674 conditions for the mitigation of nitrous oxide $\left(\mathrm{N}_{2} \mathrm{O}\right)$ emissions from aerobic nitrifying granular sludge system. 675 Environ. Sci. Pollut. Res. 23, 9518-9528. https://doi.org/10.1007/s11356-016-6178-3

676 Liu, Y., Pan, Y., Sun, Z., Huang, D., 2014. Statistical Monitoring of Wastewater Treatment Plants Using 677 Variational Bayesian PCA. Ind. Eng. Chem. Res. 53, 3272-3282. https://doi.org/10.1021/ie403788v

678 Maere, T., Villez, K., Marsili-Libelli, S., Naessens, W., Nopens, I., 2012. Membrane bioreactor fouling 679 behaviour assessment through principal component analysis and fuzzy clustering. Water Res. 46, 6132-6142. 680 https://doi.org/10.1016/j.watres.2012.08.027

681 Mampaey, K.E., De Kreuk, M.K., van Dongen, U.G.J.M., van Loosdrecht, M.C.M., Volcke, E.I.P., 2016. 682 Identifying $\mathrm{N}_{2} \mathrm{O}$ formation and emissions from a full-scale partial nitritation reactor. Water Res. 88, 575-585. 683 https://doi.org/10.1016/j.watres.2015.10.047

684 Mannina, G., Ekama, G., Caniani, D., Cosenza, A., Esposito, G., Gori, R., Garrido-Baserba, M., Rosso, D., 685 Olsson, G., 2016. Greenhouse gases from wastewater treatment - A review of modelling tools. Sci. Total 686 Environ. 551-552, 254-270. https://doi.org/10.1016/j.scitotenv.2016.01.163

687 Massara, T.M., Malamis, S., Guisasola, A., Baeza, J.A., Noutsopoulos, C., Katsou, E., 2017. A review on 688 nitrous oxide (N 2 O) emissions during biological nutrient removal from municipal wastewater and sludge 689 reject water. Sci. Total Environ. 596, 106-123.

690 Mirin, S.N.S., Wahab, N.A., 2014. Fault Detection and Monitoring Using Multiscale Principal Component 691 Analysis at a Sewage Treatment Plant. J. Teknol. 70.

692 Monteith, H.D., Sahely, H.R., MacLean, H.L., Bagley, D.M., 2005. A Rational Procedure for Estimation of 693 Greenhouse-Gas Emissions from Municipal Wastewater Treatment Plants. Water Environ. Res. 77, 390-403. 694 https://doi.org/10.2175/106143005X51978 
Moon, T.S., Kim, Y.J., Kim, J.R., Cha, J.H., Kim, D.H., Kim, C.W., 2009. Identification of process operating 696 state with operational map in municipal wastewater treatment plant. J. Environ. Manage. 90, 772-778. 697 https://doi.org/10.1016/j.jenvman.2008.01.008

698 Ni, B.-J., Pan, Y., van den Akker, B., Ye, L., Yuan, Z., 2015. Full-Scale Modeling Explaining Large Spatial 699 Variations of Nitrous Oxide Fluxes in a Step-Feed Plug-Flow Wastewater Treatment Reactor. Environ. Sci. 700 Technol. 49, 9176-9184. https://doi.org/10.1021/acs.est.5b02038

701 Olsson, G., Carlsson, B., Comas, J., Copp, J., Gernaey, K.V., Ingildsen, P., Jeppsson, U., Kim, C., Rieger, L., 702 Rodriguez-Roda, I., others, 2014. Instrumentation, control and automation in wastewater-from London 1973 703 to Narbonne 2013. Water Sci. Technol. 69, 1373-1385.

704 Pan, Y., van den Akker, B., Ye, L., Ni, B.-J., Watts, S., Reid, K., Yuan, Z., 2016. Unravelling the spatial 705 variation of nitrous oxide emissions from a step-feed plug-flow full scale wastewater treatment plant. Sci. 706 Rep. 6. https://doi.org/10.1038/srep20792

707 Pan, Y., Ye, L., Ni, B.-J., Yuan, Z., 2012. Effect of $\mathrm{pH}$ on $\mathrm{N}_{2} \mathrm{O}$ reduction and accumulation during 708 denitrification by methanol utilizing denitrifiers. Water Res. 46, 4832-4840. 709 https://doi.org/10.1016/j.watres.2012.06.003

710 Platikanov, S., Rodriguez-Mozaz, S., Huerta, B., Barceló, D., Cros, J., Batle, M., Poch, G., Tauler, R., 2014. 711 Chemometrics quality assessment of wastewater treatment plant effluents using physicochemical parameters 712 and UV absorption measurements. J. Environ. Manage. 140, 33-44.

713 Pocquet, M., Wu, Z., Queinnec, I., Spérandio, M., 2016. A two pathway model for $\mathrm{N}_{2} \mathrm{O}$ emissions by 714 ammonium oxidizing bacteria supported by the $\mathrm{NO} / \mathrm{N}_{2} \mathrm{O}$ variation. Water Res. 88, 948-959. 715 https://doi.org/10.1016/j.watres.2015.11.029

716 R Core Team, 2017. R: A language and environment for statistical computing. R Foundation for Statistical 717 Computing, Vienna, Austria [WWW Document]. URL https://www.R-project.org/ 
718 Ravishankara, A.R., Daniel, J.S., Portmann, R.W., 2009. Nitrous oxide $\left(\mathrm{N}_{2} \mathrm{O}\right)$ : the dominant ozone-depleting 719 substance emitted in the 21st century. science $326,123-125$.

720 Rodriguez-Caballero, A., Aymerich, I., Poch, M., Pijuan, M., 2014. Evaluation of process conditions 721 triggering emissions of green-house gases from a biological wastewater treatment system. Sci. Total Environ. 722 493, 384-391. https://doi.org/10.1016/j.scitotenv.2014.06.015

723 Rosén, C., Lennox, J.A., 2001. Multivariate and multiscale monitoring of wastewater treatment operation. 724 Water Res. 35, 3402-3410.

725 Rosén, C., Olsson, G., 1998. Disturbance detection in wastewater treatment plants. Water Sci. Technol. 37, $726 \quad 197-205$.

727 Rosen, C., Yuan, Z., 2001. Supervisory control of wastewater treatment plants by combining principal 728 component analysis and fuzzy c-means clustering. Water Sci. Technol. 43, 147-156.

729 Rousseeuw, P.J., 1987. Silhouettes: a graphical aid to the interpretation and validation of cluster analysis. 730 Journal of computational and applied mathematics 20, 53-65.

731 Rustum, R., Adeloye, A.J., Scholz, M., 2008. Applying Kohonen Self-Organizing Map as a Software Sensor 732 to Predict Biochemical Oxygen Demand. Water Environ. Res. 80, 32-40. 733 https://doi.org/10.2175/106143007X184500

734 Schulthess, R.V., Gujer, W., 1996. Release of nitrous oxide $\left(\mathrm{N}_{2} \mathrm{O}\right)$ from denitrifying activated sludge: 735 Verification and application of a mathematical model. Water Res. 30, 521-530. https://doi.org/10.1016/0043$736 \quad \underline{1354(95) 00204-9}$

737 Schulthess, R. von, Wild, D., Gujer, W., 1994. Nitric and nitrous oxides from denitrifying activated sludge at 738 low oxygen concentration. Water Sci. Technol. 30, 123-132.

739 Scott, A.J., Knott, M., 1974. A cluster analysis method for grouping means in the analysis of variance. $740 \quad$ Biometrics 507-512. 
741 Spearman, C., 1904. “General Intelligence,” Objectively Determined and Measured. Am. J. Psychol. 15, 201742 292. https://doi.org/10.2307/1412107

743 Sun, S., Cheng, X., Sun, D., 2013. Emission of $\mathrm{N}_{2} \mathrm{O}$ from a full-scale sequencing batch reactor wastewater 744 treatment plant: Characteristics and influencing factors. Int. Biodeterior. Biodegrad. 85, 545-549. 745 https://doi.org/10.1016/j.ibiod.2013.03.034

746 Ward Jr, J.H., 1963. Hierarchical grouping to optimize an objective function. J. Am. Stat. Assoc. 58, 236-244.

747 Wunderlin, P., Mohn, J., Joss, A., Emmenegger, L., Siegrist, H., 2012. Mechanisms of $\mathrm{N}_{2} \mathrm{O}$ production in 748 biological wastewater treatment under nitrifying and denitrifying conditions. Water Res. 46, 1027-1037. 749 https://doi.org/10.1016/j.watres.2011.11.080

750 Yang, X., Wang, S., Zhou, L., 2012. Effect of carbon source, C/N ratio, nitrate and dissolved oxygen 751 concentration on nitrite and ammonium production from denitrification process by Pseudomonas stutzeri D6. 752 Bioresour. Technol. 104, 65-72. https://doi.org/10.1016/j.biortech.2011.10.026

753 Yu, R., Kampschreur, M.J., Loosdrecht, M.C.M. van, Chandran, K., 2010. Mechanisms and Specific 754 Directionality of Autotrophic Nitrous Oxide and Nitric Oxide Generation during Transient Anoxia. Environ. 755 Sci. Technol. 44, 1313-1319. https://doi.org/10.1021/es902794a

756 Zheng, M., Tian, Y., Liu, T., Ma, T., Li, L., Li, C., Ahmad, M., Chen, Q., Ni, J., 2015. Minimization of 757 nitrous oxide emission in a pilot-scale oxidation ditch: Generation, spatial variation and microbial 758 interpretation. Bioresour. Technol. 179, 510-517.

759 Zhou, Y.A.N., Pijuan, M., Zeng, R.J., Yuan, Z., 2008. Free nitrous acid inhibition on nitrous oxide reduction 760 by a denitrifying-enhanced biological phosphorus removal sludge. Environmental Science \& Technology 42, $761 \quad 8260-8265$ 
Table 1:Average value and standard deviation (std) of variables monitored in the Northern carrousel reactor

(C: carrousel reactor, N: Northern, PF: plug-flow reactor)

\begin{tabular}{lcclcc}
\hline \multicolumn{1}{c}{ Online variables } & Average & Std & Offline variables & Average & Std \\
\hline $\mathrm{N}_{2} \mathrm{O}(\mathrm{kg} / \mathrm{h})$ & 1.4 & 2.1 & COD influent $(\mathrm{mg}$ COD/ L) & 238.8 & 79.5 \\
$\mathrm{NH}_{4}-\mathrm{N} \mathrm{C}(\mathrm{mg} / \mathrm{L})$ & 1.63 & 2.2 & TKN influent $(\mathrm{mg} / \mathrm{L})$ & 42.1 & 10.0 \\
$\mathrm{NO}_{3}-\mathrm{N} \mathrm{C}(\mathrm{mg} / \mathrm{L})$ & 5.8 & 4 & TP influent $(\mathrm{mg} / \mathrm{L})$ & 7.0 & 2.1 \\
$\mathrm{NO}_{2}-\mathrm{N} \mathrm{C}(\mathrm{mg} / \mathrm{L})$ & 1.2 & 1.1 & Flow-rate $\left(\mathrm{m}^{3} / \mathrm{d}\right)$ & 85,898 & 41,786 \\
$\mathrm{DO} 1(\mathrm{mg} / \mathrm{L})$ & 0.6 & 0.9 & COD effluent $(\mathrm{mg} / \mathrm{L})$ & 36.9 & 6.9 \\
$\mathrm{DO} 2(\mathrm{mg} / \mathrm{L})$ & 0.8 & 0.9 & TKN efffluent $(\mathrm{mg} / \mathrm{L})$ & 2.8 & 1.2 \\
$\mathrm{DO} 3(\mathrm{mg} / \mathrm{L})$ & 1.9 & 0.6 & TP effluent $(\mathrm{mg} / \mathrm{L})$ & 1.1 & 0.6 \\
$\mathrm{Temperature}\left({ }^{\circ} \mathrm{C}\right)$ & 16 & 3.5 & $\mathrm{pH}$ effluent & 8.0 & 0.2 \\
$\mathrm{~N}_{2} \mathrm{O}$ PF $(\mathrm{kg} / \mathrm{h})$ & 0.71 & 1.21 & & & \\
$\mathrm{NH}_{4}-\mathrm{N} \mathrm{PF}(\mathrm{mg} / \mathrm{L})$ & 12.41 & 5.35 & & & \\
$\mathrm{NO}_{3}-\mathrm{N} \mathrm{PF}(\mathrm{mg} / \mathrm{L})$ & 2.38 & 2.2 & & & \\
Influent Flow-rate $\left(\mathrm{m}^{3} / \mathrm{h}\right)$ & 3973 & 2375 & & & \\
$\mathrm{DO} \mathrm{PF}(\mathrm{mg} / \mathrm{L})$ & 2.61 & 0.65 & & & \\
\hline
\end{tabular}


766

\begin{tabular}{|c|c|c|c|c|c|c|c|c|c|c|c|c|c|c|c|c|c|c|c|c|}
\hline \multirow[t]{2}{*}{ Variables } & \multicolumn{2}{|c|}{$\begin{array}{c}\mathrm{N}_{2} \mathrm{O} \\
(\mathrm{kg} / \mathrm{h})\end{array}$} & \multicolumn{2}{|c|}{$\begin{array}{c}\mathrm{NO}_{3}-\mathrm{C} \mathrm{N} \\
(\mathrm{mg} / \mathrm{l})\end{array}$} & \multicolumn{2}{|c|}{$\begin{array}{c}\mathrm{NO}_{3}-\mathrm{N} \text { PF } \\
(\mathrm{mg} / \mathrm{l})\end{array}$} & \multicolumn{2}{|c|}{$\begin{array}{c}\mathrm{NH}_{4}-\mathrm{N} \mathrm{C} \\
(\mathrm{mg} / \mathrm{l})\end{array}$} & \multicolumn{2}{|c|}{$\begin{array}{c}\mathrm{NH}_{4}-\mathrm{N} \text { PF } \\
(\mathrm{mg} / \mathrm{l})\end{array}$} & \multicolumn{2}{|c|}{$\begin{array}{c}\mathrm{NO}_{2}-\mathrm{N} \mathrm{C}^{*} \\
(\mathrm{mg} / \mathrm{l})\end{array}$} & \multicolumn{2}{|c|}{$\begin{array}{c}\text { Temperature } \\
\left({ }^{\circ} \mathrm{C}\right)\end{array}$} & \multicolumn{2}{|c|}{$\begin{array}{c}\mathrm{DO} 1 \\
(\mathrm{mg} / \mathrm{l})\end{array}$} & \multicolumn{2}{|c|}{$\begin{array}{c}\mathrm{DO} 2 \\
(\mathrm{mg} / \mathrm{l})\end{array}$} & \multicolumn{2}{|c|}{$\begin{array}{c}\mathrm{DO} 3 \\
(\mathrm{mg} / \mathrm{l})\end{array}$} \\
\hline & Mean & Std & Mean & Std & Mean & Std & Mean & Std & Mean & Std & Mean & Std & Mean & Std & Mean & Std & Mean & Std & Mean & Std \\
\hline 1 & 0 & 0.1 & 6.1 & 3.1 & 1.8 & 1.6 & 1.8 & 2.67 & 11.4 & 4.1 & & & 15.7 & 1.4 & 0.62 & 0.7 & 0.62 & 0.5 & 1.5 & 0.4 \\
\hline 2 & 0.6 & 0.6 & 7.2 & 3.1 & 2.5 & 2 & 1.5 & 1.7 & 13 & 4 & & & 11.2 & 1.0 & 0.77 & 1 & 1.31 & 0.8 & 2 & 0.4 \\
\hline 3 & 2.7 & 1.4 & 6.1 & 3.2 & 1.6 & 2.1 & 1.6 & 2.1 & 15.2 & 4.5 & & & 11.5 & 0.7 & 0.67 & 0.8 & 1.49 & 1 & 2.07 & 0.4 \\
\hline 4 & 5.6 & 2. 6 & 3 & 0.1 & 0.5 & 0.7 & 1.3 & 1.6 & 15 & 4.8 & 2.6 & 1.9 & 12.9 & 1. & 0.64 & 0.9 & 1.95 & 0.9 & 1.9 & 0.4 \\
\hline 5 & 2.6 & 2.2 & 4.3 & 4.2 & 3.1 & 1.9 & 1.3 & 2 & 11.5 & 5.2 & 0.8 & 1 & 18.2 & 1.7 & 0.34 & 0.7 & 0.39 & 0.8 & 1.94 & 0.5 \\
\hline 6 & 0.8 & 1.4 & 3.3 & 3.2 & 2.3 & 1.9 & 2 & 3.1 & 14.7 & 6.1 & 0.5 & 0.5 & 20 & 1.0 & 0.42 & 0.7 & 0.26 & 0.5 & 2.27 & 0.5 \\
\hline 7 & 0.2 & 0.3 & 7.2 & 5 & 2.8 & 2.4 & 2 & 3.1 & 9.8 & 5.2 & 0.6 & 0.4 & 20 & 0.7 & 0.42 & 0.6 & 0.29 & 0.4 & 2.64 & 0.5 \\
\hline 8 & 0.1 & 0.2 & 10.1 & 5.7 & 5.2 & 2.6 & 1.4 & 1 & 9.6 & 5.5 & 0.8 & 0.5 & 19.6 & 0.5 & 0.27 & 0.5 & 0.2 & 0.5 & 2.71 & 0.6 \\
\hline 9 & 0.1 & 0.2 & 7.9 & 3.6 & 2.8 & 2.8 & 2 & 2 & 13.2 & 5.4 & 1.9 & 0.8 & 12.9 & 2.1 & 1.12 & 1.2 & 1.07 & 1 & 1.58 & 0.4 \\
\hline 10 & 1.3 & 1.1 & 6.3 & 3.5 & 1.4 & 0.9 & 1.6 & 3.7 & 16.4 & 4.3 & 2.1 & 0.9 & 13 & 0.7 & 0.58 & 1.0 & 1.04 & 1 & 1.52 & 0.3 \\
\hline
\end{tabular}

$* \mathrm{NO}_{2}-\mathrm{N}$ concentration was monitored between $11 / 03 / 2011$ and 19/01/2012 
Table 3: Operating variables (average) for all clusters defined by hierarchical clustering in the carrousel reactor (P: Sub-period, Cl: Clusters)

\begin{tabular}{|c|c|c|c|c|c|c|c|c|c|c|c|}
\hline $\mathrm{P}$ & $\mathrm{Cl}$ & $\begin{array}{c}\mathrm{N}_{2} \mathrm{O} \\
\mathrm{C}\end{array}$ & $\begin{array}{l}\mathrm{NH}_{4^{-}} \\
\mathrm{N} \mathrm{PF}\end{array}$ & $\begin{array}{l}\mathrm{NO}_{3^{-}} \\
\mathrm{N} \quad \mathrm{PF}\end{array}$ & Influent & $\begin{array}{l}\mathrm{NH}_{4^{-}} \\
\mathrm{N} \mathrm{C}\end{array}$ & $\begin{array}{l}\mathrm{NO}_{3^{-}} \\
\mathrm{N} \quad \mathrm{C}\end{array}$ & DO1 & DO2 & DO3 & $\begin{array}{c}\mathrm{NO}_{2-} \\
\mathrm{N}\end{array}$ \\
\hline & & $\mathrm{kg} / \mathrm{h}$ & $\mathrm{mg} / \mathrm{l}$ & $\mathrm{mg} / \mathrm{l}$ & $\mathrm{m}^{3} / \mathrm{h}$ & $\mathrm{mg} / \mathrm{l}$ & $\mathrm{mg} / \mathrm{l}$ & $\mathrm{mg} / \mathrm{l}$ & $\mathrm{mg} / \mathrm{l}$ & $\mathrm{mg} / \mathrm{l}$ & $\mathrm{mg} / \mathrm{l}$ \\
\hline \multirow{3}{*}{1} & 1 & 0.09 & 14.13 & 1.48 & 3883 & 1.47 & 8.66 & 1.04 & 0.78 & 1.72 & \\
\hline & 2 & 0.01 & 8.55 & 2.41 & 3824 & 0.87 & 4.26 & 0.13 & 0.47 & 1.25 & \\
\hline & 3 & 0.05 & 14.74 & 0.30 & 8892 & 7.91 & 4.63 & 1.37 & 0.77 & 1.58 & \\
\hline \multirow{3}{*}{2} & 4 & 0.87 & 15.30 & 2.05 & 3827 & 1.51 & 8.61 & 0.94 & 1.53 & 2.22 & \\
\hline & 5 & 0.21 & 9.13 & 3.69 & 3419 & 0.74 & 5.28 & 0.03 & 0.62 & 1.41 & \\
\hline & 6 & 0.24 & 12.51 & 0.81 & 11132 & 4.52 & 5.42 & 2.27 & 2.31 & 2.22 & \\
\hline \multirow{3}{*}{3} & 7 & 3.22 & 16.85 & 1.52 & 3383 & 1.36 & 7.36 & 0.87 & 1.88 & 2.35 & \\
\hline & 8 & 1.72 & 10.96 & 1.91 & 3672 & 0.82 & 4.29 & 0.05 & 0.85 & 1.56 & \\
\hline & 9 & 2.40 & 21.40 & 0.12 & 7935 & 7.52 & 4.15 & 2.10 & 1.28 & 2.10 & \\
\hline \multirow{3}{*}{4} & 10 & 6.60 & 17.30 & 0.32 & 3207 & 1.26 & 3.79 & 2.14 & 0.95 & 2.41 & 4.10 \\
\hline & 11 & 3.83 & 10.82 & 0.77 & 2747 & 0.79 & 1.80 & 1.51 & 0.05 & 1.20 & 1.40 \\
\hline & 12 & 6.89 & 25.45 & 0.48 & 6375 & 10.86 & 3.62 & 1.98 & 2.12 & 2.34 & 4.28 \\
\hline \multirow[b]{2}{*}{6} & 15 & 2.54 & 17.66 & 0.75 & 5922 & 5.00 & 5.07 & 1.30 & 0.73 & 2.34 & 1.08 \\
\hline & 16 & 0.51 & 8.20 & 2.84 & 3811 & 0.98 & 2.64 & 0.10 & 0.10 & 2.21 & 0.35 \\
\hline
\end{tabular}

$* \mathrm{NO}_{2}-\mathrm{N}$ concentration was monitored between 11/03/2011 and 19/01/2012 
Table 4: PCA loadings sub-period 2, carrousel reactor

\begin{tabular}{ccccc}
\hline Variable & $\mathrm{PC} 1$ & $\mathrm{PC} 2$ & $\mathrm{PC} 3$ & $\mathrm{PC} 4$ \\
\hline $\mathrm{NH}_{4}-\mathrm{N} \mathrm{PF}$ & -0.28 & 0.47 & -0.24 & 0.29 \\
$\mathrm{NO}_{3}-\mathrm{N} \mathrm{PF}$ & 0.36 & 0.21 & 0.14 & -0.67 \\
Influent & -0.38 & -0.31 & -0.09 & -0.37 \\
$\mathrm{NH}_{4}-\mathrm{N} \mathrm{C}$ & -0.34 & 0.03 & -0.59 & -0.29 \\
$\mathrm{NO}_{3}-\mathrm{N} \mathrm{C}$ & -0.04 & 0.58 & 0.21 & -0.31 \\
$\mathrm{DO} 1$ & -0.43 & 0.06 & -0.15 & -0.18 \\
$\mathrm{DO} 2$ & -0.40 & 0.08 & 0.48 & -0.17 \\
$\mathrm{DO} 3$ & -0.37 & 0.21 & 0.40 & 0.28 \\
Temperature & 0.22 & 0.49 & -0.33 & 0.11 \\
\hline
\end{tabular}

772

773 
Table 5: PCA loadings sub-period 4, carrousel reactor

\begin{tabular}{ccccc}
\hline & PC1 & PC2 & PC3 & PC4 \\
\hline $\mathrm{NH}_{4}-\mathrm{N} \mathrm{PF}$ & -0.48 & 0.04 & -0.11 & 0.25 \\
$\mathrm{NO}_{3}-\mathrm{N} \mathrm{PF}$ & 0.26 & 0.56 & -0.04 & -0.35 \\
Influent & -0.33 & -0.07 & -0.52 & -0.17 \\
$\mathrm{NH}_{4}-\mathrm{N} \mathrm{C}$ & -0.28 & 0.14 & -0.50 & -0.46 \\
$\mathrm{NO}_{3}-\mathrm{N} \mathrm{C}$ & -0.17 & 0.59 & 0.32 & 0.04 \\
$\mathrm{DO} 1$ & -0.37 & 0.24 & -0.13 & 0.59 \\
$\mathrm{DO} 2$ & -0.40 & 0.08 & 0.41 & -0.14 \\
$\mathrm{DO} 3$ & -0.37 & 0.01 & 0.33 & -0.40 \\
Temperature & 0.23 & 0.51 & -0.27 & 0.19 \\
\hline
\end{tabular}




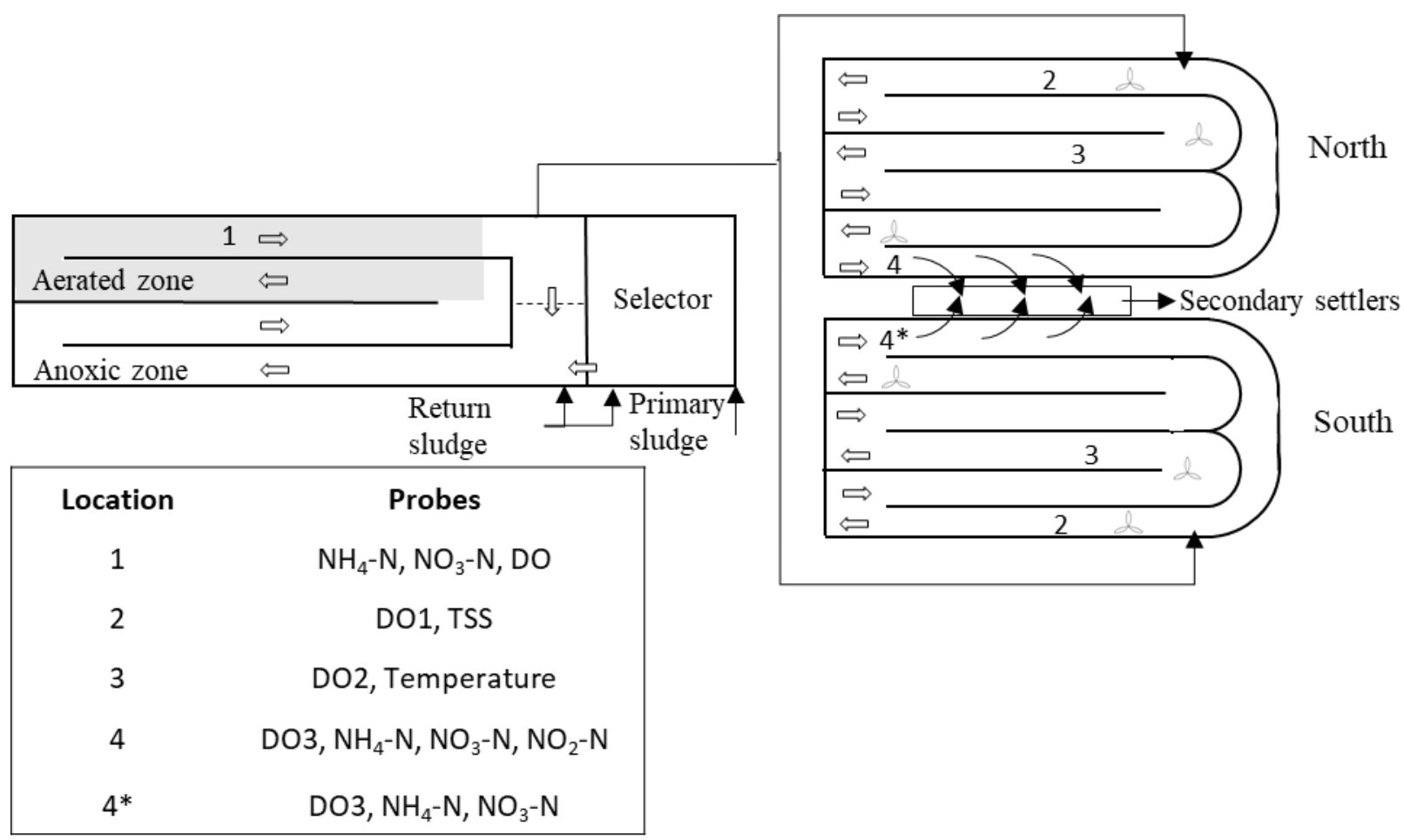

Figure 1: Layout of Kralingseveer WWTP with Plug-flow and Carrousel reactors, adapted from

Daelman et al., (2015). 


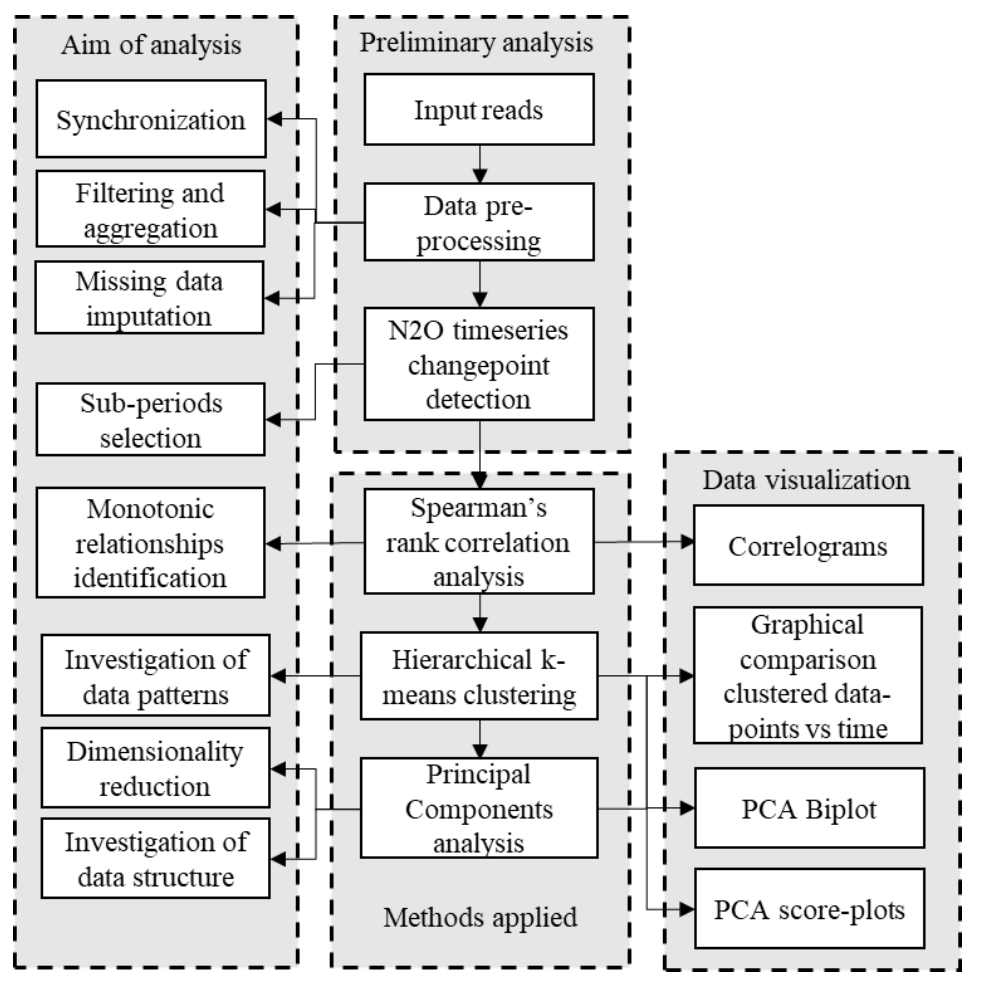

Figure 1: Methodology followed in the current study for data processing and visualization 

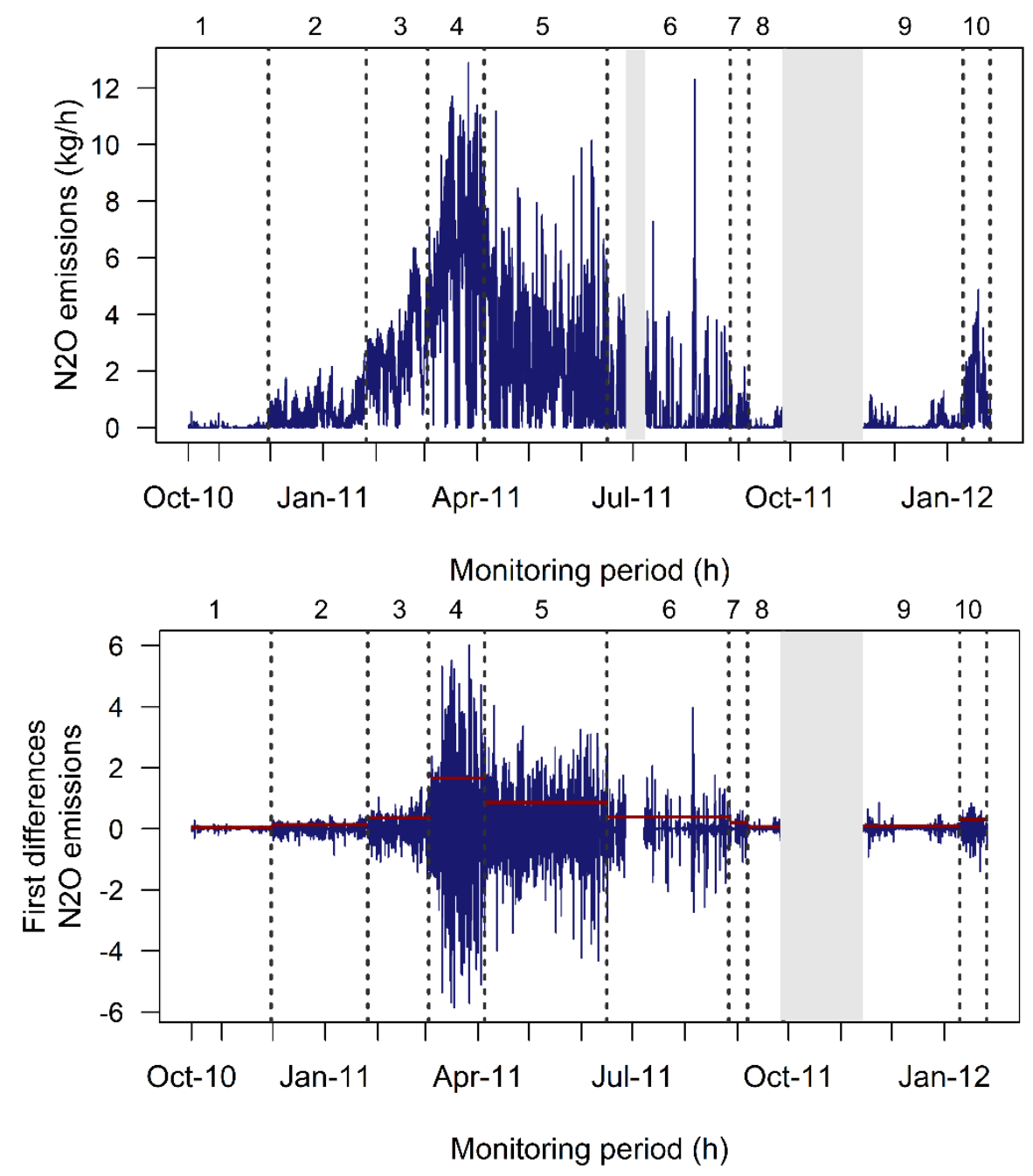

Figure 3 (top): N2O emissions profile in the Northern Carrousel reactor (grey area: periods with missing N2O data) (bottom): First difference of the N2O emissions timeseries (blue line) showing the sub-periods identified by the application of binary segmentation (grey area: periods with missing N2O data, blue dotted lines: changepoints identified by the algorithm, red horizontal lines: standard deviation in each sub-period) 
Figure

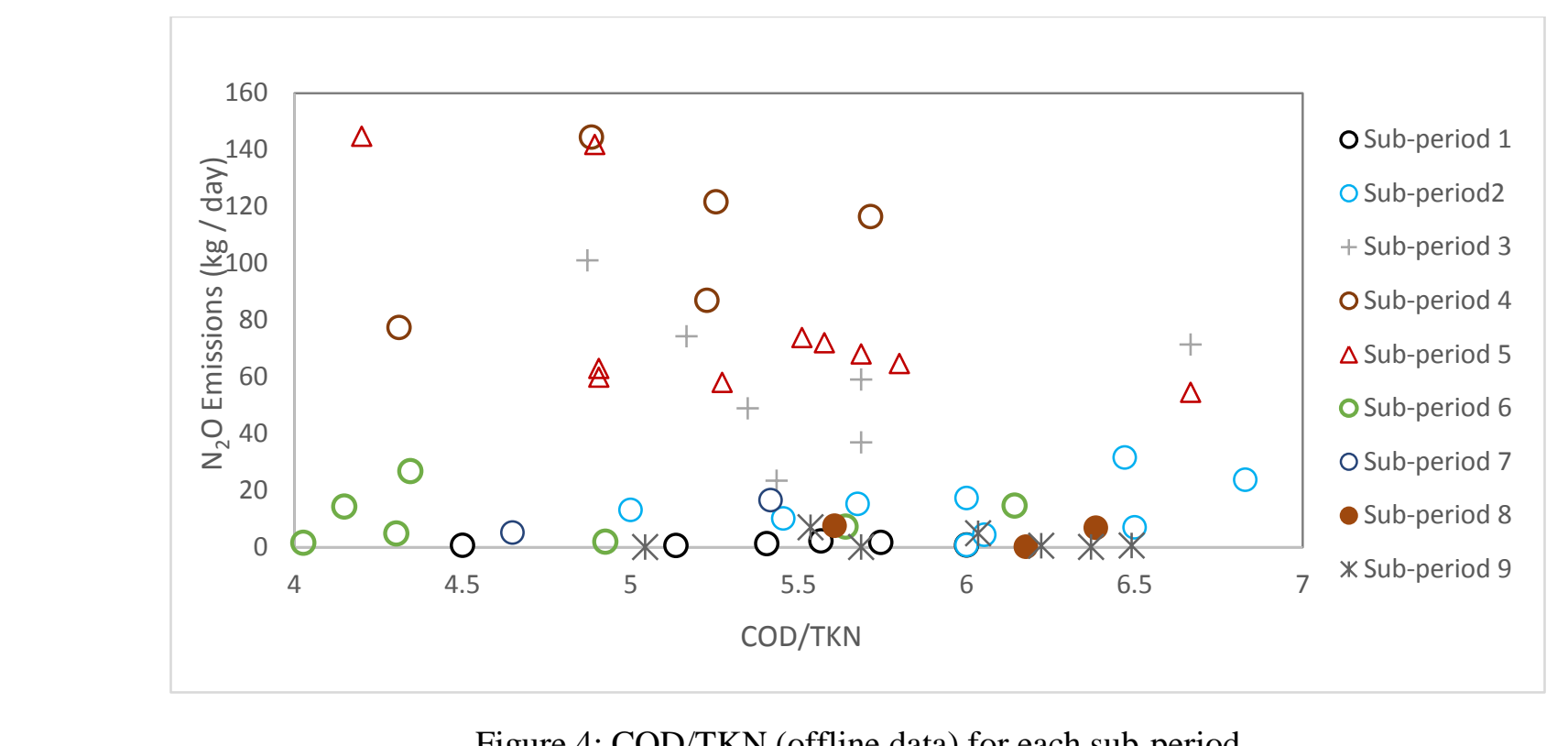

Figure 4: COD/TKN (offline data) for each sub-period

Figure 4: COD/TKN (offline data) for each sub-period -

\section{Figure}

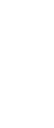
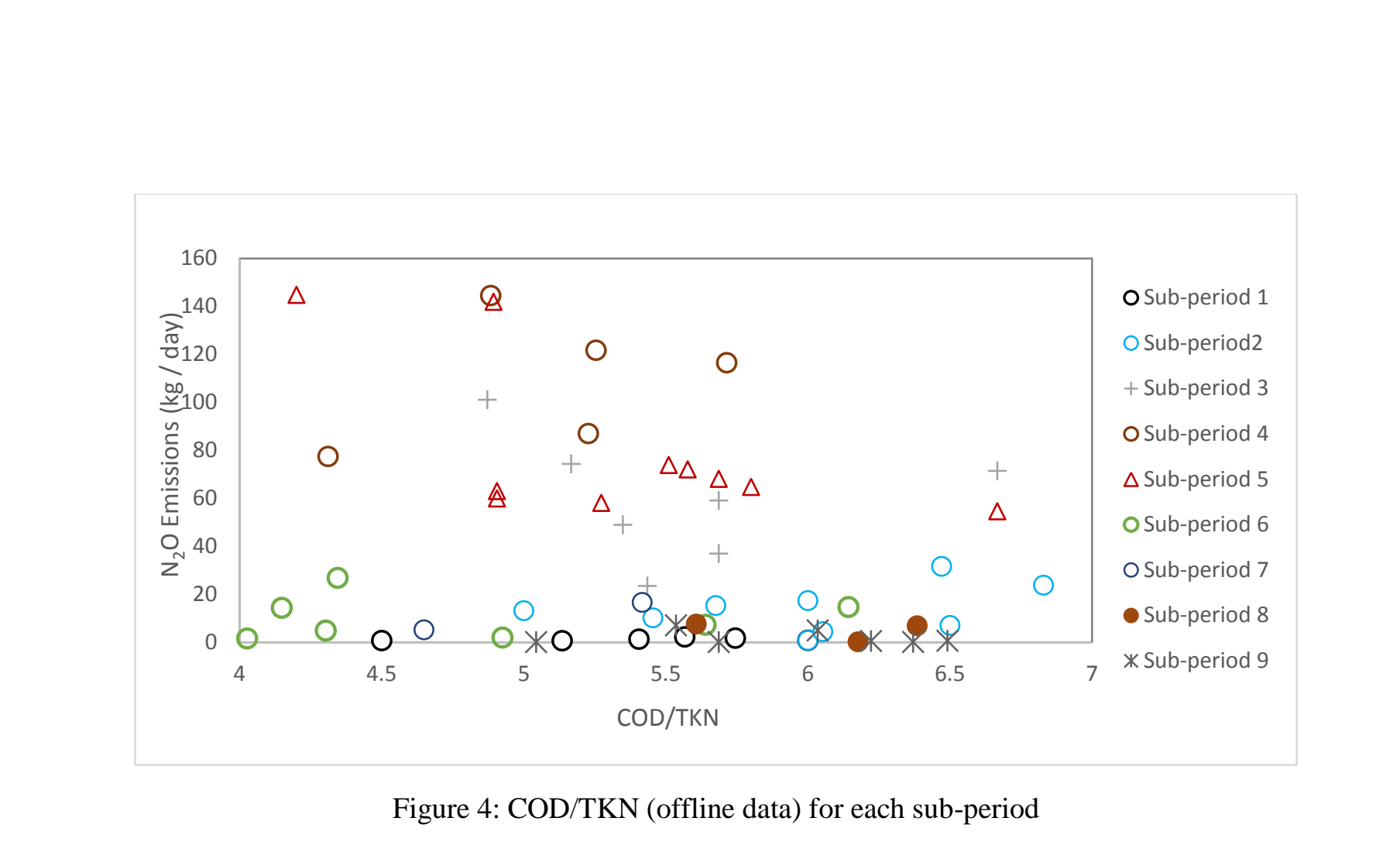

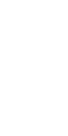
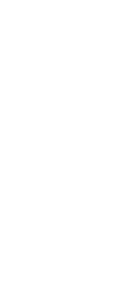


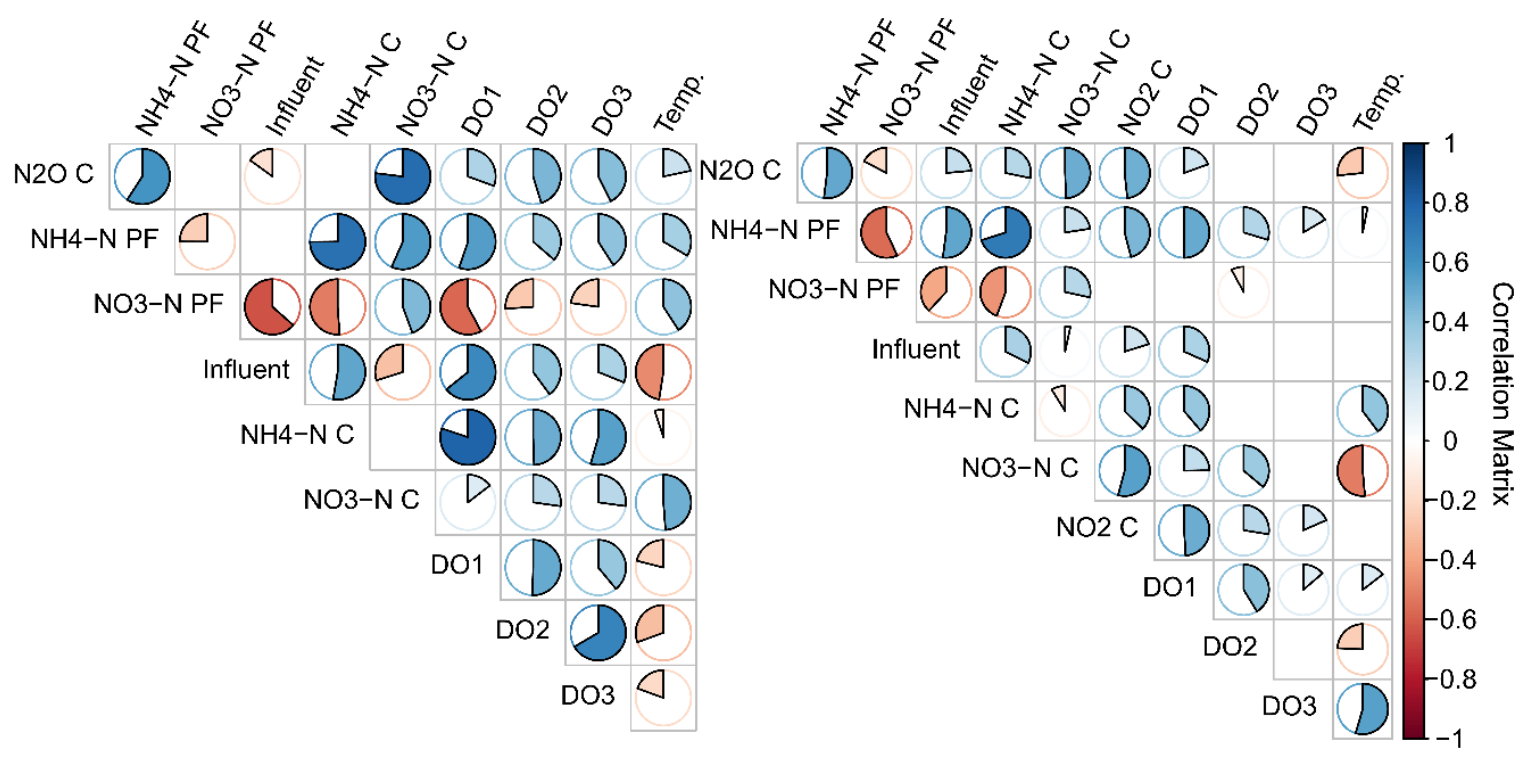

Figure 5: Spearman's rank correlation coefficient for sensor signals in Northern Carrousel reactor. (Left): Sub-period 2. (Right): Sub-period 5. (Red: negative correlation, blue: positive correlation, the coloured part of the circles is proportional to the correlation coefficient, only results with p-value $<0.01$ are shown) 

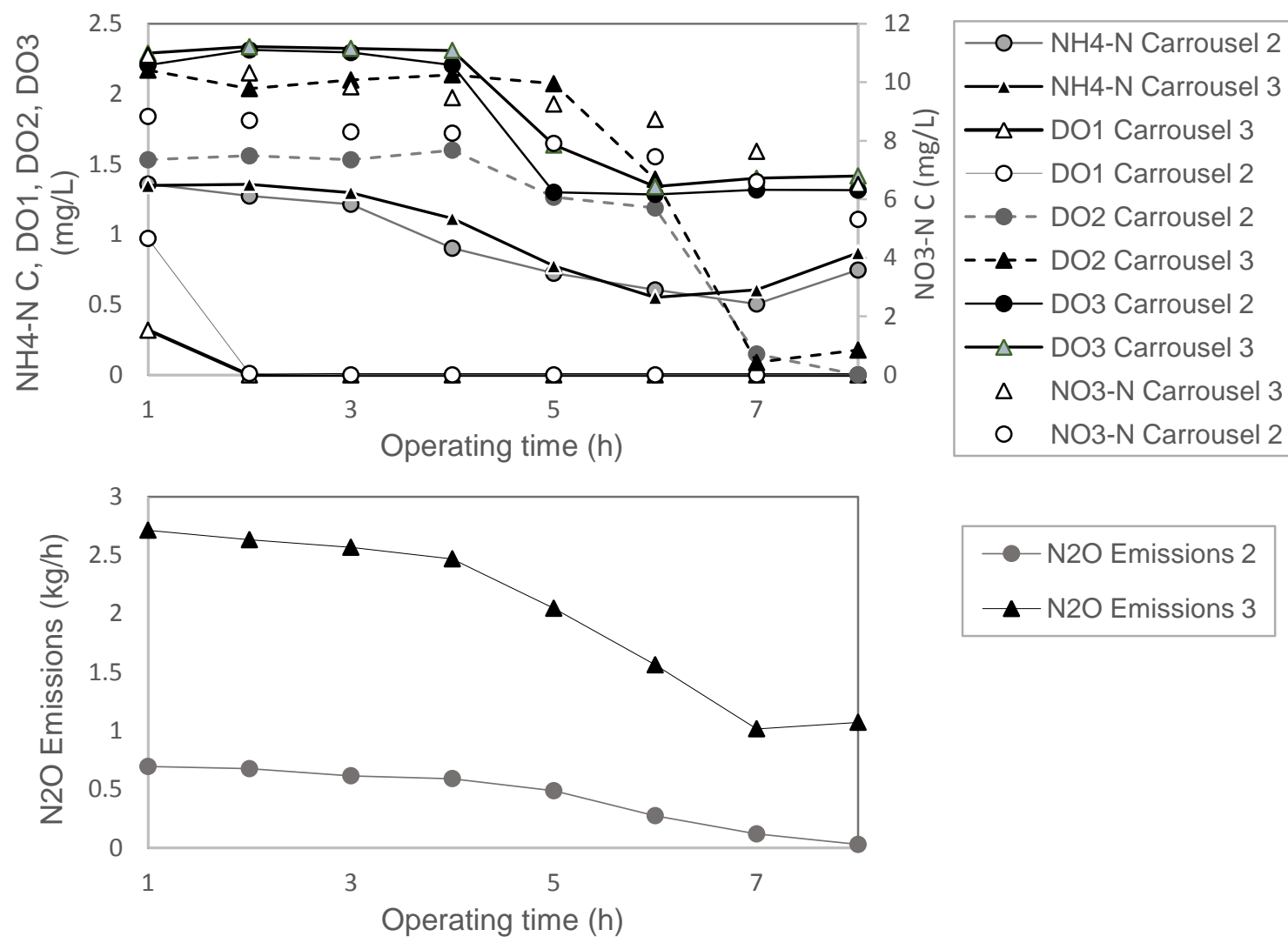

- N2O Emissions 2

\-N2O Emissions 3

Figure 6: (Top): Variables monitored online for two separate occasions in sub-periods 2 and 3

(from 00:00 am until 8:00 am), (Bottom): The respective $\mathrm{N} 2 \mathrm{O}$ emissions profiles 

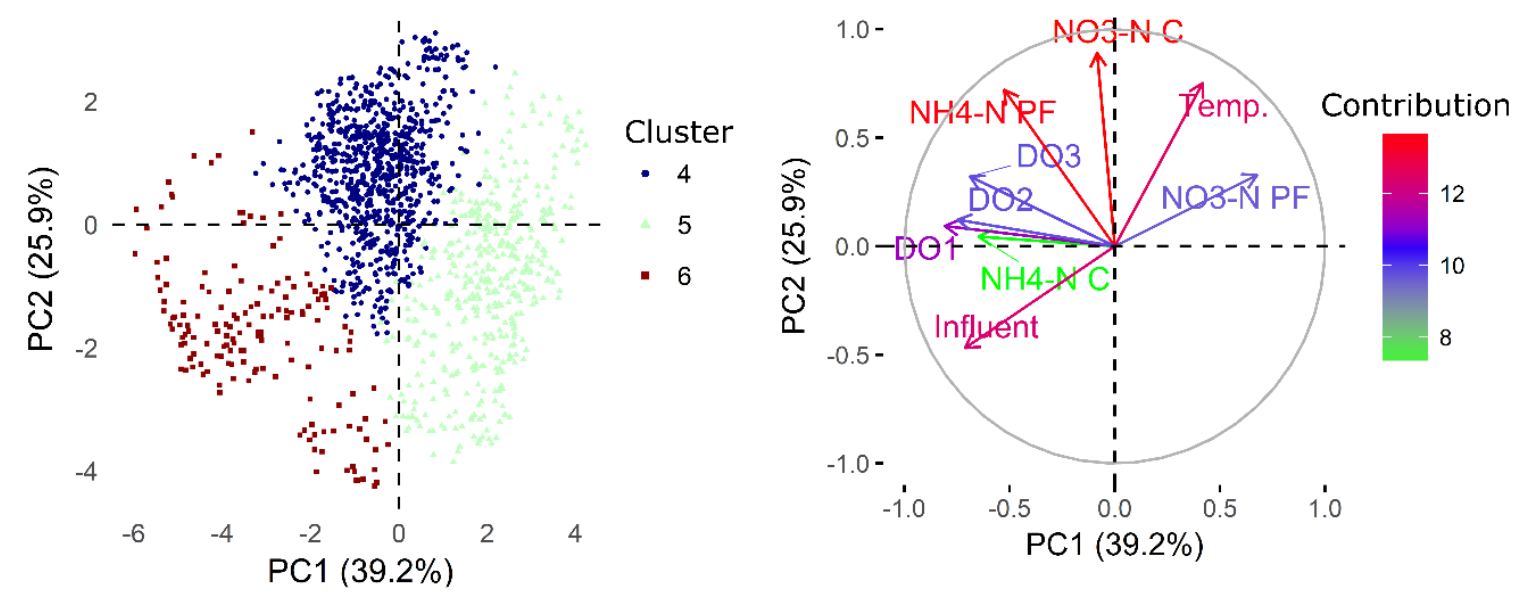

Figure 7: (left) Biplot of the first 2 PC scores, sub-period 2. The colored data-points represent the scores of the first two principal components. Groups 4, 5, and 6 represent sub-period 2, clusters.

(right) Variable correlation plot. The arrows represent the direction and strength (variable coordinates $=$ loading $\mathrm{x}$ component std) of the variables monitored in the system as projected into the 2-d plane. The contrib. legend represents the contribution (\%) of the variables to the first two PCs. The arrows for each variable point to the direction of increase for that variable. The percentage given on each axis label represents the value of the total variance explained by that PC. 

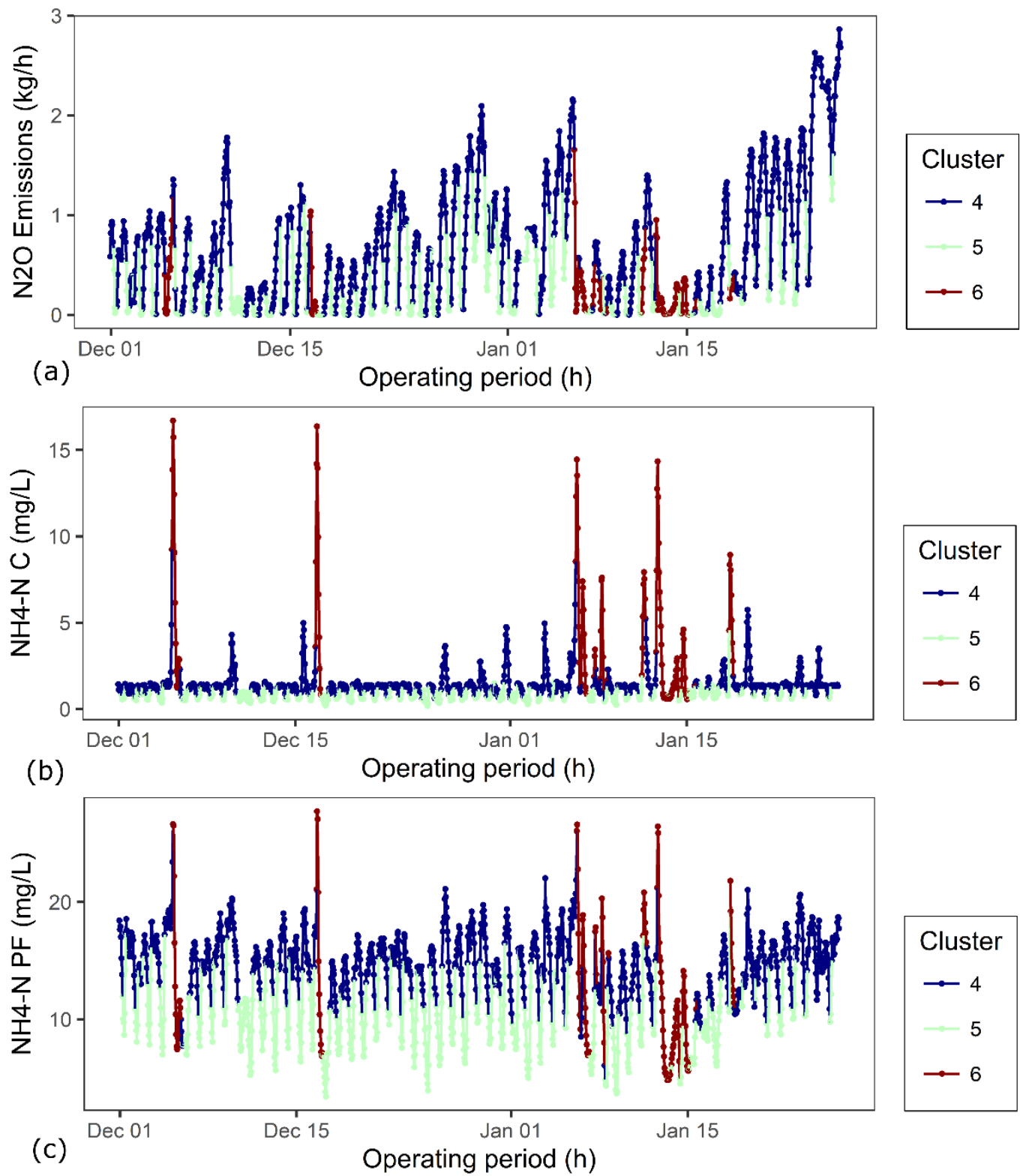

Figure 8: Profile of (a) $\mathrm{N}_{2} \mathrm{O}$ emissions, (b) $\mathrm{NH}_{4}-\mathrm{N}$ concentration in the Carrousel reactor and (c)

$\mathrm{NH}_{4}-\mathrm{N}$ concentration in the plug-flow reactor for sub-period 2; coloured points indicate the respective clusters 


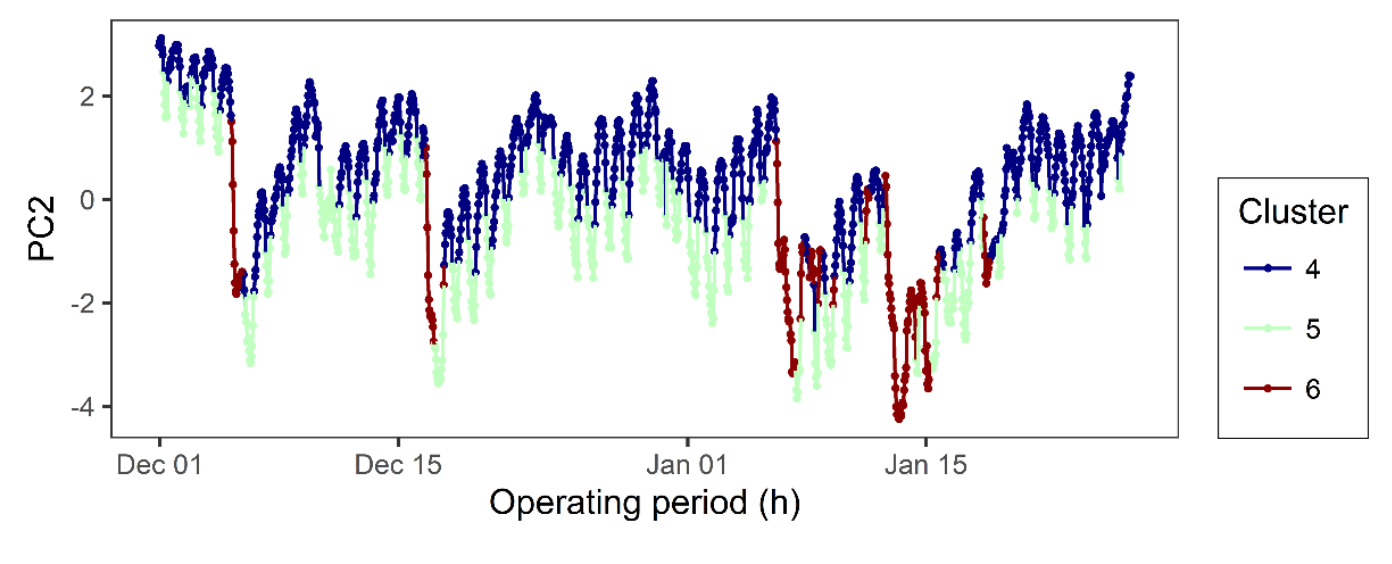

Figure 9: PC2 scores for sub-period 2

Figure

Figure 9: PC2 scores for sub-period 2

\section{.}

(2)

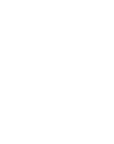

.

.

.

(

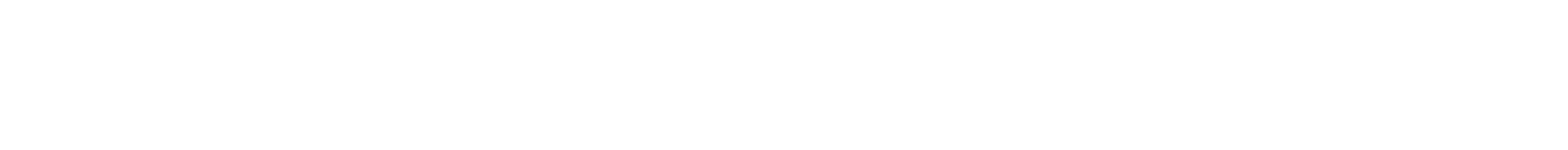
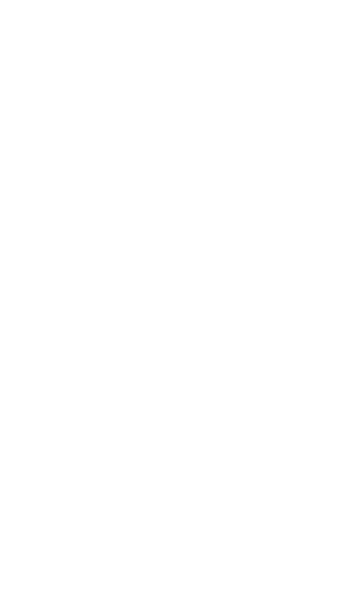

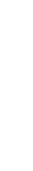

(1)

. 

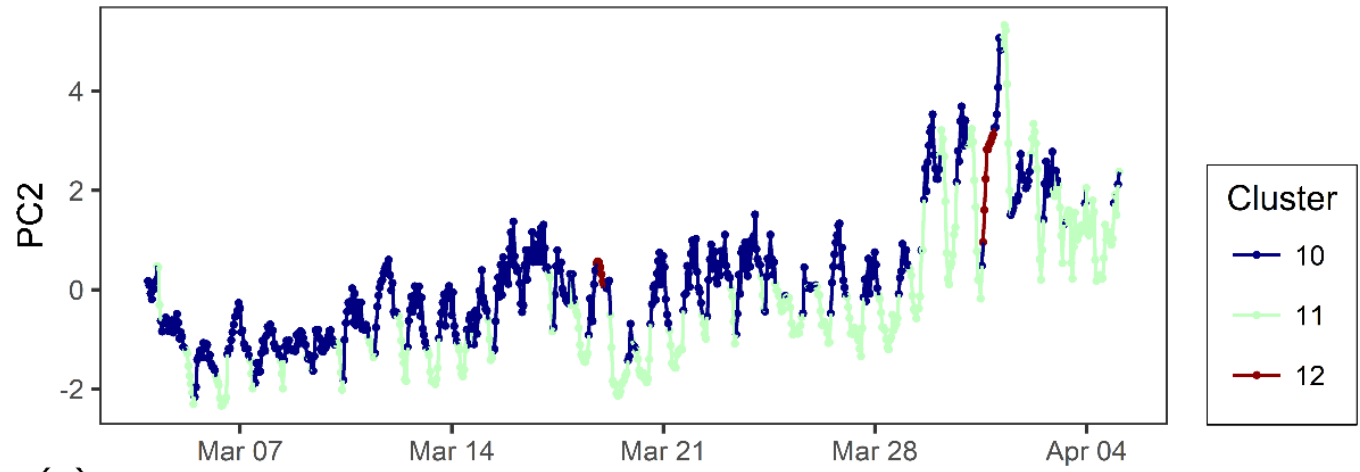

(a)

Operating period $(h)$

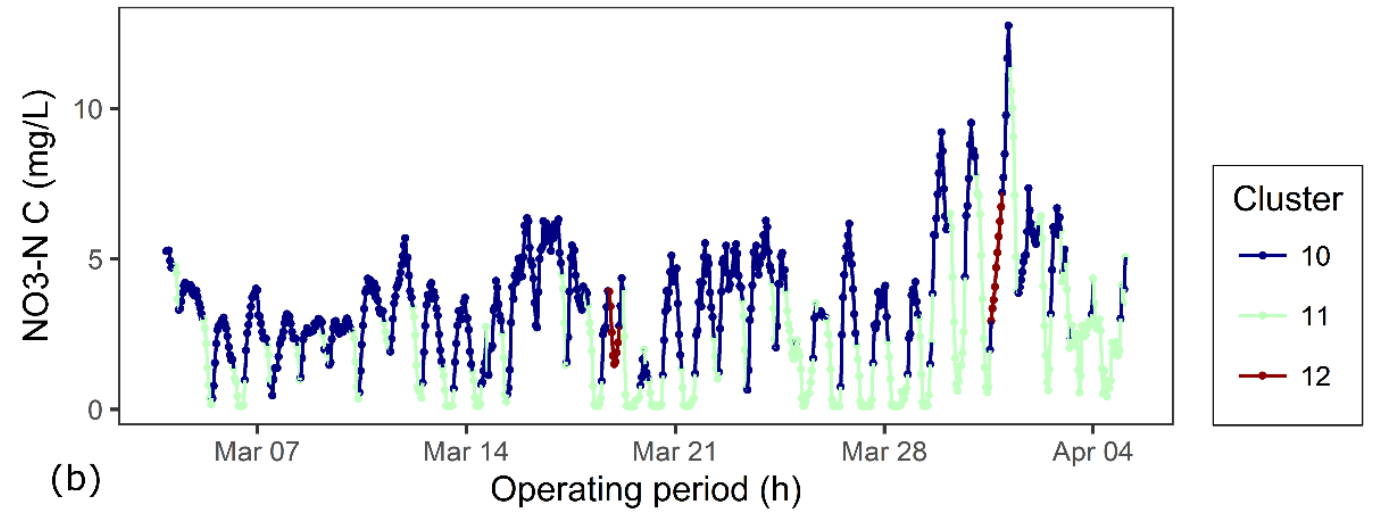

Figure 10: (a) PC2 scores for sub-period 4 and (b) $\mathrm{NO}_{3}-\mathrm{N}$ concentration in the Carrousel reactor for sub-period 4 . 


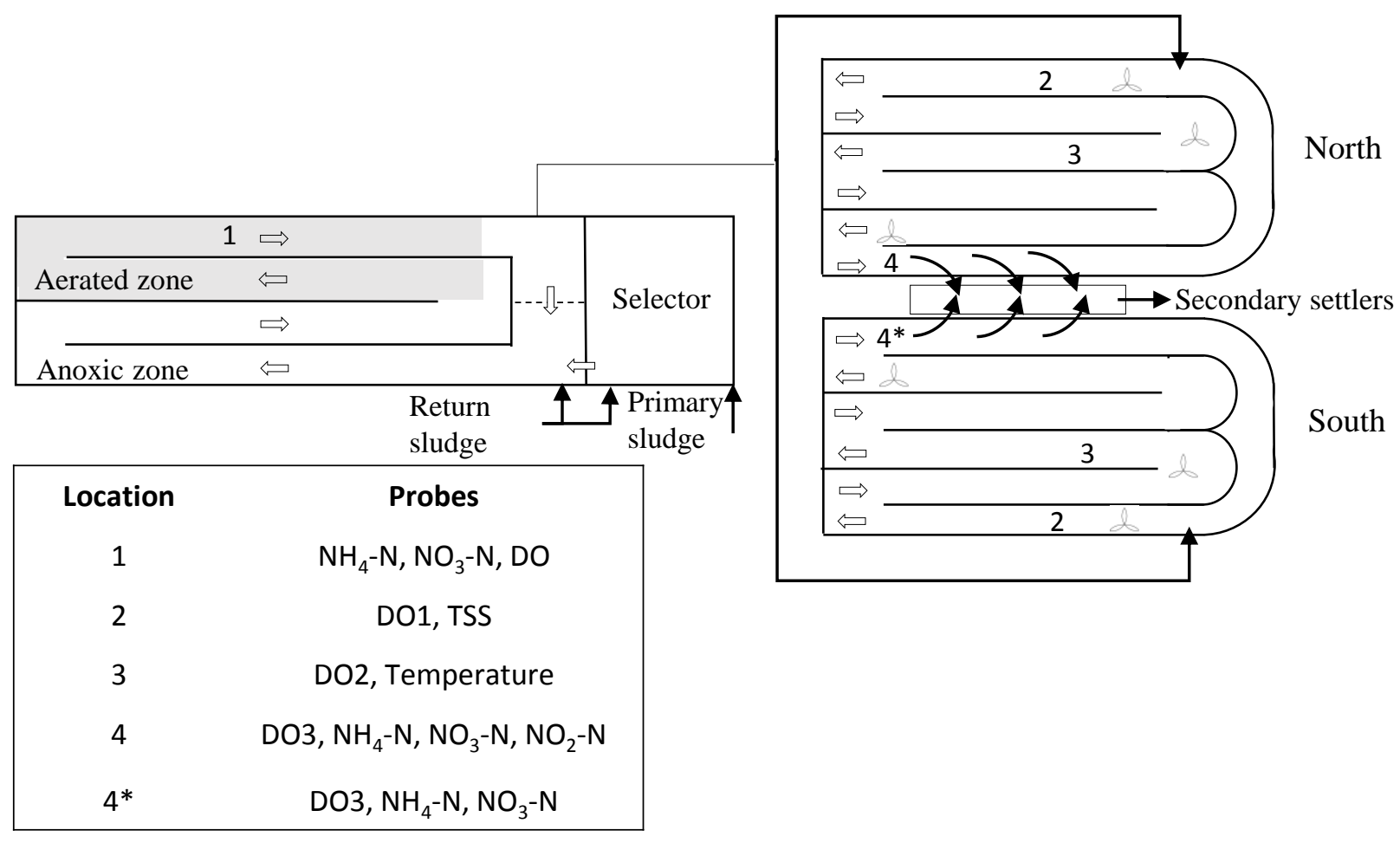




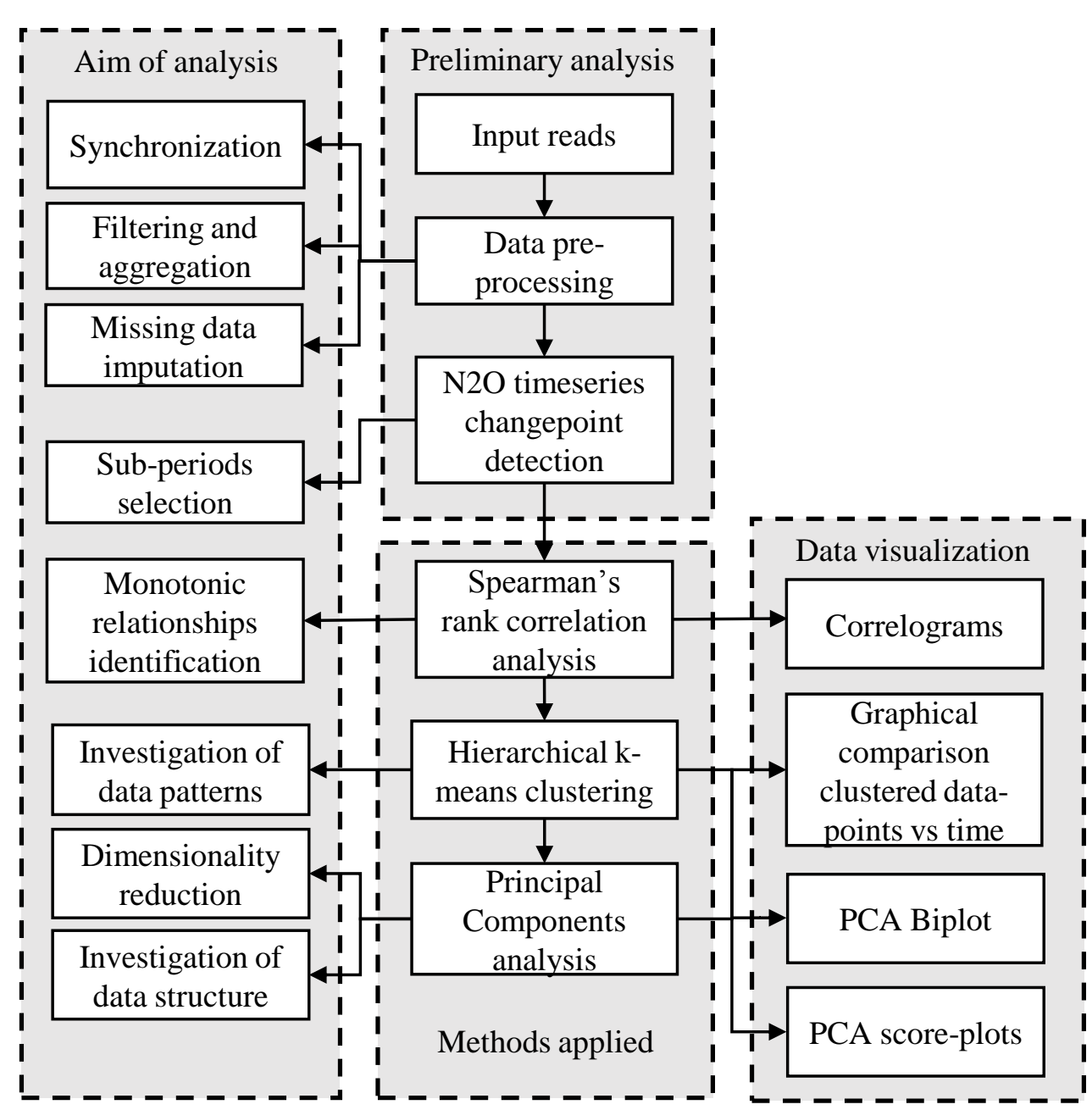



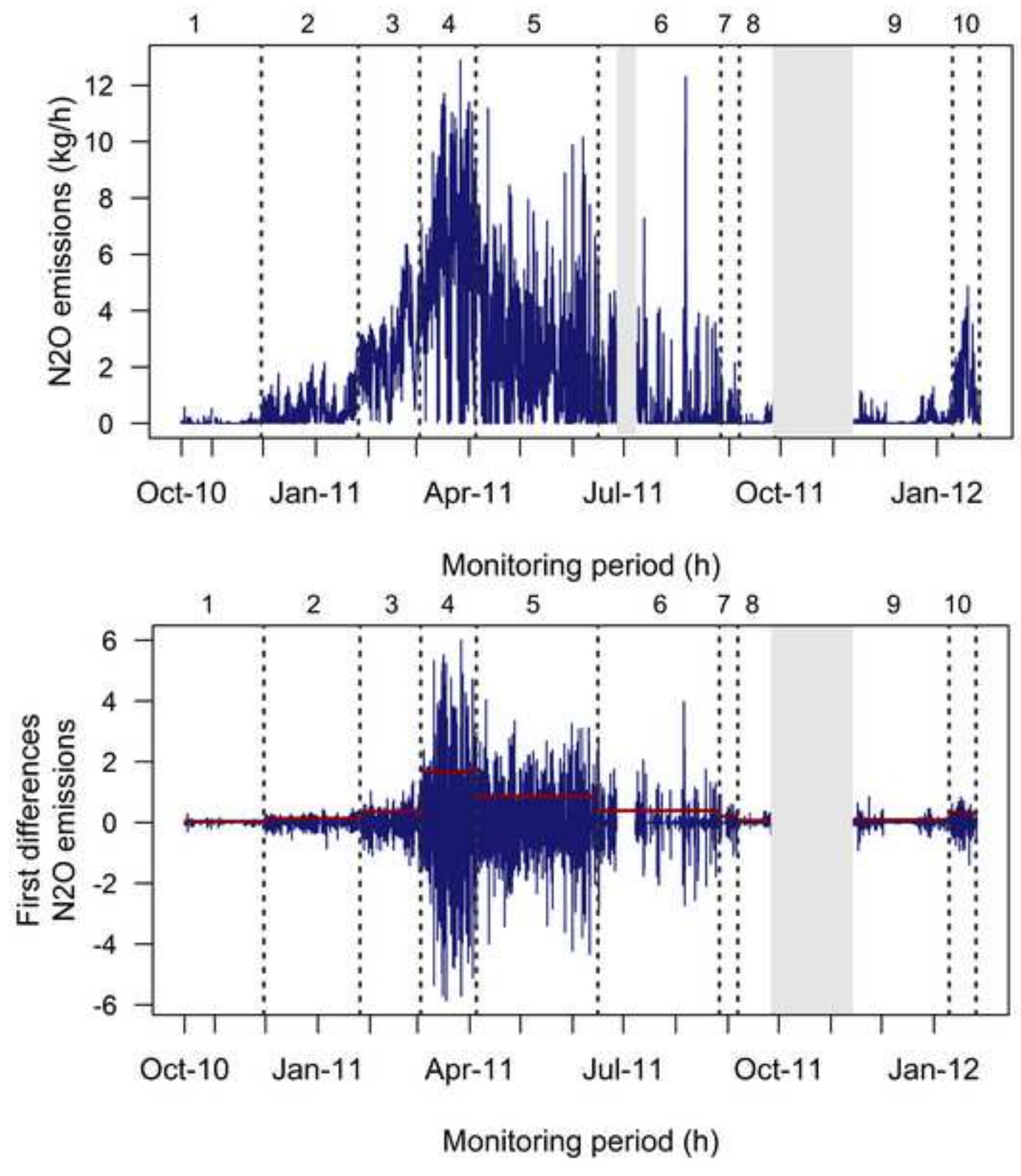


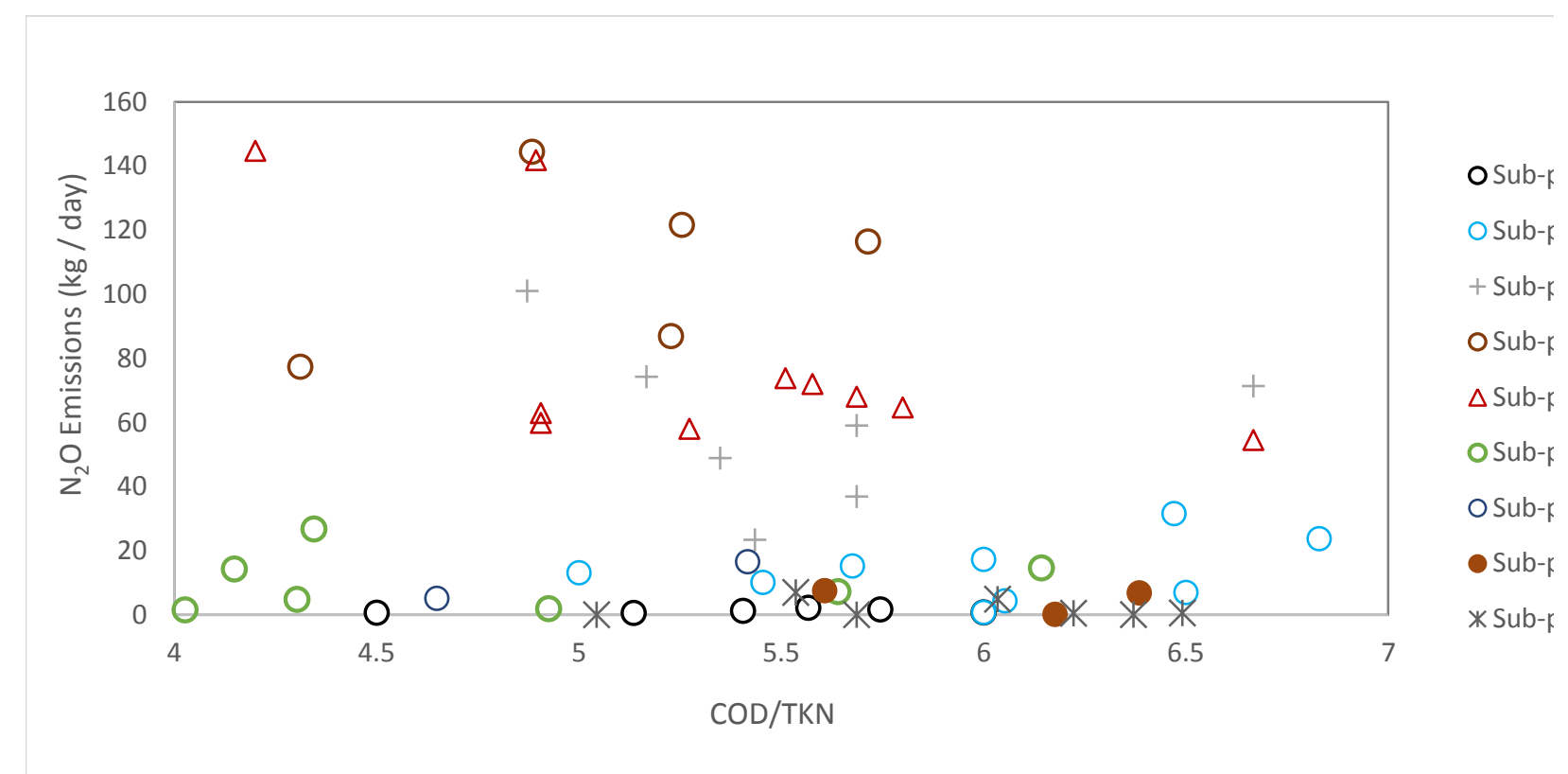

Figure 


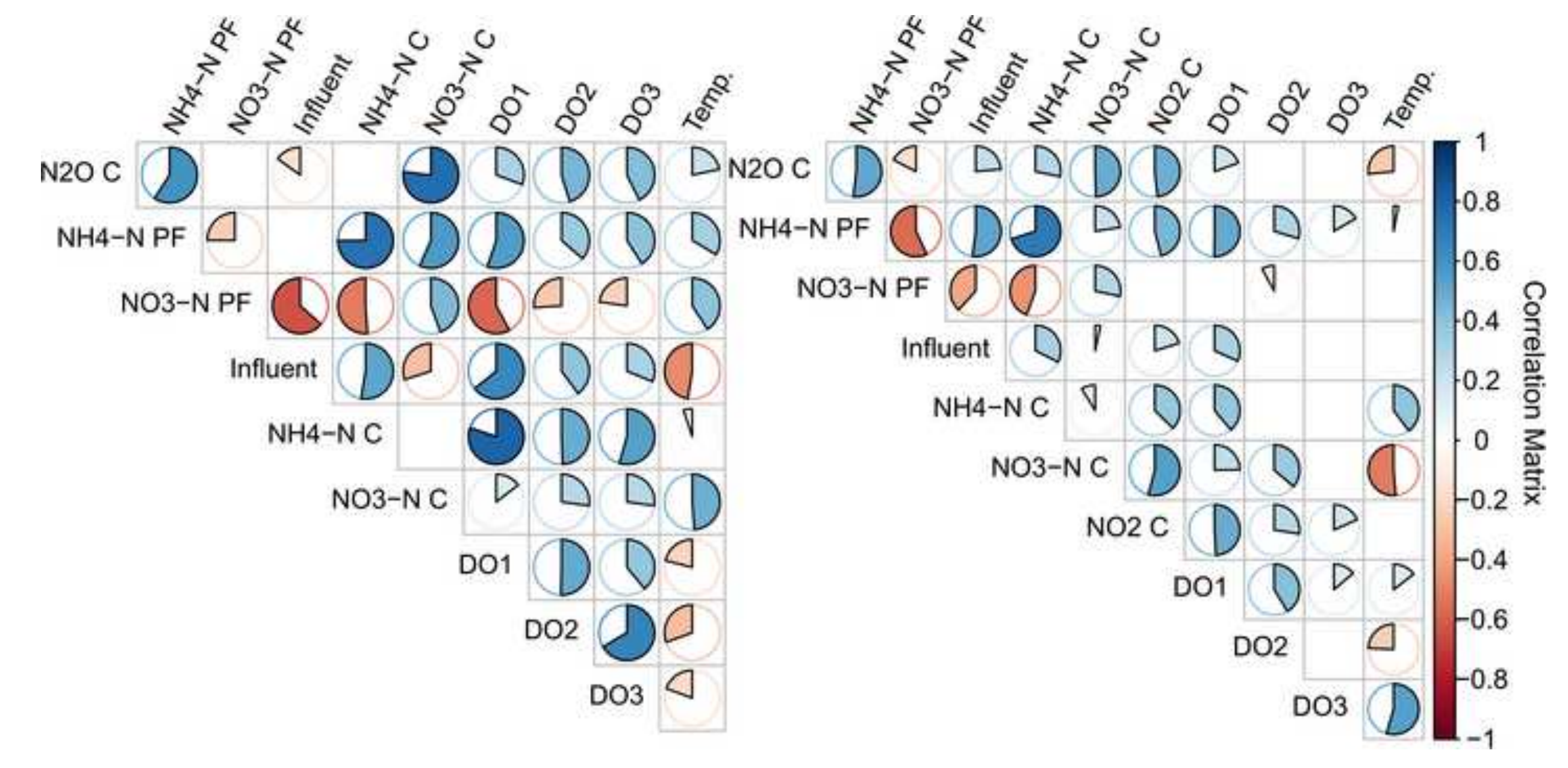



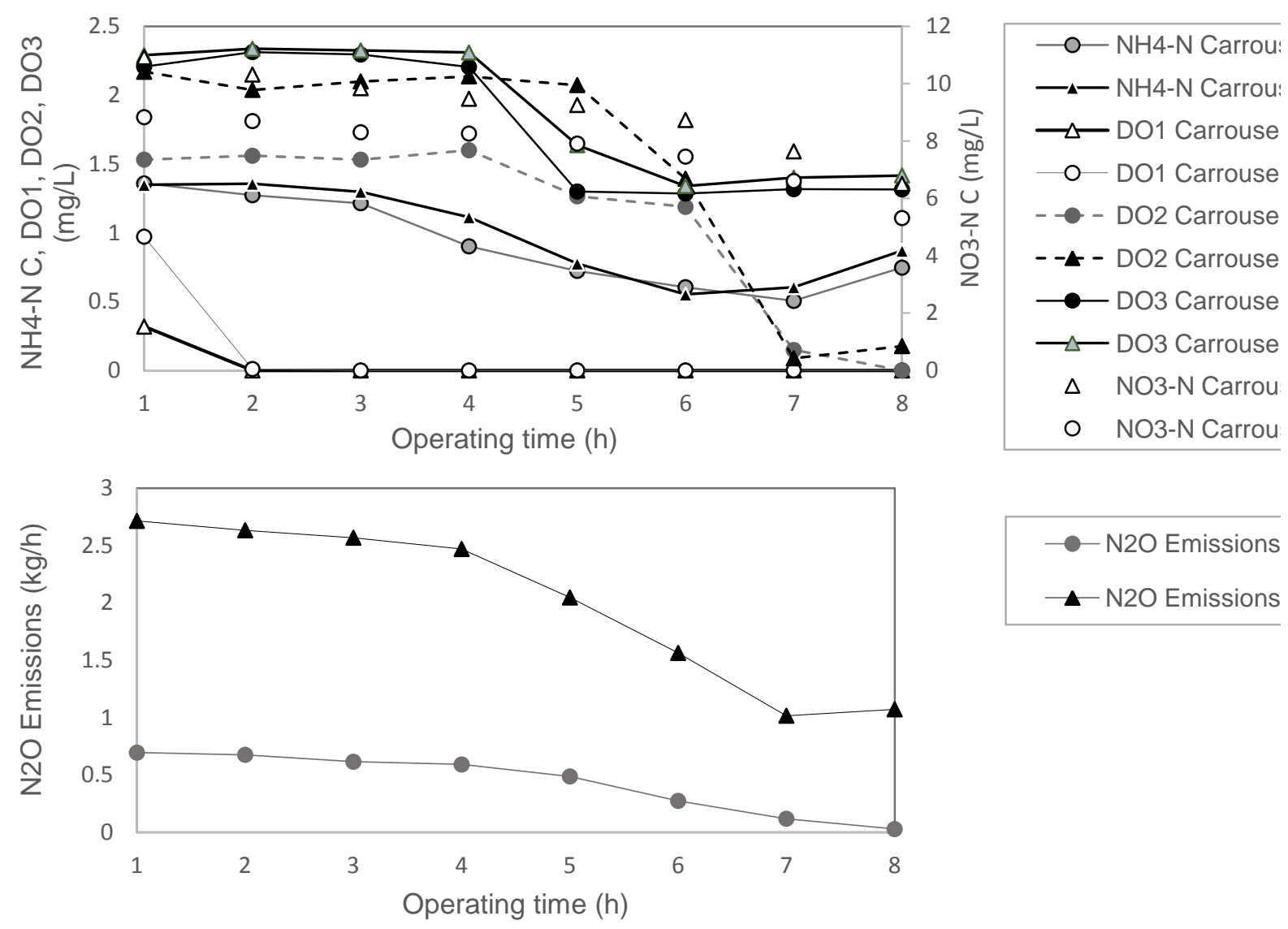

- N2O Emissions

^ N2O Emissions

Operating time (h) 

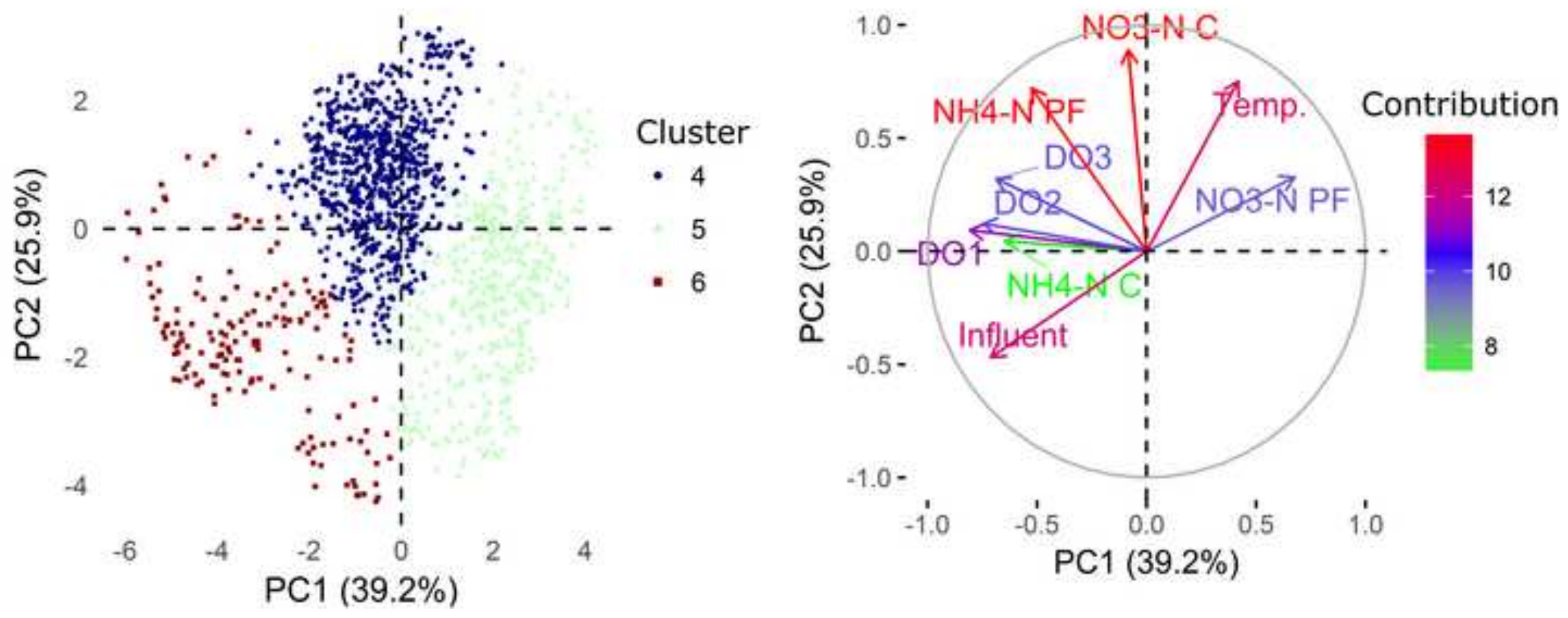


\section{Figure}

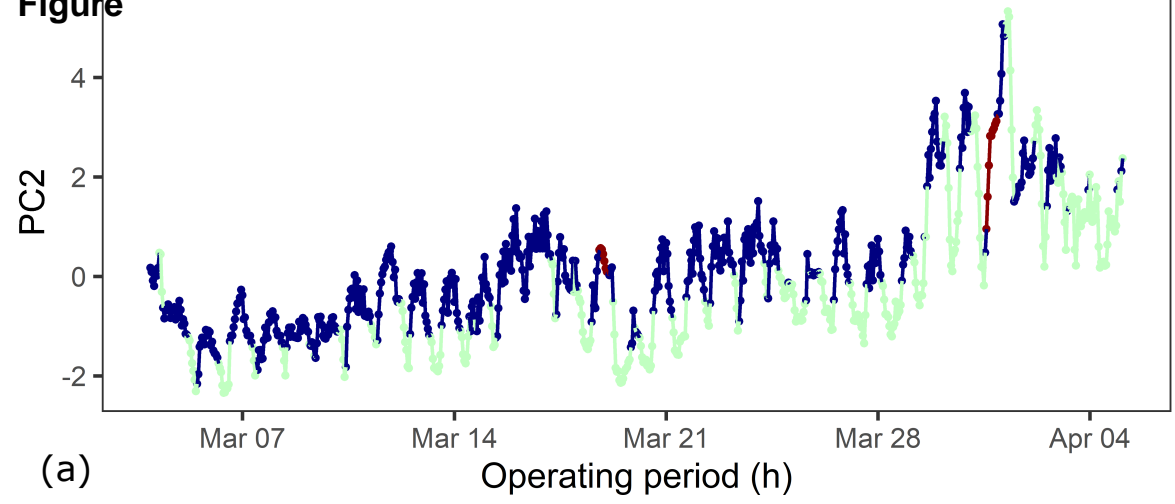

Cluster

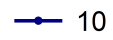

$-11$

$\rightarrow 12$

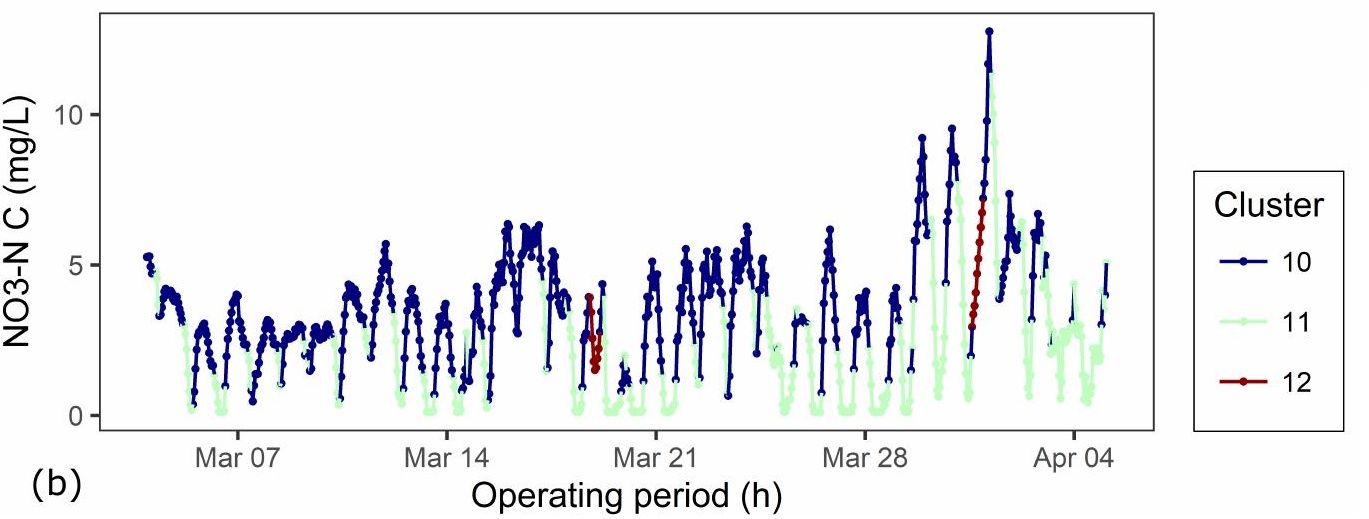


Electronic Supplementary Material (for online publication only)

Click here to download Electronic Supplementary Material (for online publication only): Supplementary_Material_revised.docx 